GEAP-13595

AEC RESEARCH AND

DEVELOPMENT REPORT

APRIL 1970

\title{
FABRICATION OF NON-FUEL CORE COMPONENTS FOR SEFOR
}

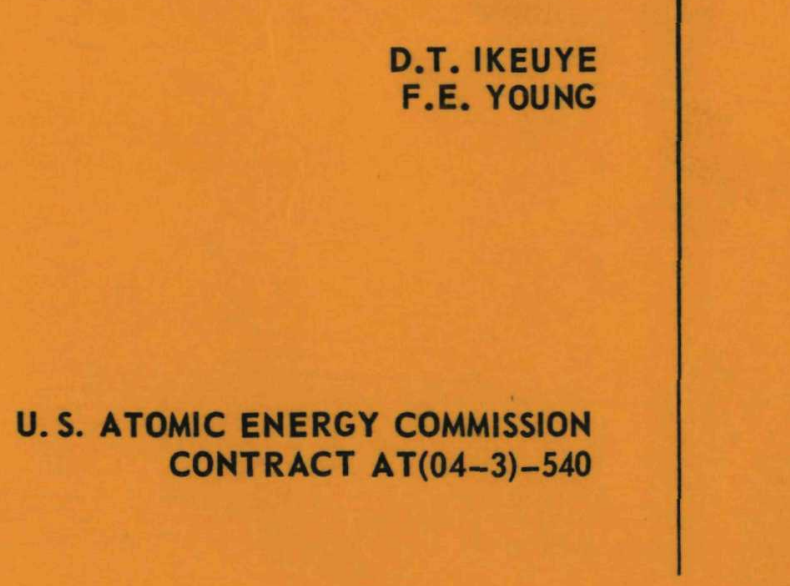

\section{GENERAL ELECTRIC}




\section{DISCLAIMER}

This report was prepared as an account of work sponsored by an agency of the United States Government. Neither the United States Government nor any agency Thereof, nor any of their employees, makes any warranty, express or implied, or assumes any legal liability or responsibility for the accuracy, completeness, or usefulness of any information, apparatus, product, or process disclosed, or represents that its use would not infringe privately owned rights. Reference herein to any specific commercial product, process, or service by trade name, trademark, manufacturer, or otherwise does not necessarily constitute or imply its endorsement, recommendation, or favoring by the United States Government or any agency thereof. The views and opinions of authors expressed herein do not necessarily state or reflect those of the United States Government or any agency thereof. 


\section{DISCLAIMER}

Portions of this document may be illegible in electronic image products. Images are produced from the best available original document. 



\section{FABRICATION OF NON-FUEL CORE COMPONENTS FOR SEFOR}

GEAP-13595

AEC Research

and Development

February 1970

D. T. Ikeuye

F. E. Young Approved:
G. R. Pflasterer, Deveropment Project Engineer
SEFOR Research and Development
Approved:

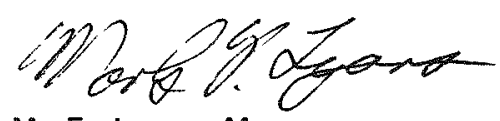

M. F. Lyons, Manager

Fuel Development - Water Reactors

Prepared for the

Southwest Atomic Energy Associates

for transmittal to the

United States Atomic Energy Commission

under

Contract Number AT(03-3)-540

Printed in U.S.A. Available from the

Clearing House for Federal Scientific and Technical Information

National Bureau of Standards, U.S. Department of Commerce

Springfield, Virginia

Price: $\$ 3.00$ per copy 


\section{LEGAL NOTICE}

This report was prepared account of Government sponsored work. Neitber the United States, nor tbe Commission, nor y person acting on bebalf of the Commission:

A. Makes any warranty or representation, expressed or implied, with respect to the accuracy, completeness, or usefulmess of the information contained in this report, or that the use of any information, apparatus, method, or process disclosed in this report may not infringe privately owned rights; or

B. Assumes any liabilities with respect to the use of, or for damages resulting from the use of any information, apparatus, metbod, or process disclosed in this report.

As used in the above, "person acting on bebalf of the Commission" includes any employee or contractor of the Commission, or em. ployee of such contractor, to the extent that such employee or contractor of the Commission, or employee of such contractor prepares, disseminates, or provides access to, any information pursuant to bis employment or contract with the Commission, or bis employment with such contractor. 


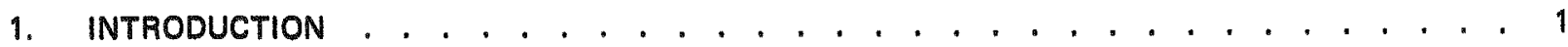

2. SUMMARY . . . . . . . . . . . . . . . . . . . . . 1

3. REFERENCE DRAWINGS . . . . . . . . . . . . . . . . . . . . . . . . . . . 1

4. DESCRIPTION . . . . . . . . . . . . . . . . . . . . . . . . 2

4.1 Plant Description. . . . . . . . . . . . . . . . . . . . . . . . . . . . 2

4.2 Component Description ... . . . . . . . . . . . . . . . . . . . . . . 2

4.2.1 Extension Rods . . . . . . . . . . . . . . . . . . . . . . . . . 2

4.2.2 Tightener Rod . . . . . . . . . . . . . . . . . . . . . . . . . 2

4.2.3 Tightener Sleeve . . . . . . . . . . . . . . . . . . . . . . . . . 2

4.2.4 Upper and Lower Tightener Sleeves . . . . . . . . . . . . . . . . . . 2

4.2.5 Surveillance Specimen Holder . . . . . . . . . . . . . . . . . . . . 2

4.2.6 Foil Holder Rods. . . . . . . . . . . . . . . . . . . . . . . . . 2

5. EXTENSION ROD . . . . . . . . . . . . . . . . . . . . . . . . . . . 26

5.1 Tooling . . . . . . . . . . . . . . . . . . . . . . . . . . 26

5.1.1 Welding Fixtures . . . . . . . . . . . . . . . . . . . . . 26

5.2 Fabrication Development . . . . . . . . . . . . . . . . . . . . . . . . . 26

5.2 .1 Welding. . . . . . . . . . . . . . . . . . . . 26

5.2 Tube Forming. . . . . . . . . . . . . . . . . . . . . . . . . . 26

$5.2 .3 \mathrm{~B}_{4} \mathrm{C}$ Loading . . . . . . . . . . . . . . . . . . . . . . . . . . 26

5.3 Assembly . . . . . . . . . . . . . . . . . . . . . . . . . . . . . . 26

6. TIGHTENER ROD . . . . . . . . . . . . . . . . . . . . . . . . . . . . . 33

6.1 Tooling . . . . . . . . . . . . . . . . . . . . . . . . . . . . . 33

6.1.1 Welding Fixture . . . . . . . . . . . . . . . . . . . . . . . . . 33

6.1.2 BeO Loading Box . . . . . . . . . . . . . . . . . . . . . . . . 33

6.2 Fabrication Development . . . . . . . . . . . . . . . . . . . . . . . . . 33

6.2.1 Welding. . . . . . . . . . . . . . . . . . . . . . . . 33

6.2 Tube Forming. . . . . . . . . . . . . . . . . . . . . . . . . . 33

6.2.3 BeO Pellets. . . . . . . . . . . . . . . . . . . . . . . . 33

6.3 Assembly . . . . . . . . . . . . . . . . . . . . . . . . 33

7. TIGHTENER SLEEVE . . . . . . . . . . . . . . . . . . . . . . . . 36

7.1 Tooling . . . . . . . . . . . . . . . . . . . . . . . 36

7.1.1 Dimpling Tools . . . . . . . . . . . . . . . . . . . . . . . . . 36

7.1.2 Spring Welding Tools . . . . . . . . . . . . . . . . . . . . . . . 36

7.1.3 Tightener Sleeve Assembly Stations . . . . . . . . . . . . . . . . . . 36

7.2 Fabrication Development . . . . . . . . . . . . . . . . . . . . . . . . . 36

7.2 .1 Hexagonal Tubes. . . . . . . . . . . . . . . . . . . . . . . . . 36

7.2 .2 Springs . . . . . . . . . . . . . . . . . . . . . 36

7.2 .3 Fins . . . . . . . . . . . . . . . . . . . . 36

7.2 .4 Design Modifications . . . . . . . . . . . . . . . . . . . . . . . 36

7.3 Assembly and Final Testing . . . . . . . . . . . . . . . . . . . . . . . . 44 
TABLE OF CONTENTS (Continued)

8. INSTRUMENTED TIGHTENER SLEEVE (UPPER AND LOWER) . . . . . . . . . . . . . . . 47

9. FOIL HOLDER ROD AND SURVEILLANCE RODS $\quad$. . . . . . . . . . . . . . . . . . . . . . . . 47

10. QUALITY CONTROL . . . . . . . . . . . . . . . . . . . . . . . . . . . 47

10.1 Process Guides . . . . . . . . . . . . . . . . . . . . . . . . . . . . . . 47

10.2 Quality Control Plan . . . . . . . . . . . . . . . . . . . . . . . . . 47

10.3 Process Control . . . . . . . . . . . . . . . . . . . . . . . . . . . 47

ACKNOWLEDGEMENT . . . . . . . . . . . . . . . . . . . . . . . . . . . . . . . . . 47

APPENDIX I . . . . . . . . . . . . . . . . . . . . . . . . . . . . . . . . . . 49

APPENDIX $\|$. . . . . . . . . . . . . . . . . . . . . . . . . . . . . . 67

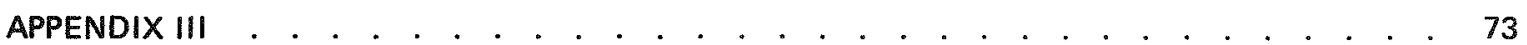

APPENDIX IV . . . . . . . . . . . . . . . . . . . . . . . . . . . . . . . . . 99

APPENDIXV . . . . . . . . . . . . . . . . . . . . . . . . . . . 103

APPENDIX VI . . . . . . . . . . . . . . . . . . . . . . . . . . . . . . . 113

APPENDIX VII . . . . . . . . . . . . . . . . . . . . . . . . . . . . . . . 139

DISTRIBUTION . . . . . . . . . . . . . . . . . . . . . . . . . . . . . . . . . 149 


\section{LIST OF ILLUSTRATIONS}

Figure

Title

4-1 Cross Section of SEFOR Core . . . . . . . . . . . . . . . . . . . . . . . . . . . 3

4-2 Core Element Arrangement . . . . . . . . . . . . . . . . . . . . . . . . . . . . . . . . 5

4-3 Drawing of Extension Rod . . . . . . . . . . . . . . . . . . . . . . . . . . . . . . 7

4.4 Extension Rod . . . . . . . . . . . . . . . . . . . . . . . . . . . . . . 8

4.5 Drawing of Tightener Rod . . . . . . . . . . . . . . . . . . . . . . . . . . . . . . . 9

4.6 Tightener Rod . . . . . . . . . . . . . . . . . . . . . . . . . . . . . . 11

4.7 Drawing of Tightener Sleeve . . . . . . . . . . . . . . . . . . . . . . . . . . . . . . . 13

4.8 Tightener Sleeve . . . . . . . . . . . . . . . . . . . . . . . . . . . . . . 15

4.9 Drawing of Upper Tightener Sleeve . . . . . . . . . . . . . . . . . . . . . . . . . 17

4-10 Drawing of Lower Tightener Sleeve . . . . . . . . . . . . . . . . . . . . . . . . . . . . . . 19

4-11 Upper and Lower Tightener Sleeves. . . . . . . . . . . . . . . . . . . . . . . . . . . . . 21

4-12 Drawing of Surveillance Specimen Holder. . . . . . . . . . . . . . . . . . . . . . . . . . . . . . . . . 22

4-13 Surveillance Specimen Holder . . . . . . . . . . . . . . . . . . . . . . . . . . . 23

4-14 Drawing of Foil Holder Rod . . . . . . . . . . . . . . . . . . . . . . . . . . . . . . . . 24

4-15 Foil Holder Rod . . . . . . . . . . . . . . . . . . . . . . . . . . . . . . . . . . . 25

5-1 First-End Weld Fixture . . . . . . . . . . . . . . . . . . . . . . . . . . . . 27

5-2 Weld Chamber for Final Weld . . . . . . . . . . . . . . . . . . . . . . . . . 28

5-3 Weld Parameters . . . . . . . . . . . . . . . . . . . . . . . . . . . . . . 29

5-4 Weld Parameters . . . . . . . . . . . . . . . . . . . . . . . . . . . . . . 29

5-5 Typical End Plug Weld Section . . . . . . . . . . . . . . . . . . . . . . . . . . . . 30

5-6 Typical Vent Plug Weld for Extension Rod . . . . . . . . . . . . . . . . . . . . . 31

5-7 Arched Area of Tube I.D. Surface . . . . . . . . . . . . . . . . . . . . . . . . . . . . 32

6.1 BeO Handling Glove Box . . . . . . . . . . . . . . . . . . . . . . . . . . . . . . . . . . . 34

6-2 Typical Tightener Rod Vent Plug Weld . . . . . . . . . . . . . . . . . . . . . . 35

$7-1$ Tightener Sleeve Tooling: Dimpling Tools . . . . . . . . . . . . . . . . . . . . . . 37

7.2 Tightener Sleeve Tooling: Spring Welding Tools . . . . . . . . . . . . . . . . . . . . 38

7.3 Tightener Sleeve Tooling: Spring Weld Tool Detail . . . . . . . . . . . . . . . . . . . . 39

7.4 Tightener Sleeve Dimpling Station . . . . . . . . . . . . . . . . . . . . . . . . 40

7.5 Tightener Sleeve Spring Weld Station . . . . . . . . . . . . . . . . . . . . . . . 41

$7-6$ Tightener Sleeve Fin Assembly Station . . . . . . . . . . . . . . . . . . . . . . . . 42

7-7 Tightener Sleeve Springs . . . . . . . . . . . . . . . . . . . . . . . . . . . 43

7-8 Tightener Sleeve Spring Weld: Typical Upper Weld (External Spring-to-Internal Spring Weld) and Typical Spring Finger-Tip Weld . . . . . . . . . . . . . . . . . . . . . . . . $\quad$. 45

$7-9$ Tightener Sleeve Spring Weld: Typical Lower Weld (Internal Spring-to-Hexagonal Tube Weld) . . . . 46

V-1 Tightener Sleeve . . . . . . . . . . . . . . . . . . . . . . . . . . . . . . 105

V-2 Thermal Cycle Test Set-Up Showing Spring Assembly Inserted within the RF Coil . . . . . . . . 107

V-3 Thermocouple Locations . . . . . . . . . . . . . . . . . . . . . . . . . . . 108

V-4 Typical Time-Temperature Trace for Spring Assembly No. 4 . . . . . . . . . . . . . . . . . 110

V-5 Spring Assembly No. 4 Finger Weld, Post Thermocycle . . . . . . . . . . . . . . . . . . . . 111

V-6 Spring Assembly No. 4 Upper Weld, Post Thermocycle . . . . . . . . . . . . . . . . . . . 111 


\section{INTRODUCTION}

This report documents the fabrication data and processes for the production of the core components (excluding fuel) of the Southwest Experimental Fast Oxide Reactor (SEFOR) made in General Electric's Fuels Laboratory, Uranium Fuel Development.

The Southwest Experimental Fast Oxide Reactor (SEFOR) is a $20 \mathrm{MWt}$ fast spectrum reactor fueled with mixed $\mathrm{PUO}_{2}-\mathrm{UO}_{2}$ and cooled with sodium. SEFOR will have characteristics similar to large, soft spectrum, fast breeder reactors fueled with mixed $\mathrm{PuO}_{2}-\mathrm{UO}_{2}$. Economic studies of these large power reactors indicate significant potential for producing low cost power. SEFOR will be used to obtain physics and engineering data at fuel compositions, temperatures, and crystalline states characteristic of power reactor operating conditions. SEFOR is particularly designed for the systematic determination of the Doppler coefficient of reactivity at temperatures up to the vicinity of fuel melting.
The SEFOR Project consists of two major parts: the design and construction of the reactor and a related research and development program. Funds for the design and construction of the facility are being provided by the Southwest Atomic Energy Associates (a group of seventeen investor-owned utility companies located in the South and Southwest part of the United States), together with the Karisruhe Laboratory of the Federal Republic of Germany. Euratom, and the General Electric Company.

The United States Atomic Energy Commission is supporting the research and development program. The R\&D Program consists of two phases:

Phase 1 - Pre-Operational Research and Development Phase 11 - Post-Construction Research and Development

This report describes work performed under Task 9 , Fuel Fabrication, in Phase 1 of the Research and Development Program.

\section{SUMMARY}

The Uranium Fuel Development Subsection of the Nuclear Fuels Department was responsible for the materials procurement and fabrication of the extension rods, tightener rods, tightener sleeves and special rods for the SEFOR reactor. These core components were fabricated under the SEFOR R\&D program funded by the AEC. The extension rods provide the neutron and gamma shielding above the core. The functions of the tightener rods are to lock the surrounding "fuel rod-extension rod" assembly in position in the fuel channel, to provide additional shielding above the core, and to increase the Doppler effect. The tightener sleeve is the basic internal structural member of the fuel assembly and serves to provide spacing between the fuel rods.

This report describes the major tooling, techniques of fabrication, fabrication processes, and quality control efforts used in the fabrication of the non-fuel core components.

\section{REFERENCE DRAWINGS}

The following is a list of the drawing numbers and the quantities of each component fabricated.

$\begin{array}{rrl}\text { Component } & \text { Quantity } & \text { Drawing No. } \\ \text { Extension Rod } & 660 & 112 \mathrm{C} 2072-\mathrm{G} 1 \\ & 18 & 112 \mathrm{C} 2072-\mathrm{G} 2 \\ & 36 & 112 \mathrm{C} 2072-\mathrm{G} 3 \\ & 29 & 112 \mathrm{C} 2072-\mathrm{G} 4 \\ \text { Tightener Rod } & 113 & 846 \mathrm{D} 777\end{array}$

Tightener Sleeve

Upper Tightener Sleeve

Lower Tightener Sleeve

Surveillance Specimen

Holder

Foil Holder Rod

119
9
9
10
7

$706 \mathrm{E} 958$

8860587

$719 E 669$

$135 \mathrm{C} 4892$

$135 \mathrm{C} 4801$ 


\section{DESCRIPTION}

\subsection{PLANT DESCRIPTION}

SEFOR is an experimental fast reactor utilizing a mixed oxide $\left(\mathrm{PuO}_{2}-\mathrm{UO}_{2}\right)$ fuel with liquid sodium as the coolant. The core is composed of a series of fuel assemblies arranged in a hexagonal pattern as shown in Figure 4-1. A fuel assembly consists of one tightener sleeve, one tightener rod, six fuel rods, and six extension rods assembled into a hexagonal channel. A drawing of the assembly is shown in Figure 4-2.

\subsection{COMPONENT DESCRIPTION}

\subsubsection{Extension Rods}

The extension rods consist of Type $\mathbf{3 1 6}$ stainless steel tubes filled with boron-carbide $\left(B_{4} C\right)$ powder. These rods provide a blanket of $B_{4} C$ over the core of the reactor and serve as the neutron and gamma shield. $A$ drawing and photo of the component are shown in Figures 4-3 and 4-4, respectively.

\subsubsection{Tightener Rod}

The tightener rod basically consist of beryllium oxide $(\mathrm{BeO})$ pellets in the lower section of the rod, which extends the length of the fuel column, and solid Type $\mathbf{3 0 4}$ stainless steel in the upper section of the rod. The tightener rod is inserted into the tightener sleeve which locks the surrounding "fuel rod-extension rod" unit in position. The $\mathrm{BeO}$ serves to increase the Doppler effect by softening the neutron flux spectrum. The stainless steel in the upper portion of the rod functions as part of the neutron-gamma shield above the core. A drawing and photo of the tightener rod are shown in Figures 4-5 and 4-6, respectively.

\subsubsection{Tightener Sleeve}

The tightener sleeve is the basic structural member of the fuel assembly. It functions as a rod-to-rod spacer and it includes the springs by which the rods are locked into position. A drawing and photo of the tightener sleeve are shown in Figures $4-7$ and 4-8, respectively.

\subsubsection{Upper and Lower Tightener Sleeves}

The upper and lower tightener sleeves are used in the instrumented fuel assembly and are basically similar to the regular tightener sleeve. These components are shown by Figures 4-9 through 4-11.

\subsubsection{Surveillance Specimen Holder}

These rods contain the tensile specimens taken from the pressure vessel material for the surveillance program. The drawings and photo are shown in Figures 4-12 and 4-13.

\subsubsection{Foil Holder Rods}

These rods contain foils for physics measurements and are designed for easy disassembly. A drawing and photo are shown in Figures 4-14 and 4-15, respectively. 


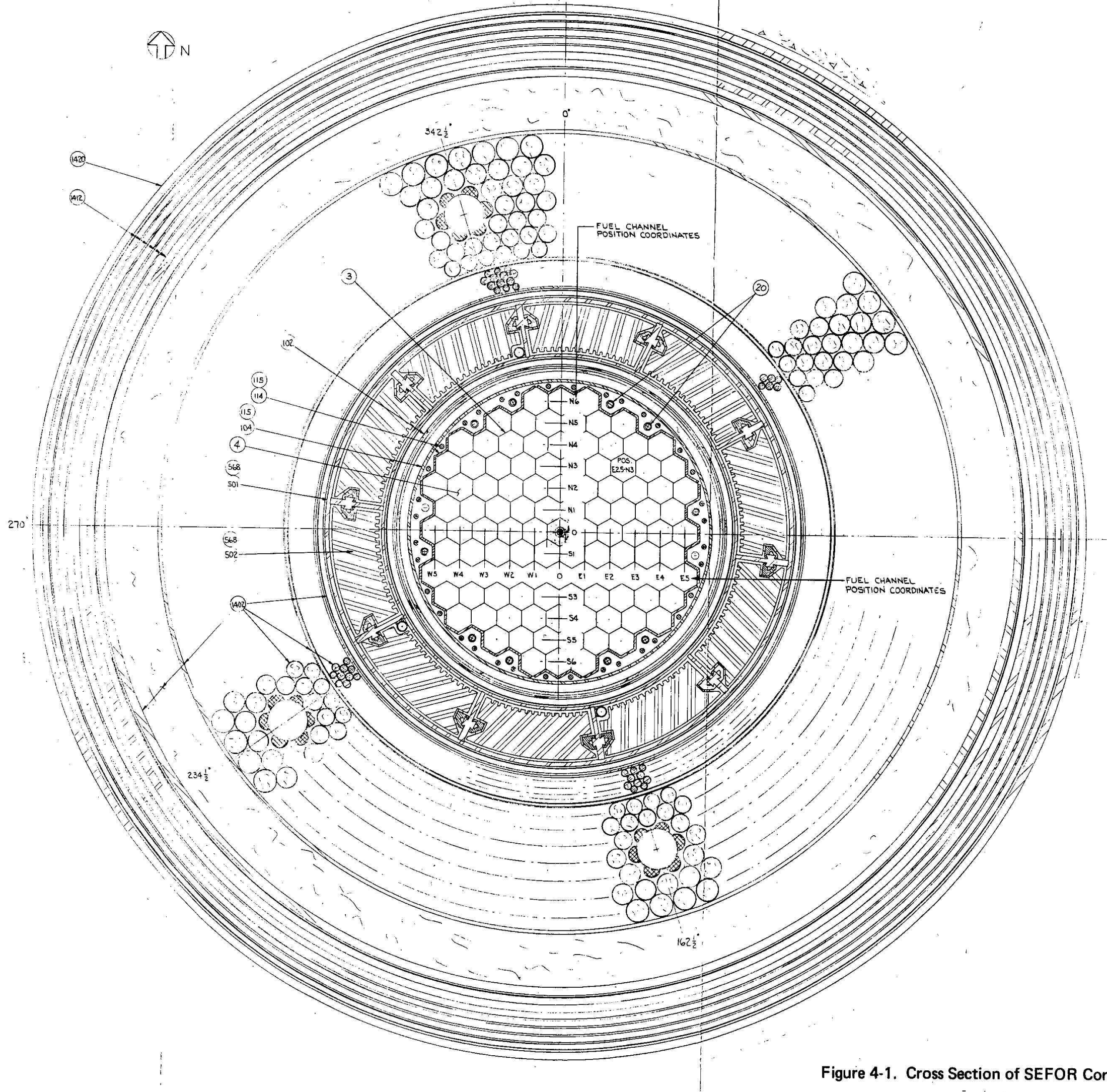




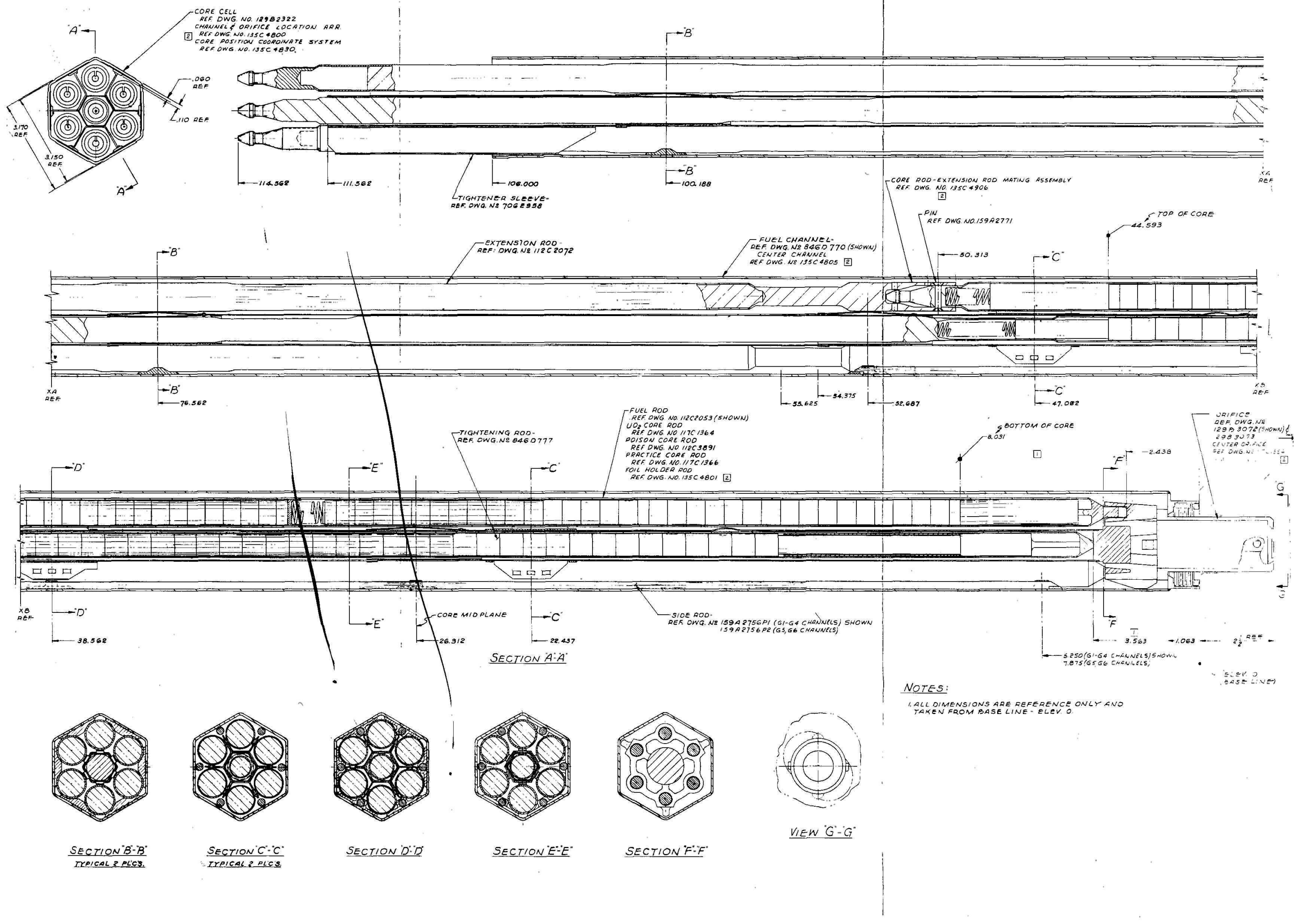

Figure 4-2. Core Element Arrangement 

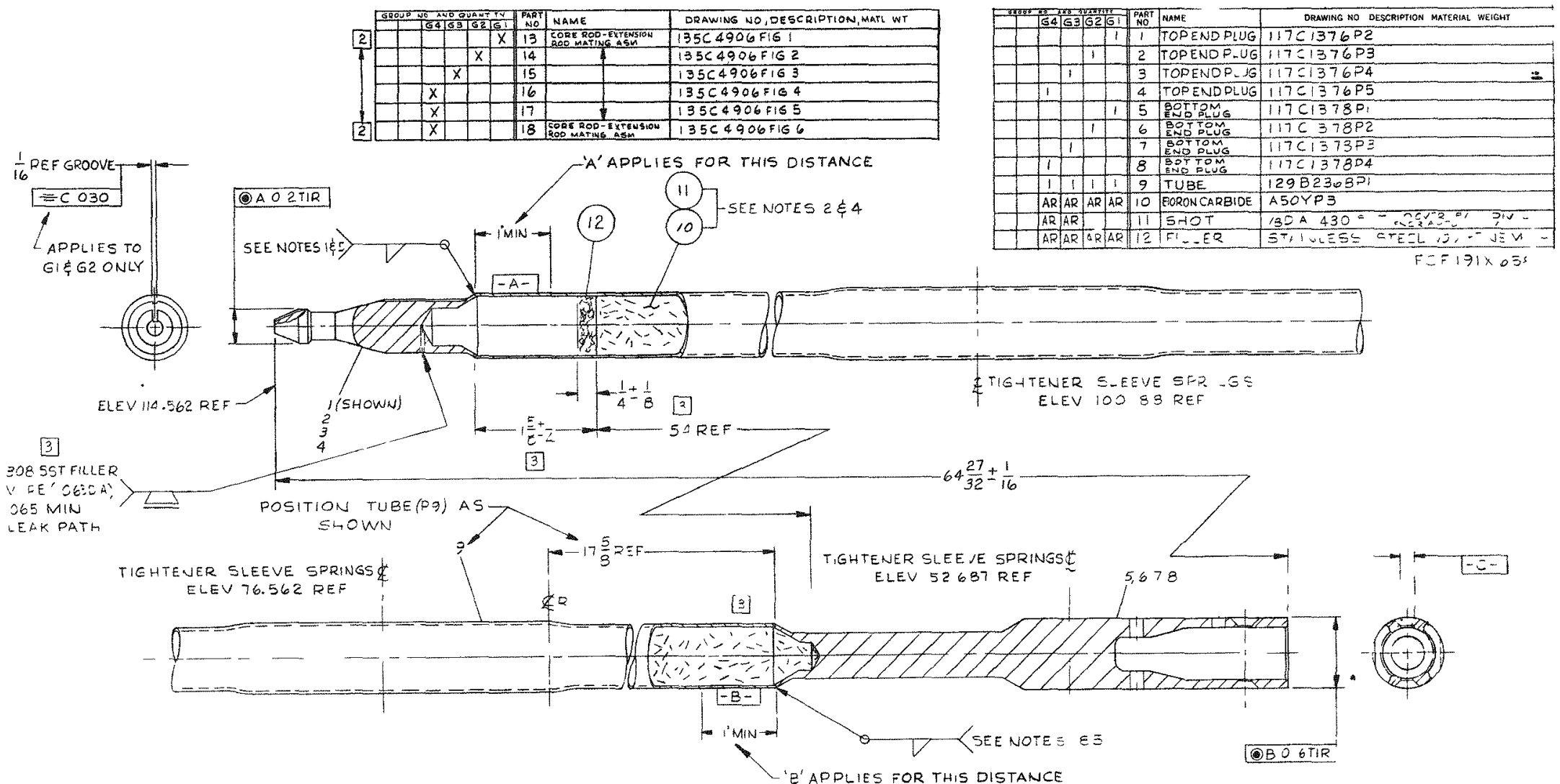

NOTES.
1 FAEEIICATION AND QUAI ITY CONTROL PRACTICES SHALL CONFOZN WITH SPEC $22 A 1658$

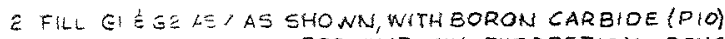
COMFMCTED TO 70 PERGENT MIN THEORETICAL DENSITY (THEORETICAL DENSITY = 2 \$ GRAMS/CC).

= -ESE $\cong$ TOEE STERIGHT W ThIN OOElET

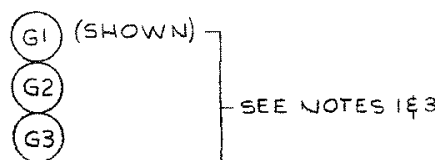

$4=\because C E=\angle A$ ASM, AS SHOWN, WITH APPROX 5C FER CENTECRCN G4

HIS ACCFETASIE WEIGHT = BORSN TARB DE (PIO)

PLUS $\equiv S-S-O T,-11) 1 S \equiv 7-E S$

EO-EDE LIA OF, ELD SHALLBE ESI MAX 


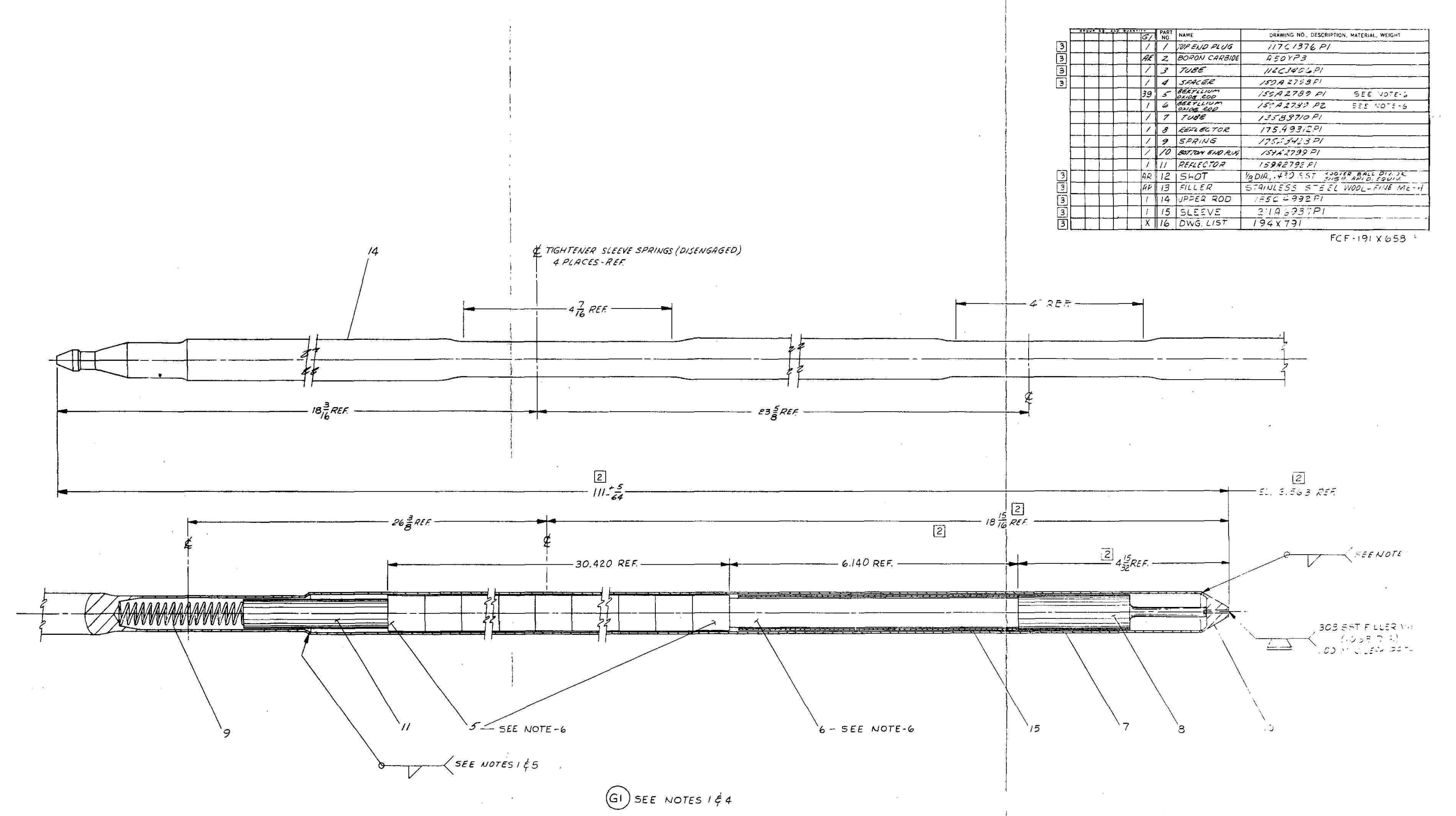

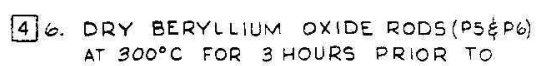
INSERTING THEM INTO TUBE (PT) AT ASSEMBLY
NOTES:
1. FARICATION AND QUALITY CONTROL PRACTICES
SHALL CONFORM WITH SPEC $22 A 1658$.

3. 2. WELD SPACER (P4) USING ELECTRON BEAM WELO.

[3] E.FILL ASSEMBLY AS SHOWN WITH APPROX. SO PERCENT IIIN. ACCEPTRBLE WEIGHT OF BORON CARBIDE (P2) ANO

4.ASSEMBLY TO BE STRAIGHT WITHIN .0O5/FT

5. OUTSIDE OIA. OF WELO SHALL EE .880 MAX.
Figure 4-5. Drawing of Tightener Rod 


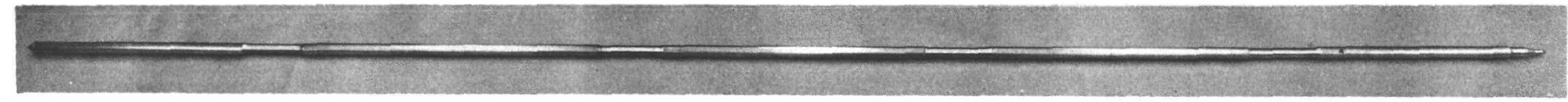



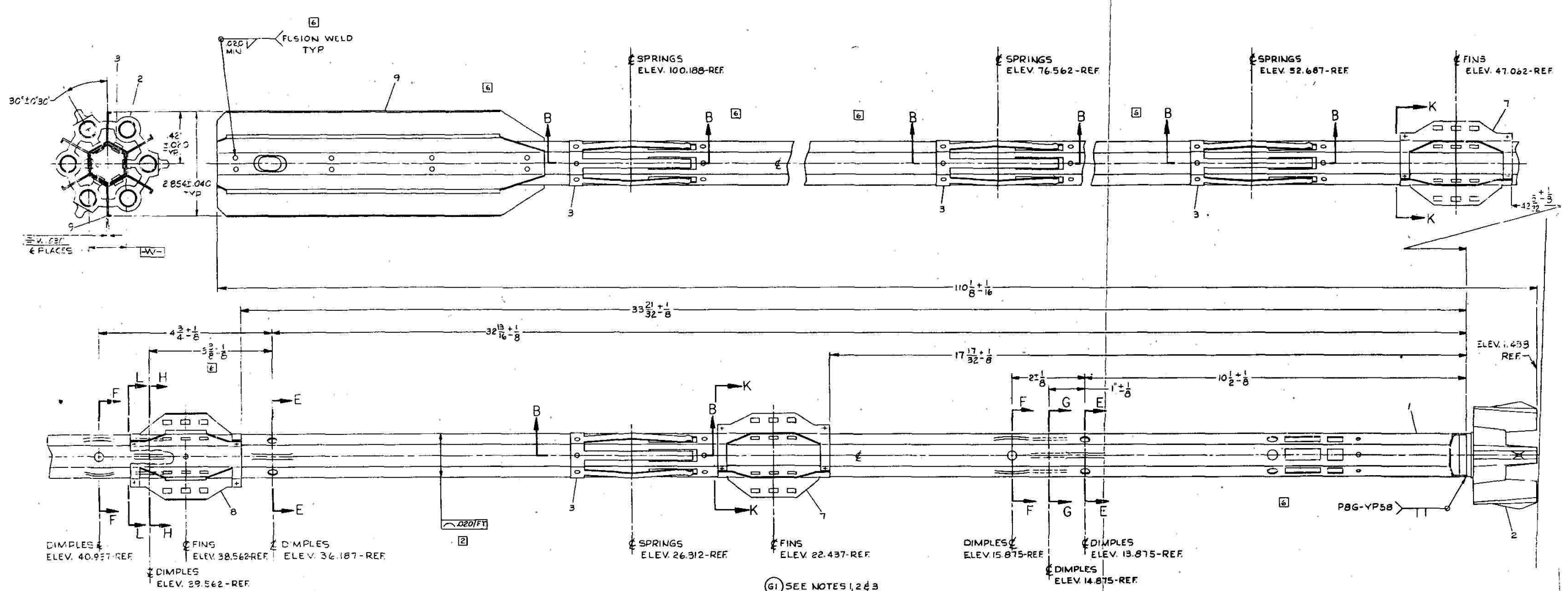

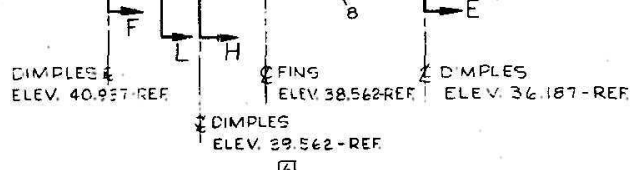
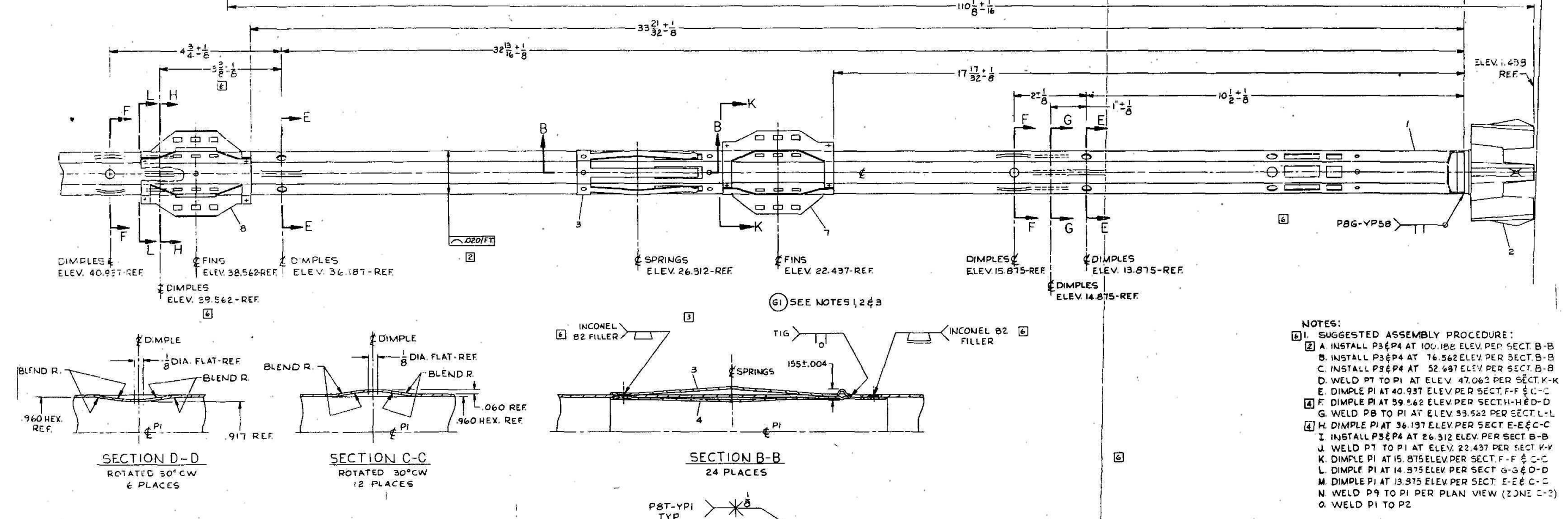
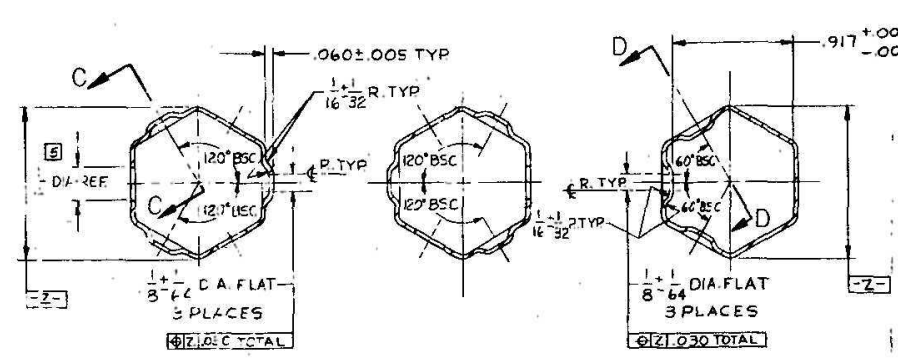

SECTION E-E $\frac{\text { SECTIONG-G }}{\frac{\text { SECTION F-F }}{2 \text { PLACES }}}$ SAMEAS SECT. E-E
EXCEFT DNFLES
RCTATED $60^{\circ}$. HS SHOWN

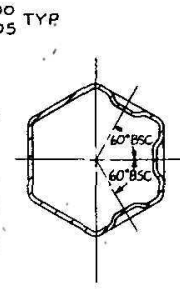

SECTION H-H

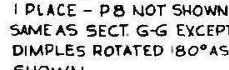

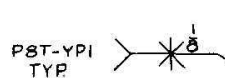

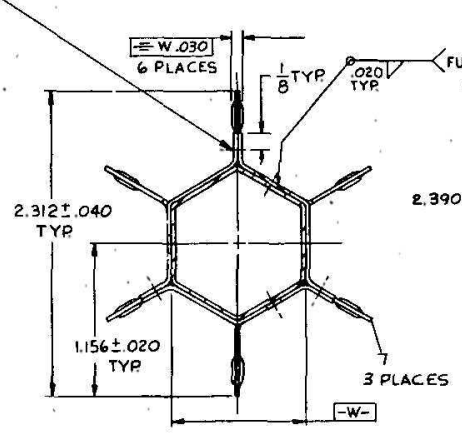

SECTION K-K
圆

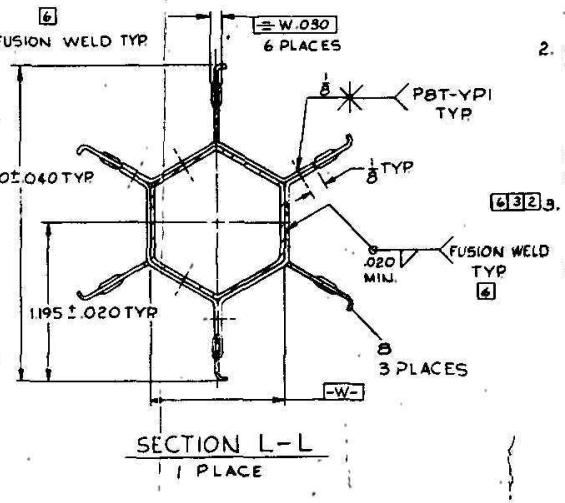

CLEN ALL PARTS PER GE SPEC DACYPZ PROOC TOASSEMBLING. HANDLE PARTS WITH WH ITE CLEANING SHALL BEEY WIPING ALL SURFACES SLEEVEI IN TCE TONE. SEAL FINISHED TIGHTENER VE IN PLASTIC COVERS

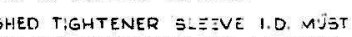

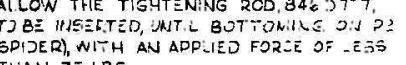



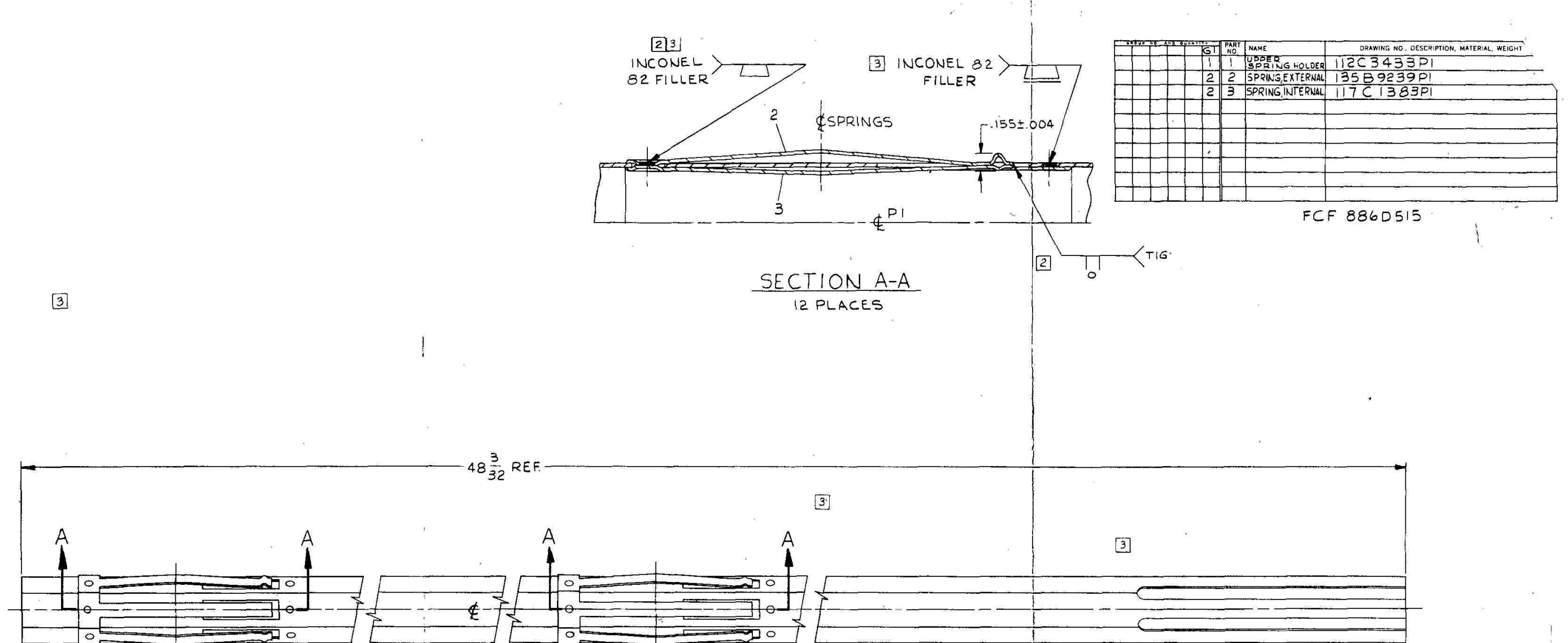

$8 \frac{3}{32} R E F$

12 PLACES

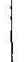

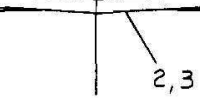

\$SPRINGS-ELEV. 100.188REF.

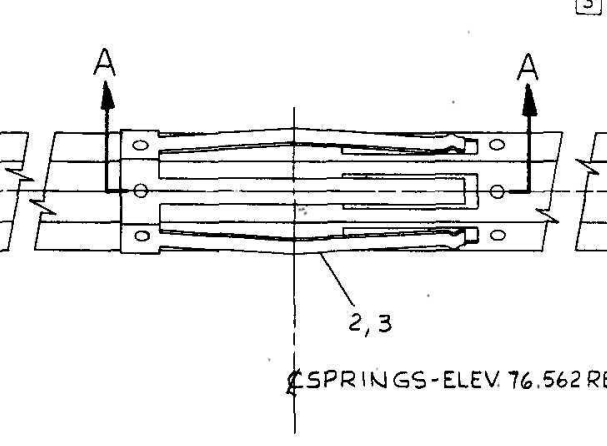

(G1) SEE NOTES $1,2,3 \xi 4$

NOTES:
91. SUGGESTED ASSEMBLY PROCEDURE:

A.INSTALL P2 \& P3 AT 100.188 ELEV. PER, SECT. A-A B. GAGE PER NOTE-3.

C.INSTALL P2ל 3 AT 76.562 ELEV. PER SECT.A.A. D. GAGE PER NOTE - 3.

32. CLEAN ALL PARTS PER G.E. SPEC. P4CYPB PRIOR

TO ASSEMBLING. HANDLE PARTS WITH WHITE COTTON

GLOVES DURING ASSEMBLY. FINAL CLEANING SHALL

IMMERSING TIGHTENING SLEEVE IN ACETONE.

[4]3[2]13. INSERT A .8900 \pm .0005 DIA. $X 6 \pm \pm \frac{1}{8}$ LG. GAGE INTO TIGHTENING

SLEEVE AND $\frac{1}{2}$ INCH MIN. DISTANCE INTO 1.D. OF INTERNAL

SPRINE(P), TYP. BOTH ENDS OF SPRING. FINISHED UPPER TIGHTENING

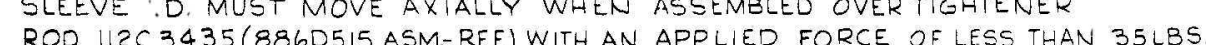

[1]4 ASSEMBLY TO BE STRAIGHT WITHIN .O2O/FT. 


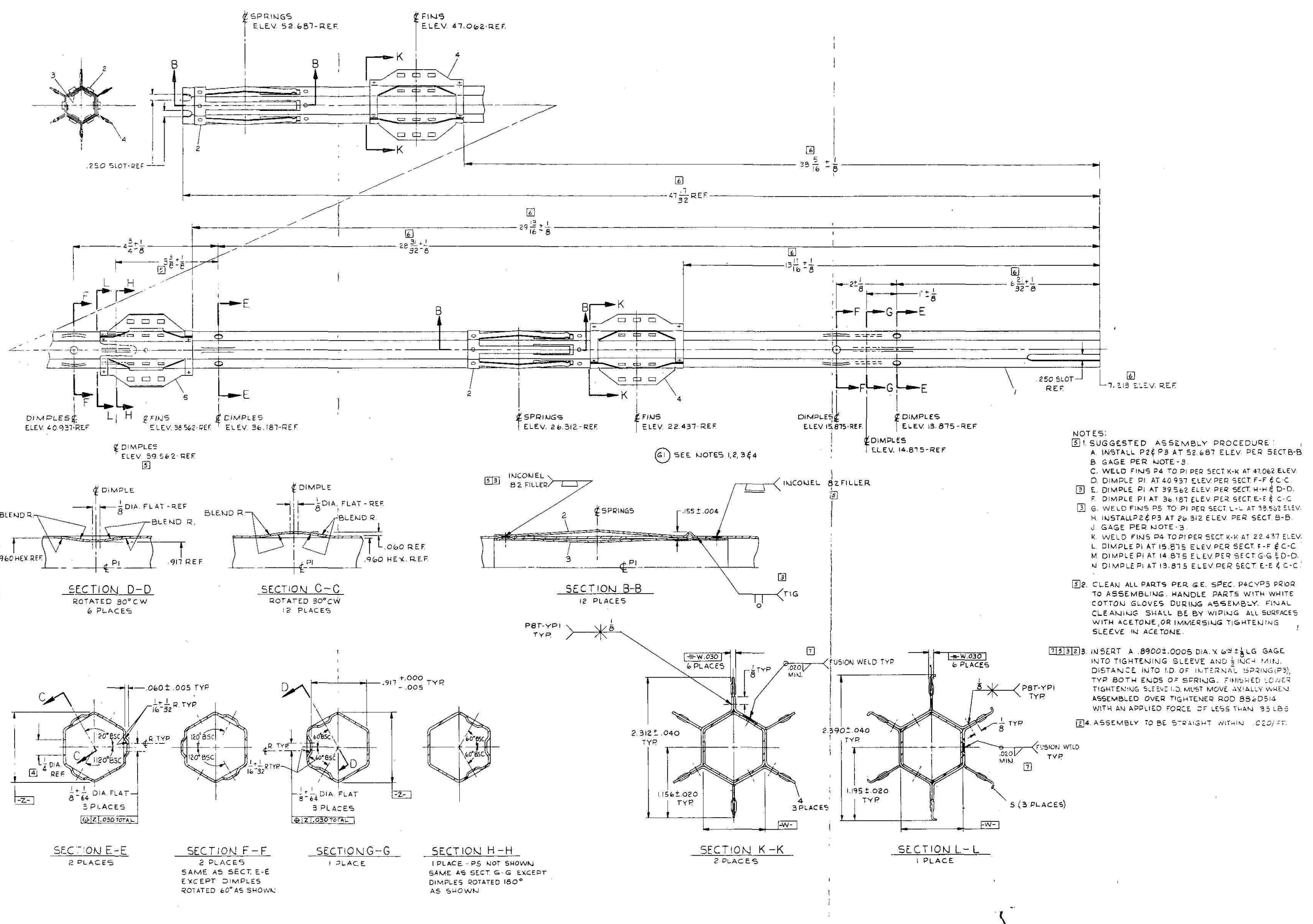

Figure 4-10. Drawing of Lower Tightener Sleeve 


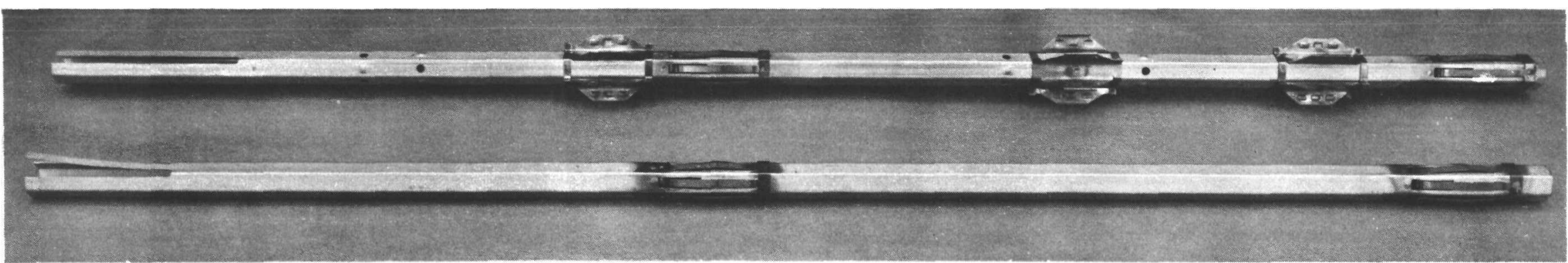




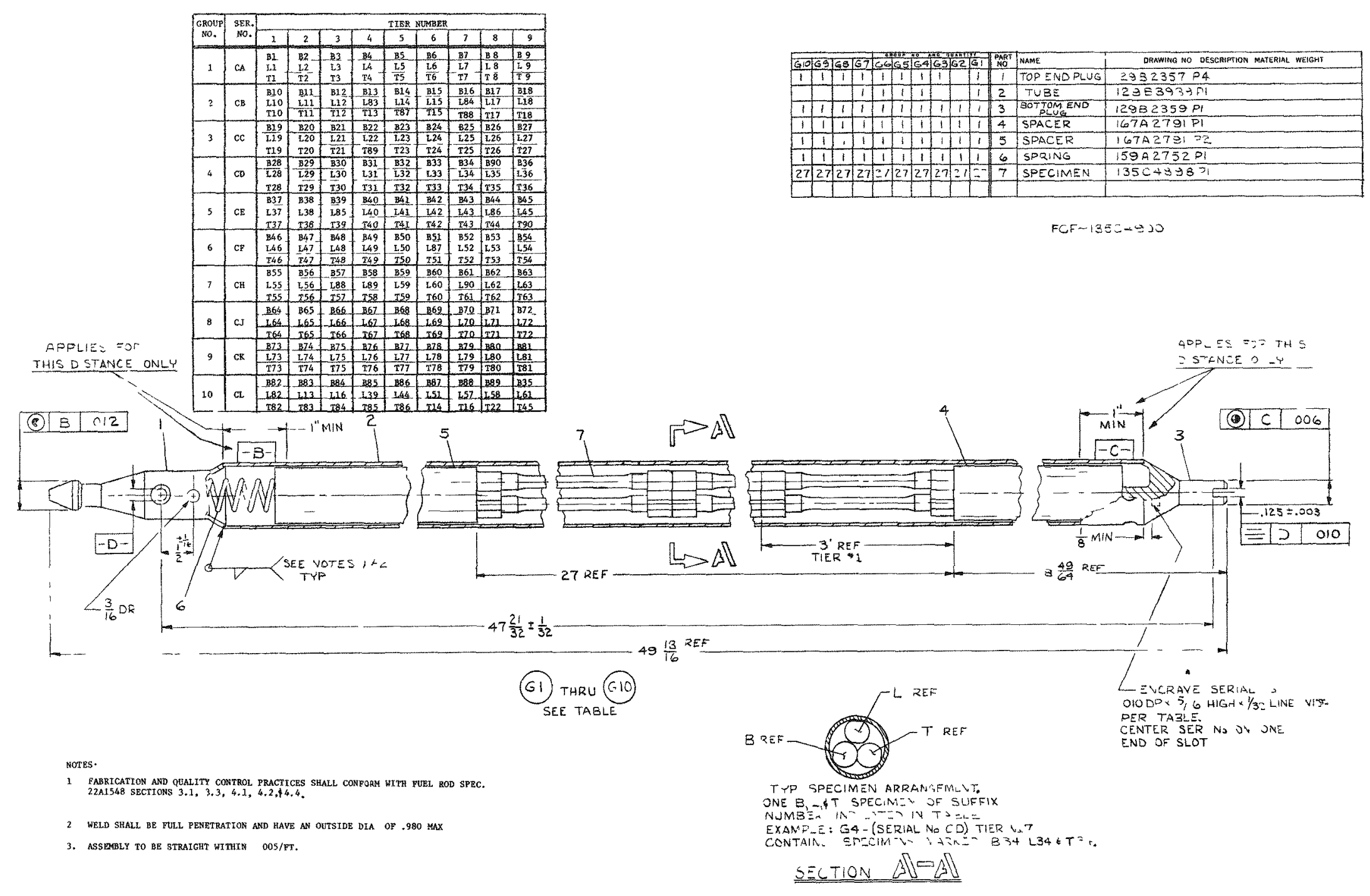




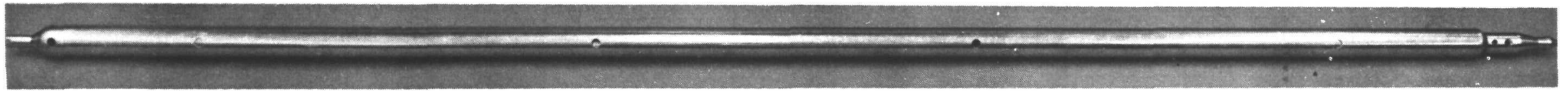



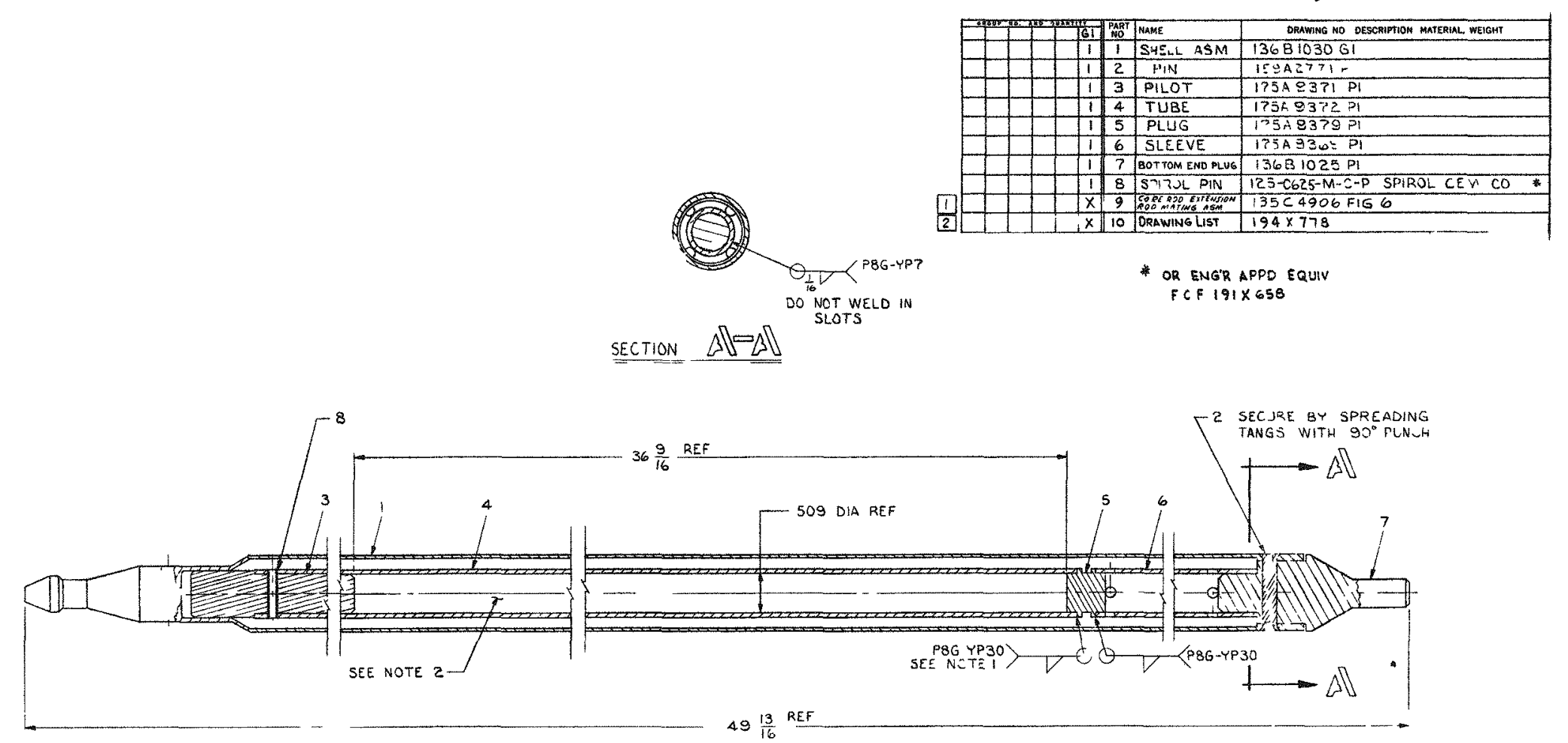

NCTES

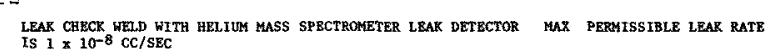

2 CONTENTS OF PA TO BE PROVIDED BY EXPERIMEN-CR 


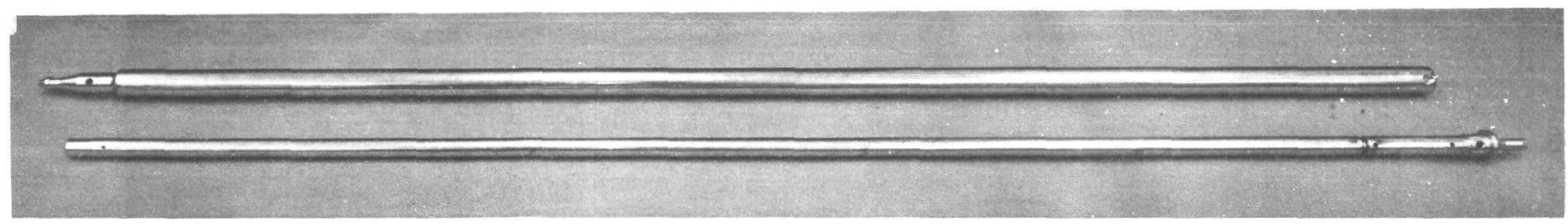




\section{EXTENSION ROD}

\subsection{TOOLING}

\subsubsection{Welding Fixtures}

Special weld fixtures were required to make the initial welds in both the extension rods and tightener rods because of the long length of the mating pieces. A fixture was designed and fabricated to help maintain alignment and allow the parts to rotate together during welding. The fixture utilizes two heavy duty indexing heads, synchronously driven by 1/3-h.p. motor. The fixture has a hydraulic speed redut o to allow variable speed adjustment. Special soft jaws were adapted to the indexing heads. A photo of the setup is shown in Figure 5-1. Figure 5-2 shows the welding chamber used for the final end weld.

\subsection{FABRICATION DEVELOPMENT}

\subsubsection{Welding}

Welds for the extension and tightener rods were made by TIG fusion on a Miller ESR 150 welding machine. Typical weld parameters established using automatic sequence welding are given in Figures 5-3 and 5-4. The weld dusigns on all weld joints are identical; however, the weld parameters differ for out-of-box and in-chamber welding conditions. Each operator was qualified by welding five consecutive welds which were acceptable by metallographic examination. Minimum leak path requirement was $93 \%$ of wall thickness. To overcome gas blowout through the molten weld metal, it was necessary to drill a vent hole in the final end plugs and plug weld them after the circumferential weld was completed. Typical welds are shown by the photomicrographs in Figures 5-5 and 5-6.

\subsubsection{Tube Forming}

The tubes for the extension rods were expanded by the magnaforming process at Advanced Kinetics, Inc., Costa Mesa, California. Further technical development of this technique is necessary and furthermore, the process is not at present capable of high production rates. Therefore, this is not recommended for future application without adequate process hardware development. The expansion for the extension rod tubes is from 0.875 inch o.d. to 0.970 inch o.d. or $10.9 \%$ circumferential deformation. Tensile tests performed on tensile specimens obtained from the expanded section are given below.

The die for tube expansion in the magnaforming operation was slightly oversize; consequently, the expanded

\begin{tabular}{|c|c|c|c|}
\hline & Yield & Ultimate & \\
\hline Sample & Strength & Strength & $\%$ \\
\hline No. & $k s i$ & $k s i$ & Elongation \\
\hline 1 & 94.4 & 107.0 & 26.3 \\
\hline 2 & 94.3 & 105.5 & 23.2 \\
\hline 3 & 90.0 & $104.5^{-}$ & 27.4 \\
\hline 4 & 97.0 & 105.0 & 25.3 \\
\hline Average & 94.1 & 105.5 & 25.5 \\
\hline
\end{tabular}

section resulted in an average o.d. of 0.983 inch. This problem was solved by swaging the sections to 0.970 inch o.d. Crater-like defects were discovered on the i.d. surface of the expanded areas of some of the tubes. This defect was caused by the arcing from the electrode to the tube surface during the expansion process. A photomicrograph take of a cratered area is shown in Figure 5-7. Structural change due to the arcing is very superficial and, therefore, was judged acceptable.

\subsection{3 $\quad \mathrm{B}_{4} \mathrm{C}$ Loading}

Special precautions were taken to prevent fatigue cracking in the welds during the vibratory compaction of $\mathrm{B}_{4} \mathrm{C}$ powder. The adapter to the vibrator was designed to clamp onto the tube above the bottom end plug weld, thus minimizing stresses on the weld. Metallographic examination of welds severely vibrated in excess of normal process time showed no evidence of damage to the welds.

\subsection{ASSEMBLY}

The tubes were formed and cut to length at Advanced Kinetics, Inc. These tubes were cleaned by brushing and immersion into a Kelite 236 caustic bath and passivated with $18-25 \%$ by volume nitric acid. The first weld was made on the bottom end plug. Because of the full penetration requirement of the weld, the inside of the tubes were purged with helium to provide a cover gas on the backside of the weld. The boron carbide $\left(\mathrm{B}_{4} \mathrm{C}\right)$ powder was then prepared for loading by drying at $100^{\circ} \mathrm{C}$ for 1 hour. Samples were obtained periodically to assure that the moisture content did not exceed $500 \mathrm{ppm}$. Groups 1 and 2 rods were vibratory compacted with $\mathrm{B}_{4} \mathrm{C}$ powder to a minimum of $70 \%$ of theoretical density. Groups 3 and 4 rods were loaded with a charge composed of $50 \%$ by volume $B_{4} C$ and $50 \%$ by volume $1 / 8$ inch diameter Type 430 stainless steel balls. The final weld (top end plug) was made in the weld chamber after the chamber was pumped down to 80 


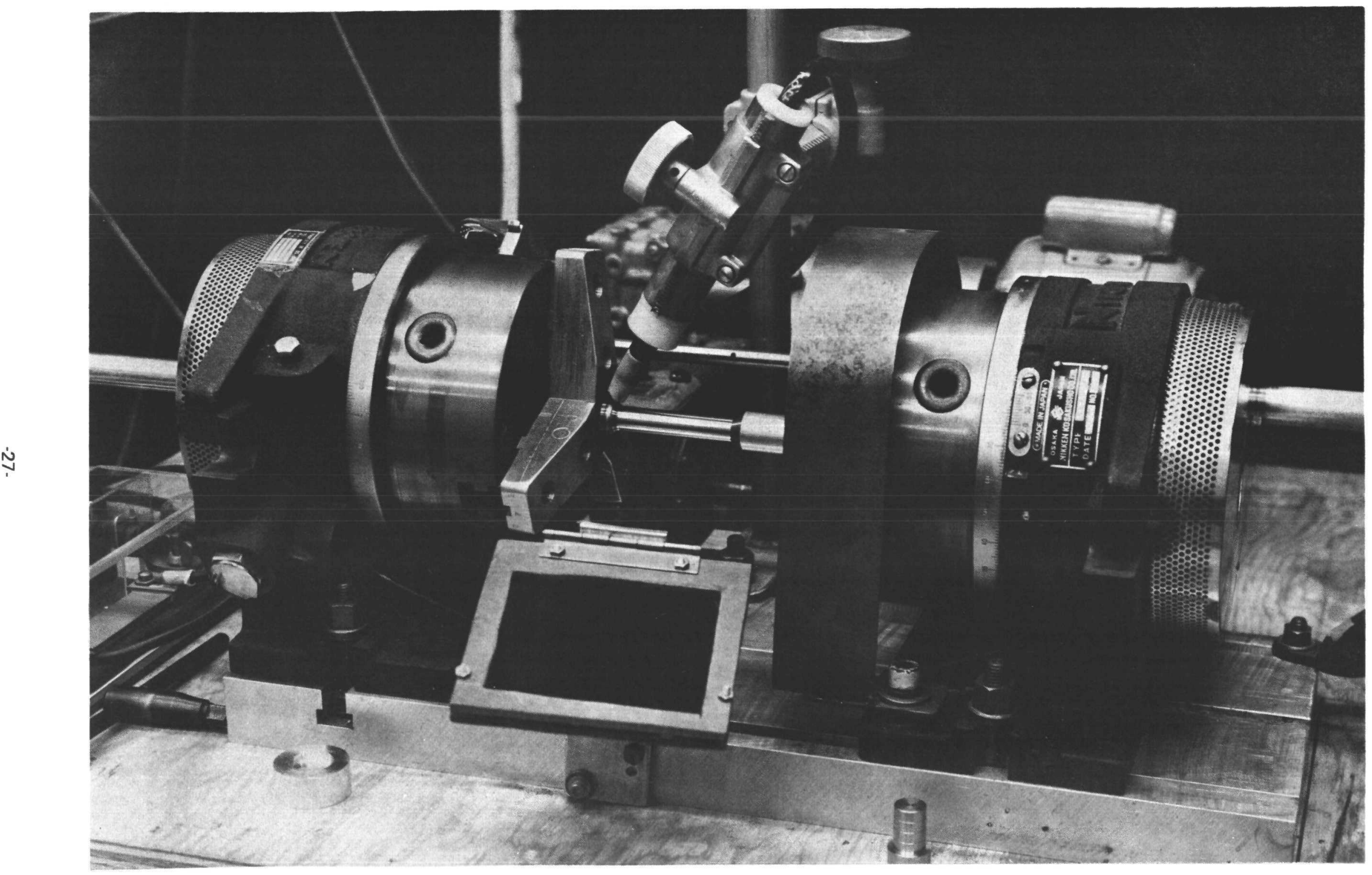


$\dot{\oplus}$

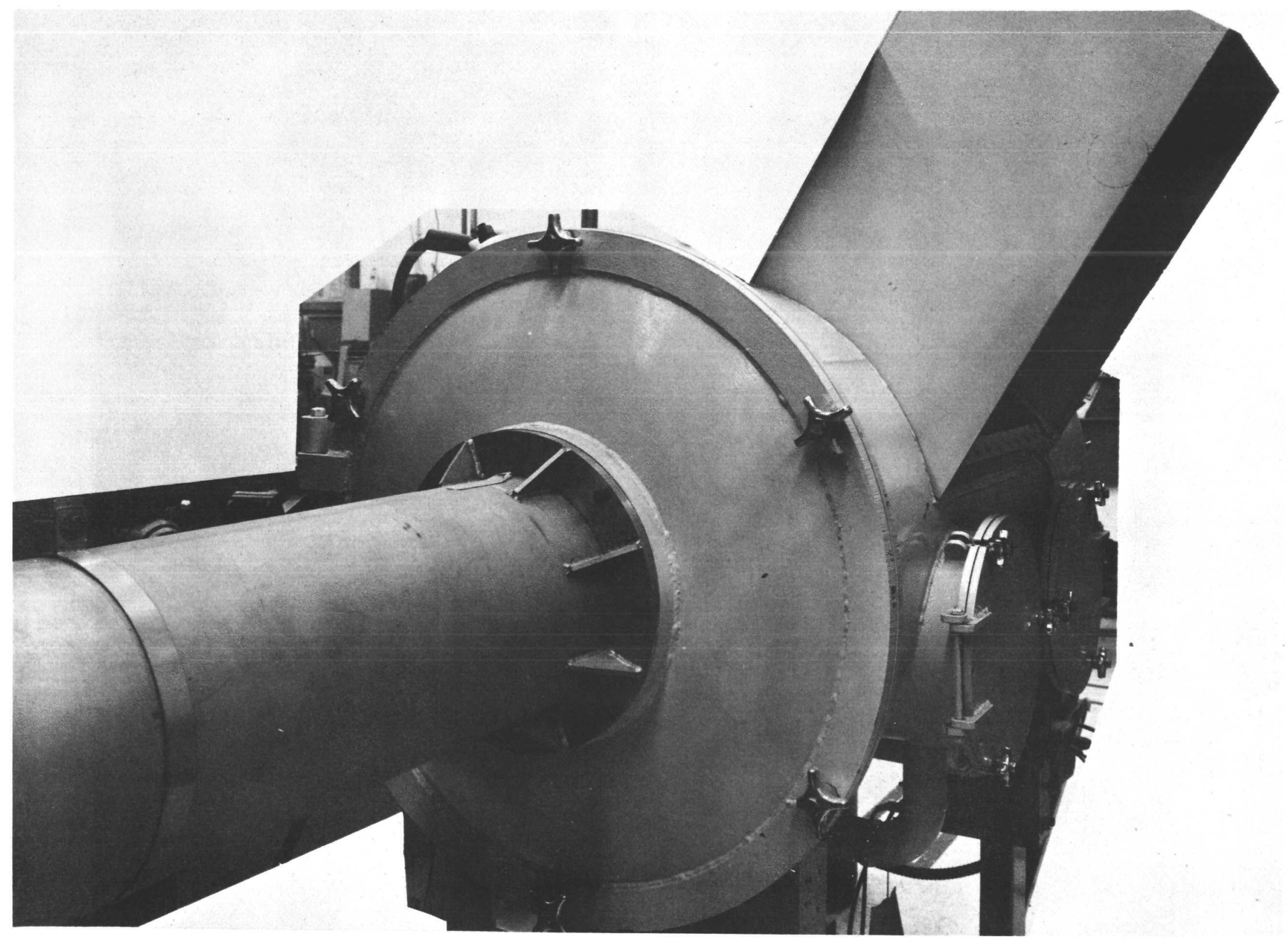




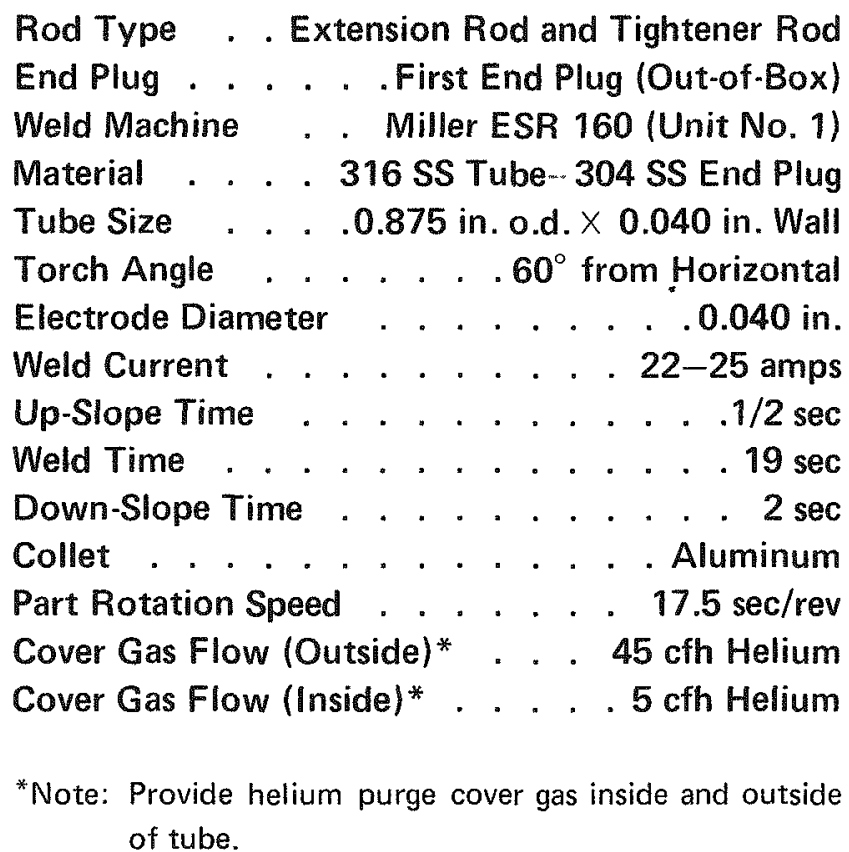

Figure 5-3. Weld Parameters

Rod Type . Extention Rod and Tightener Rod End Plug . . . . Final End Plug (In-Chamber) Weld Machine . Miller ESR 150 (Unit No. 2) Material . . . 316 SS Tube 304 SS End Plug Tube Size . . . 0.875 in. o.d. $\times 0.040$ in. Wall Torch Angle . . . . . . $60^{\circ}$ from Horizontal Electrode Diameter . . . . . . 1/16 in. Weld Current . . . . . . . 21-22 amps Up-Slope Time . . . . . . . . . . . $1 / 2 \mathrm{sec}$ Weld Time . . . . . . . . . . . $19 \mathrm{sec}$ Down-Slope Time . . . . . . . . . . . $2 \mathrm{sec}$ Collet . . . . . . . . . . Aluminum Part Rotation Speed . . . . . . . $17 \mathrm{sec} / \mathrm{rev}$ Cover Gas . . . . . . . Helium Atmosphere Note:

1. Vent pin weld for extension rod - Use hot start to 118 amps and tail off to 0 amps in $2 \mathrm{sec}$

2. Vent pin weld for tightener rod - Use hot start to 100 amps and tail off to 0 amps in 2 sec.

Figure 5-4. Weld Parameters 


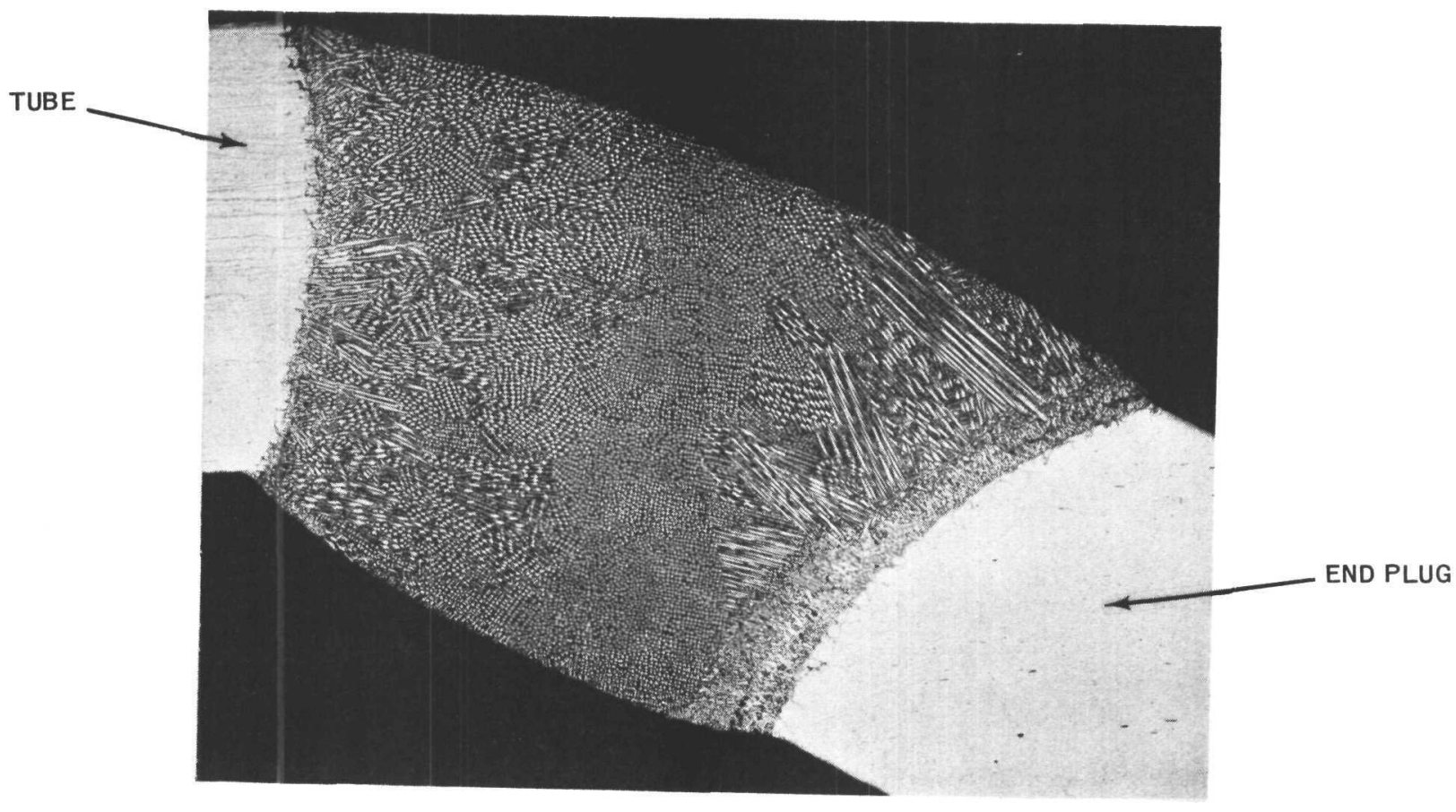

Figure 5-5. Typical End Plug Weld Section 


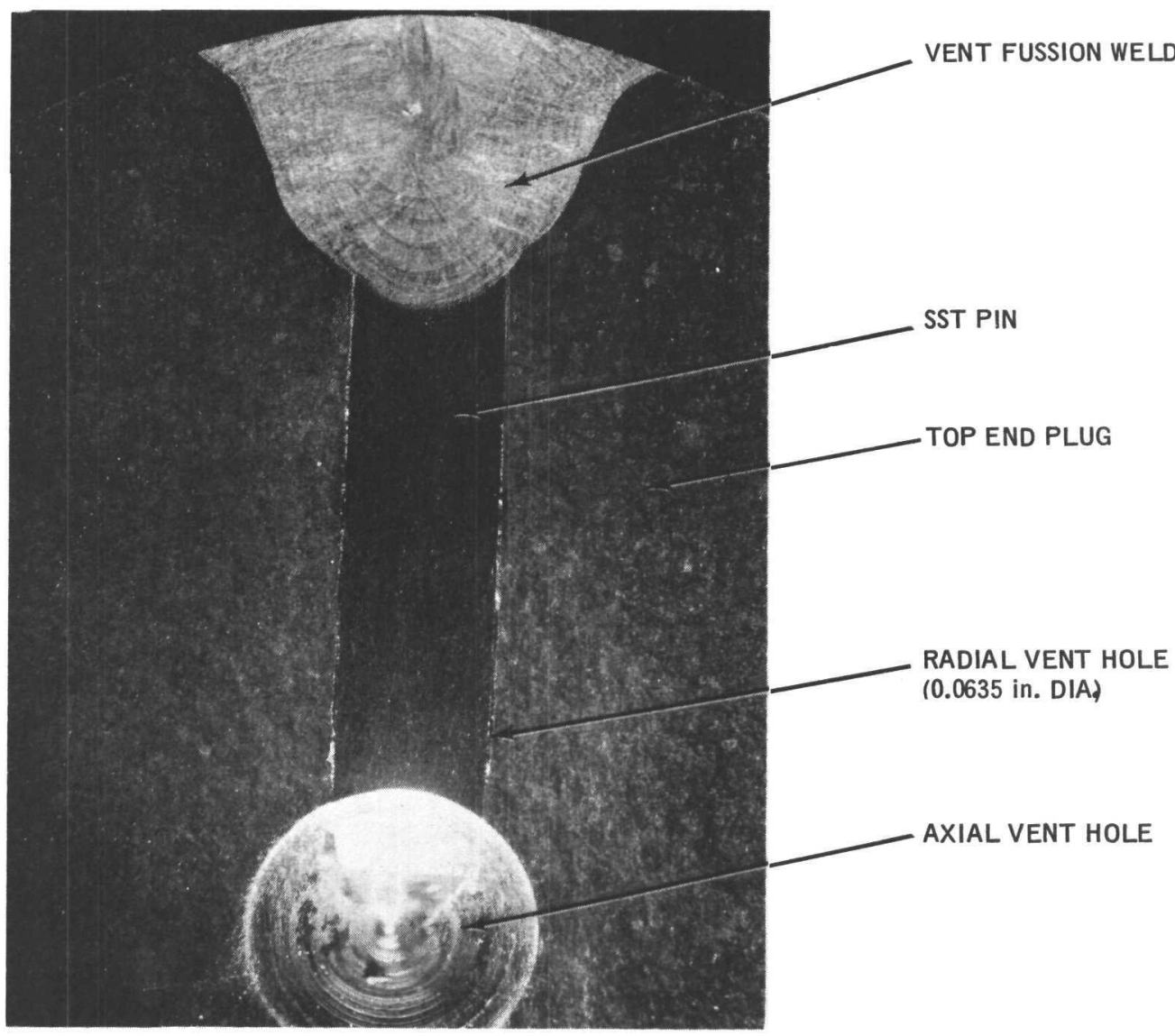

Figure 5-6. Typical Vent Plug Weld for Extension Rod 


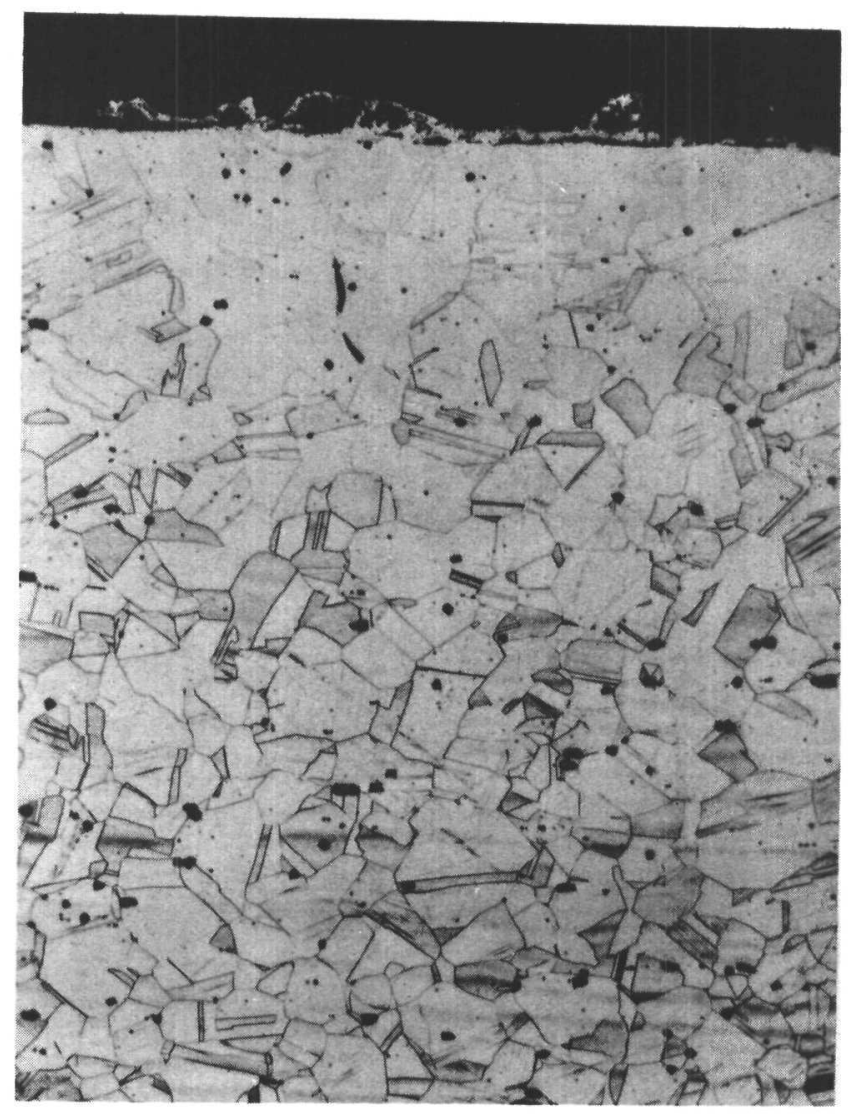

Figure 5-7. Arched Area of Tube I.D. Surface 
microns and backfilled with reactor grade helium to one atmosphere. First the top end plug circumferential weld was made followed by the vent pin weld. The rods were then $100 \%$ leak checked and the welds $x$-rayed.

A description of further nondestructive testing at the SEFOR site is found in Appendix IV.

\section{TIGHTENER ROD}

\subsection{TOOLING}

\subsubsection{Welding Fixture}

The same tooling as that developed for welding the extension rods was used for the tightener rods.

\subsubsection{BeO Loading Box}

Because of the toxicity of $\mathrm{BeO}$, a glove box was constructed for loading $\mathrm{BeO}$ into the tightener rods. The box has a negative pressure to prevent any $\mathrm{BeO}$ particulate release to the work area atmosphere. The box has a 1 inch port to allow insertion of one end of the tightener rod for loading. The $\mathrm{BeO}$ box is shown in Figure 6-1.

\subsection{FABRICATION DEVELOPMENT}

\subsubsection{Welding}

The weld design for the tightener rod is identical to that of the extension rod so that the same weld parameters were used. However, the body of the end plugs differs and the vent hole was placed in a different location. A typical vent plug weld for the tightener rod is shown in Figure 6-2.

\subsubsection{Tube Forming}

The tubes for the tightener rods originally were to be magnaformed, but due to vendor fabrication problems it appeared that the tubes could not be fabricated within a reasonable time. Therefore, the upper section of the tightener rod was redesigned to use solid stainless steel bar machined to the tube contour instead of the formed tube filled with $\mathrm{B}_{4} \mathrm{C}$ powder. In addition, an alternate process was developed to fabricate the lower section tube. The method utilized a modified pipe cutter mounted to the lathe bed and the tube was spin-reduced. This method is feasible and tubes of adequate quality were formed.

\subsubsection{BeO Pellets}

There was concern about excessive moisture in the as-fabricated BeO pellets. Results of moisture analyses on the $\mathrm{BeO}$ pellets are given below:
BeO Moisture Content, ppm*

\section{Subsequent 24-hr}

Lot No. Before Drying After Drying Exposure to Air

$\begin{array}{lllr}\text { D-2 Run 01 } & 30 & 7 & 18 \\ \text { D-3 Run 02 } & 45 & 4 & 7 \\ \text { D-3 Run 03 } & 25 & - & -\end{array}$

*Analyzed with CEC Moisture Analyzer

Based on these analyses, it was decided to dry the pellets. All the pellets were dried by Anamet Laboratories, Berkeley, California, at $300^{\circ} \mathrm{C}$ for 3 hours before loading into the tightener rods.

The final design of the tightener rods has a solid Type 304 stainless steel bar in the upper section of the rod and a straight Type 316 stainless steel tube filled with $\mathrm{BeO}$ pellets and nickel reflectors. The long $B e O$ pellet was relocated to the bottom of the BeO column with a Type 316 stainless steel tube sleeve around the long pellet.

\subsection{ASSEMBLY}

The tubes and upper rods were cleaned with Kelite 236 and passivated with $18-25 \%$ nitric acid. The first weld was made at the middle junction of the rod (rod-to-tube weld). The first weld procedure was similar to the first weld on the extension rods utilizing a helium purge gas on the inside of the tube. Beryllium oxide pellets which had been dried at $300^{\circ} \mathrm{C}$ for 3 hours were then loaded into the tube in a glove box exposure. The final weld was made in the weld chamber in the identical sequence as the final weld for the extension rods. The rods were $100 \%$ leak checked and $X$-rayed. 


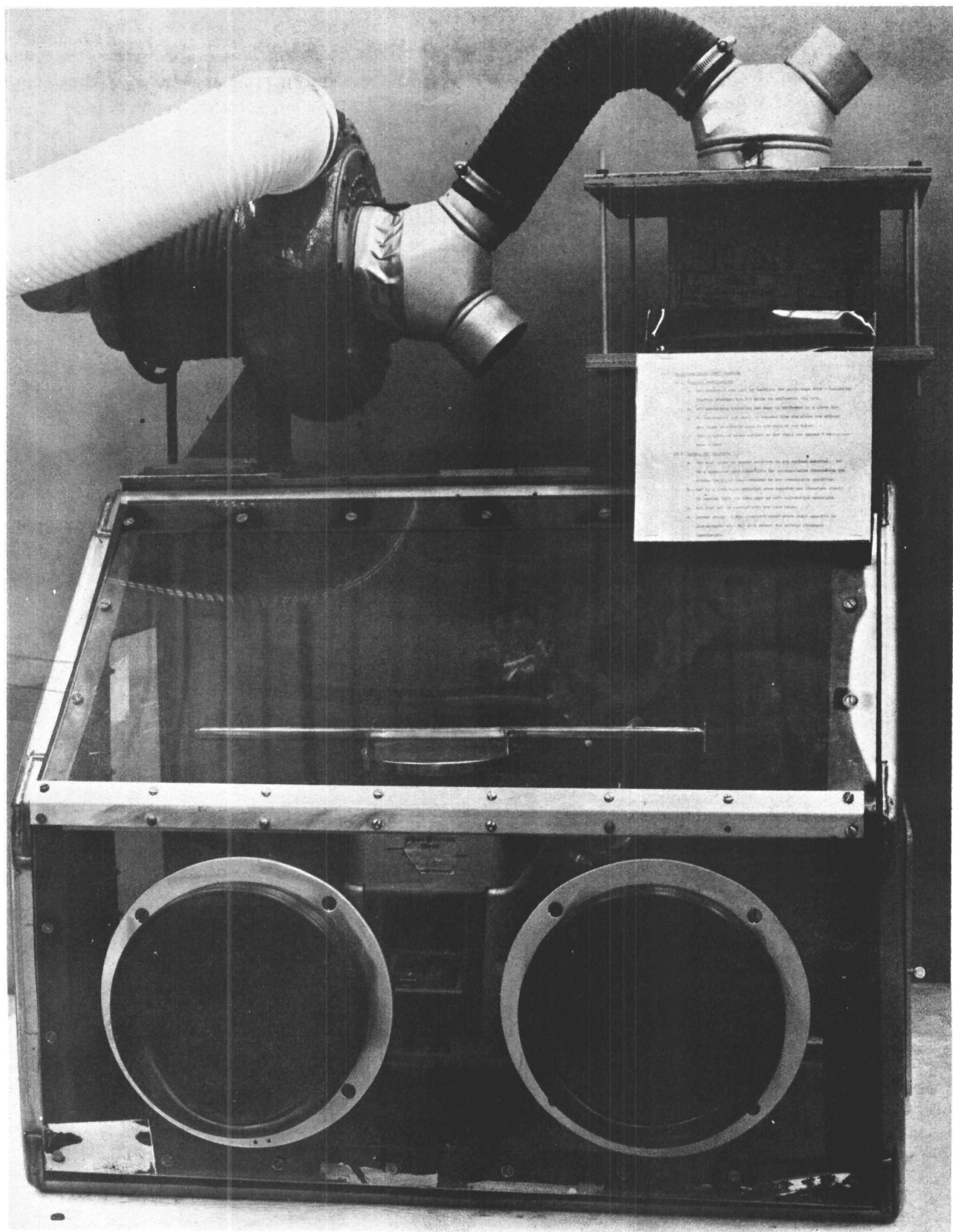

Figure 6-1. BeO Handling Glove Box 
GEAP-13595

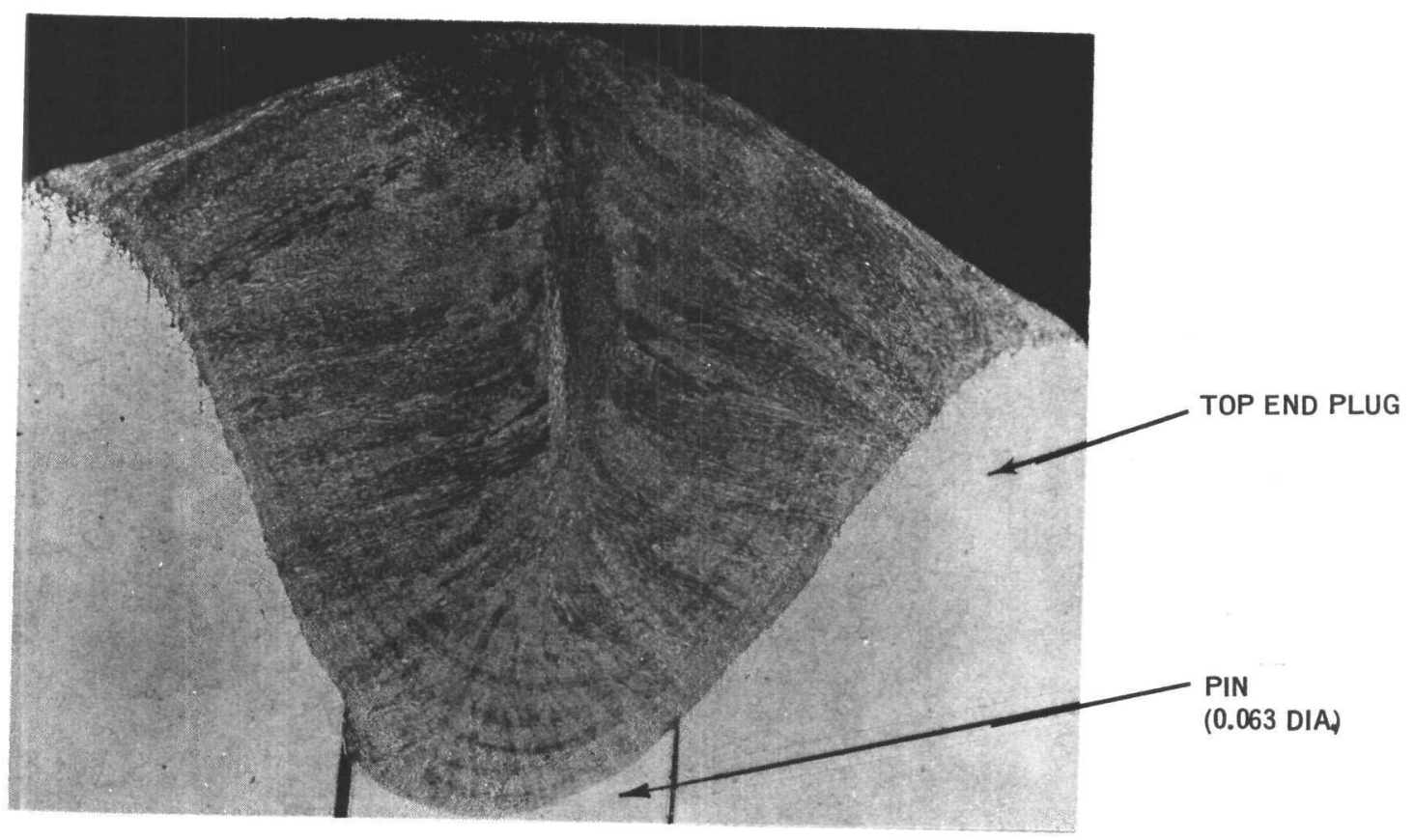

Figure 6-2. Typical Tightener Rod Vent Plug Weld 


\section{TIGHTENER SLEEVE}

\subsection{TOOLING}

\subsubsection{Dimpling Tools}

Figure $7-1$ shows the various tools which were designed for making the dimples in the hexagonal tubes.

\subsubsection{Spring Welding Tools}

The three basic tools required to make the welds on the tightener sleeve springs are shown in Figures 7.2 and 7-3. The expander tool is operated by pulling on the De Staco clamp which draws the tapered mandrel into the tool housing which, in turn, forces out the copper buttons against the internal springs. The expander tool serves a dual function. The copper buttons hold the internal spring snugly against the inside surface of the hexagonal tube and acts as a chill and bearing surface at the weld location.

\subsubsection{Tightener Sleeve Assembly Stations}

Figure 7-4 shows the dimpling station. Figure 7-5 shows a typical spring welding operation. The fin welding station shown in Figure 7-6 was optically aligned so that when the hexagonal tube is placed in the cradle and the fins clamped into position, the fins are in axial alignment.

\subsection{FABRICATION DEVELOPMENT}

\subsubsection{Hexagonal Tubes}

One of the basic sources of the problems in the fabrication of the tightener sleeves was the direct result of the nonuniform (unequal sides) hexagonal tubes. A few of the spring holder tubes had inside diameters (flat-to-flat) that varied between 0.952 to 0.968 inch in any given cross section. The remainder of the tubes were within specification 10.955 to 0.965 inch across inside flats) but the flat-to-flat dimensions varied from the high side to the low side of the tolerance over a given cross section. This severely restricted the fit-up of the internal springs and contributed to the somewhat higher pull force than anticipated to remove the tightener rod from the tightener sleeve. Further development effort would be recommended to form hexagonal tubes of more uniform dimensions if a similar design were to be employed in the future.

\subsubsection{Springs}

As a result of the nonuniform dimensions of the flats on the hexagonal tubes the internal springs as originally designed would not fit in the tightener sleeve tube. The misfit accumulates along the sides of the hexagon. The sides of the springs were shortened and the corners were made with a sharper radius, thereby allowing the proper seating of the springs on the inside surface of the hexagonal tube. Other minor modifications were made to the internal springs to allow the protruding weld locating button to clear the hexagonal tube diameter. No major problem was encountered on the external springs. It appears that a greater degree of misfit can be tolerated on the external spring dimensions. The internal and external springs are shown in Figure 7-7.

The precipitation hardening heat treatment of a sample batch of springs in air resulted in a black, lustrous oxide film which resisted removal by $\mathrm{HF}^{-\mathrm{HNO}_{3}}$ cleaning treatment. Consequently, the springs were cleaned by the Kolene DGS process at California-Doran Heat Treating Co., Los Angeles, California. Kolene DGS is an anhydrous molten oxidizing salt bath using a sodium hydroxide base. From this experience it is recommended that Inconel 718 spring material be heat treated in a dry hydrogen atmosphere or in vacuum to eliminate the oxide problem.

\subsubsection{Fins}

The design required annealed precision sheet metal parts. Because the dimensional tolerances of these complex formed parts were difficult to maintain during annealing without extensive precision fixturing, a final reforming step was required after annealing.

\subsubsection{Design Modifications}

Design changes were necessary to make the tightener sleeve functional. The design was based on the assumption that the tightener rod, when inserted into the tightener sleeve, would snake around opposing dimples in the upper section above the core. However, the tightener sleeve was too stiff; consequently, the tightener rod could not be inserted in the first prototype assembly. It was subsequently determined that the tightener springs themselves were adequate to maintain the tightener rod in a center position in the upper section of the sleeve. As a result, four (4) sets of dimples in the upper section were eliminated from the original design.

The original design of the tightener sleeve also included a bottom spring to temporarily hold the tightener rod in an intermediate (or unlocked) position to relax the tightening springs during fuel rod removal and insertion. However, pull tests performed on mock-up assemblies indicated that the bottom spring added significantly to the pull force necessary to lift the tightener rod into the unlocked 


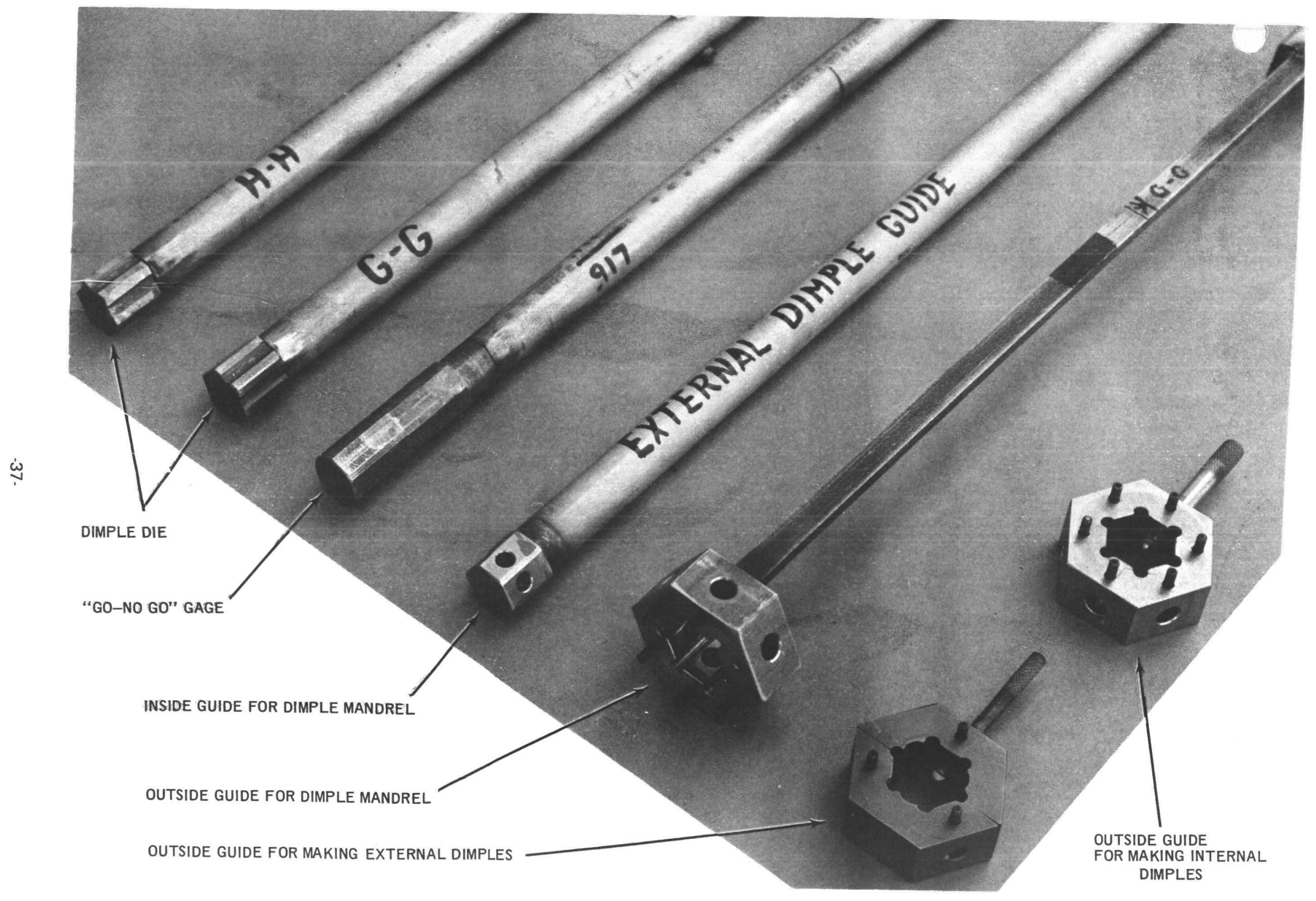




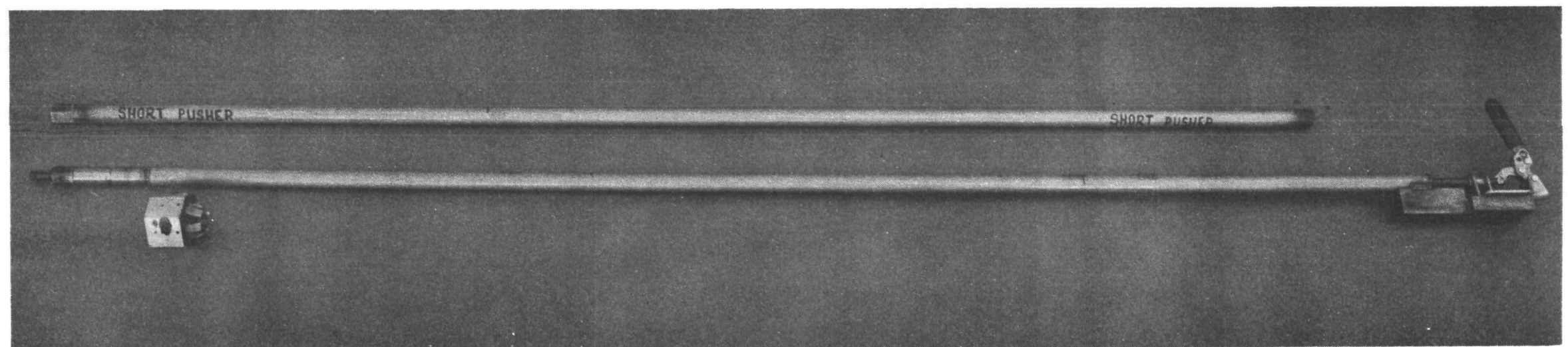




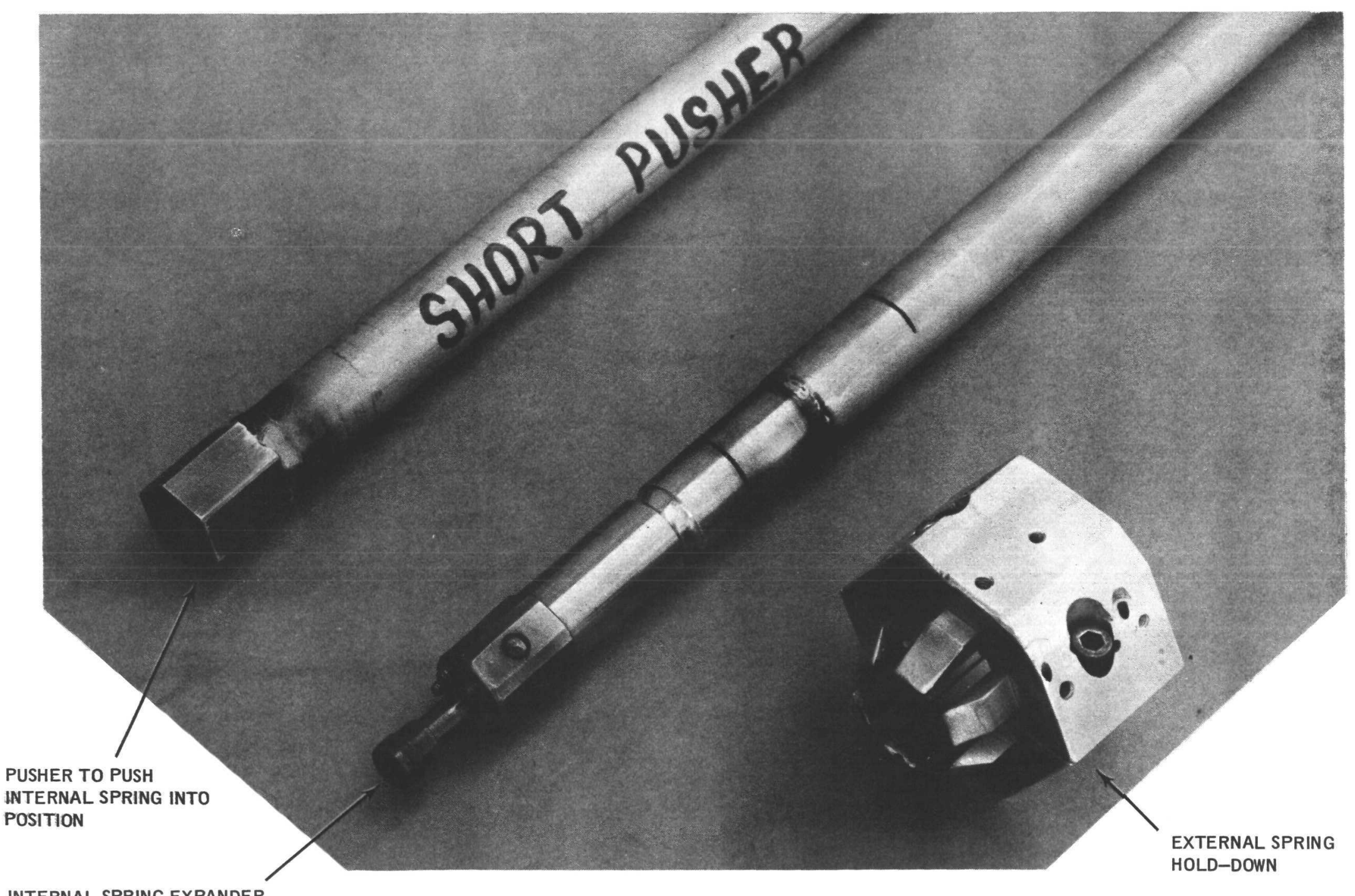




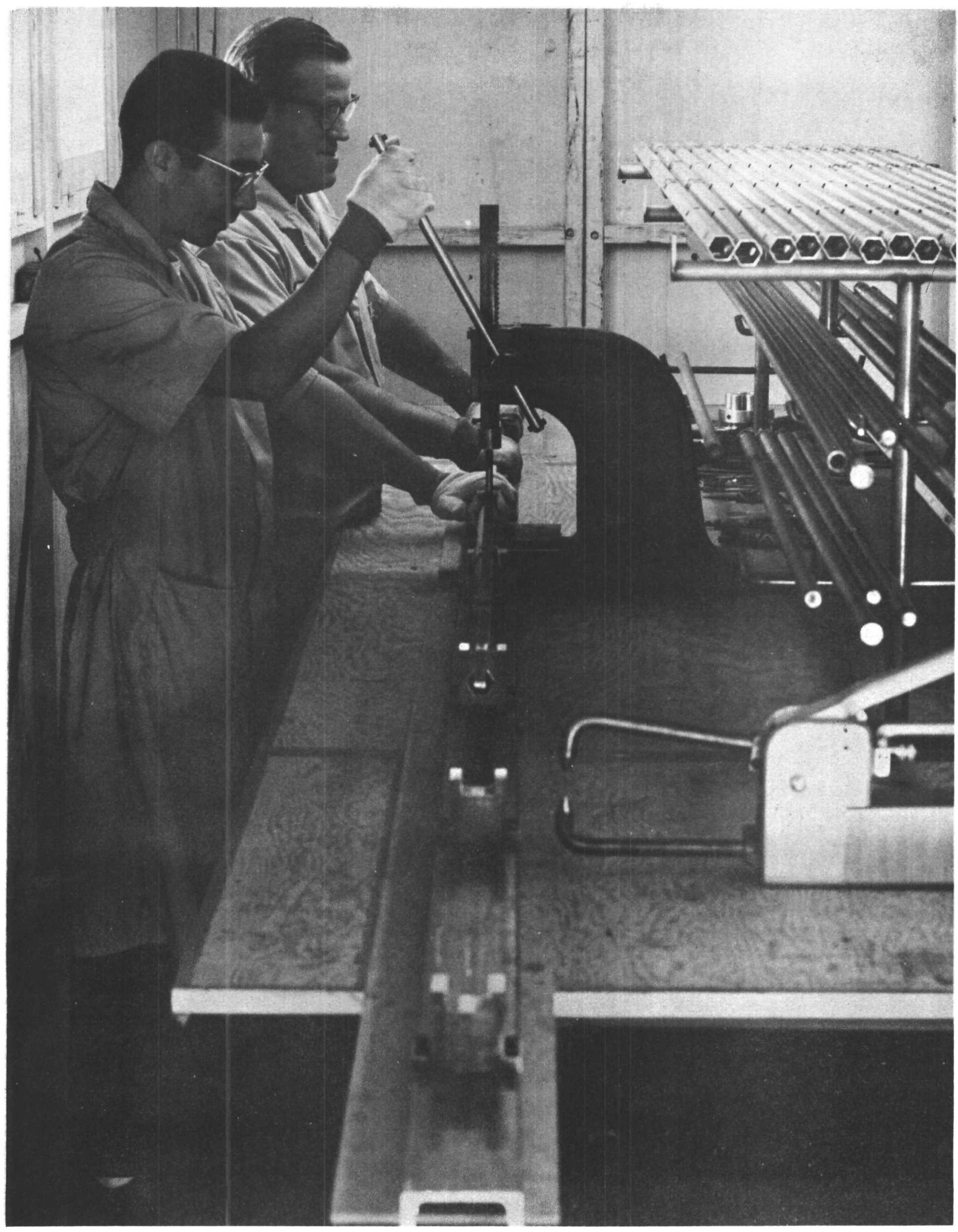

Figure 7-4. Tightener Sleeve Dimpling Station 


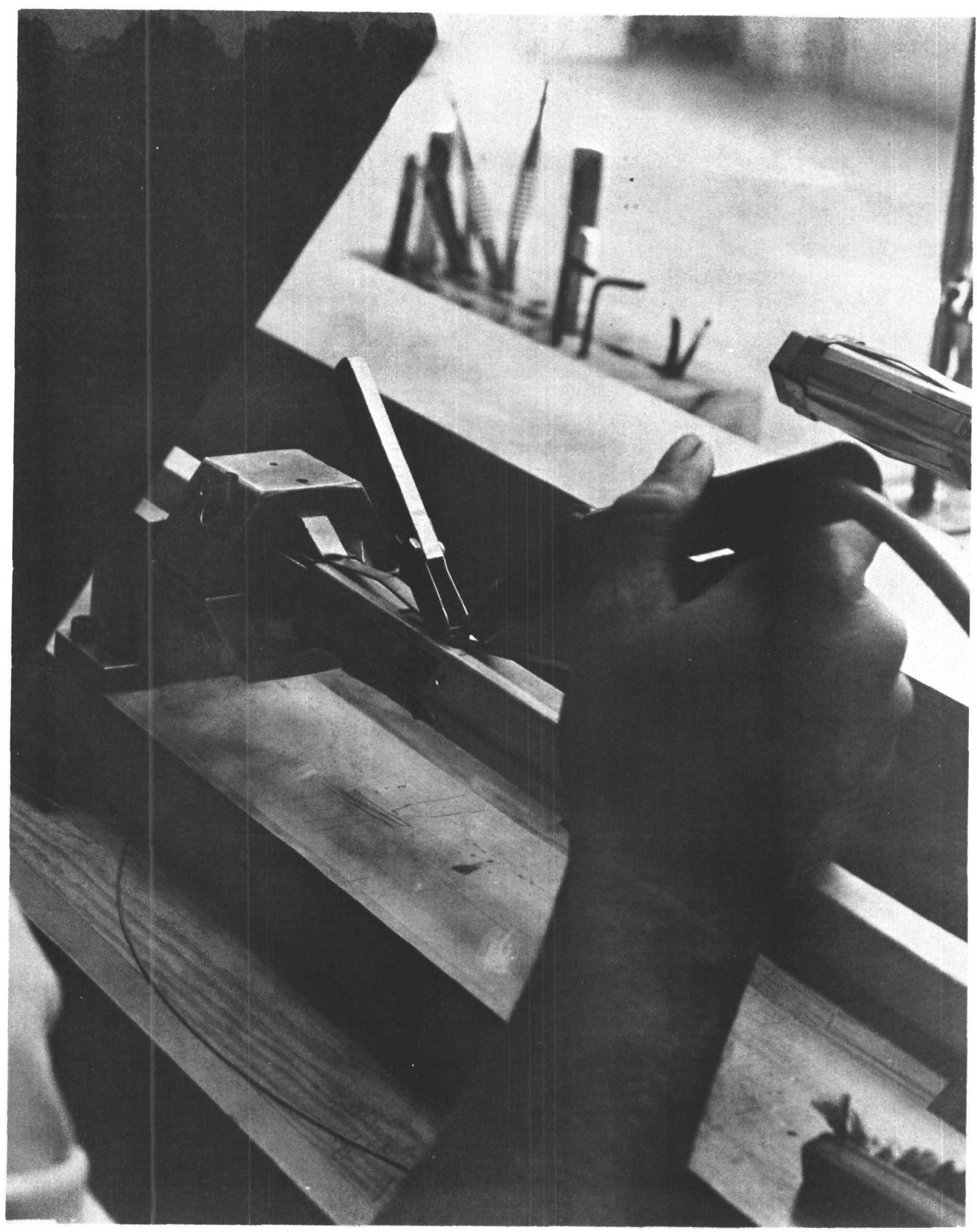

Figure 7-5. Tightener Sleeve Spring Weld Station 


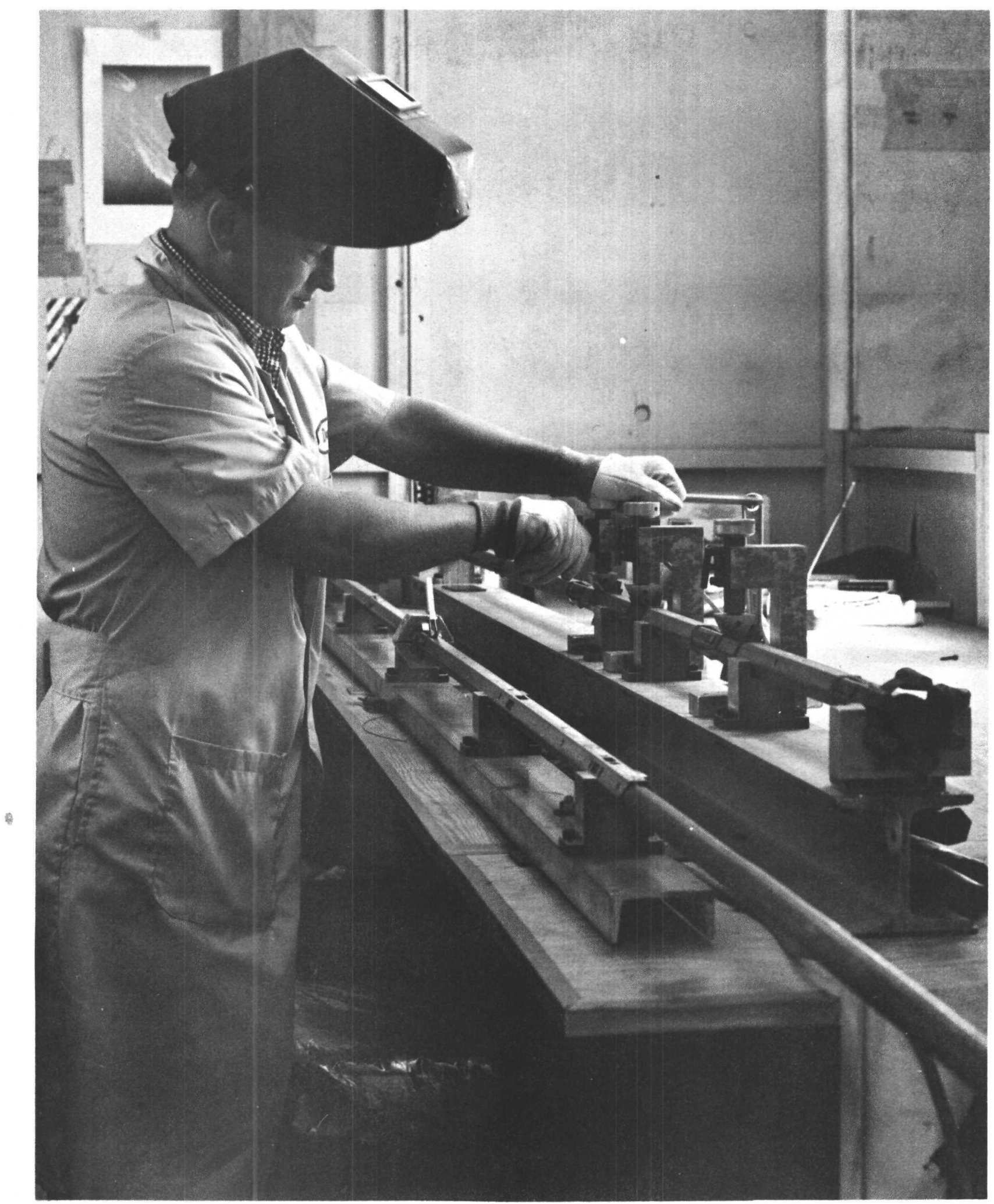

Figure 7-6. Tightener Sleeve Fin Assembly Station 


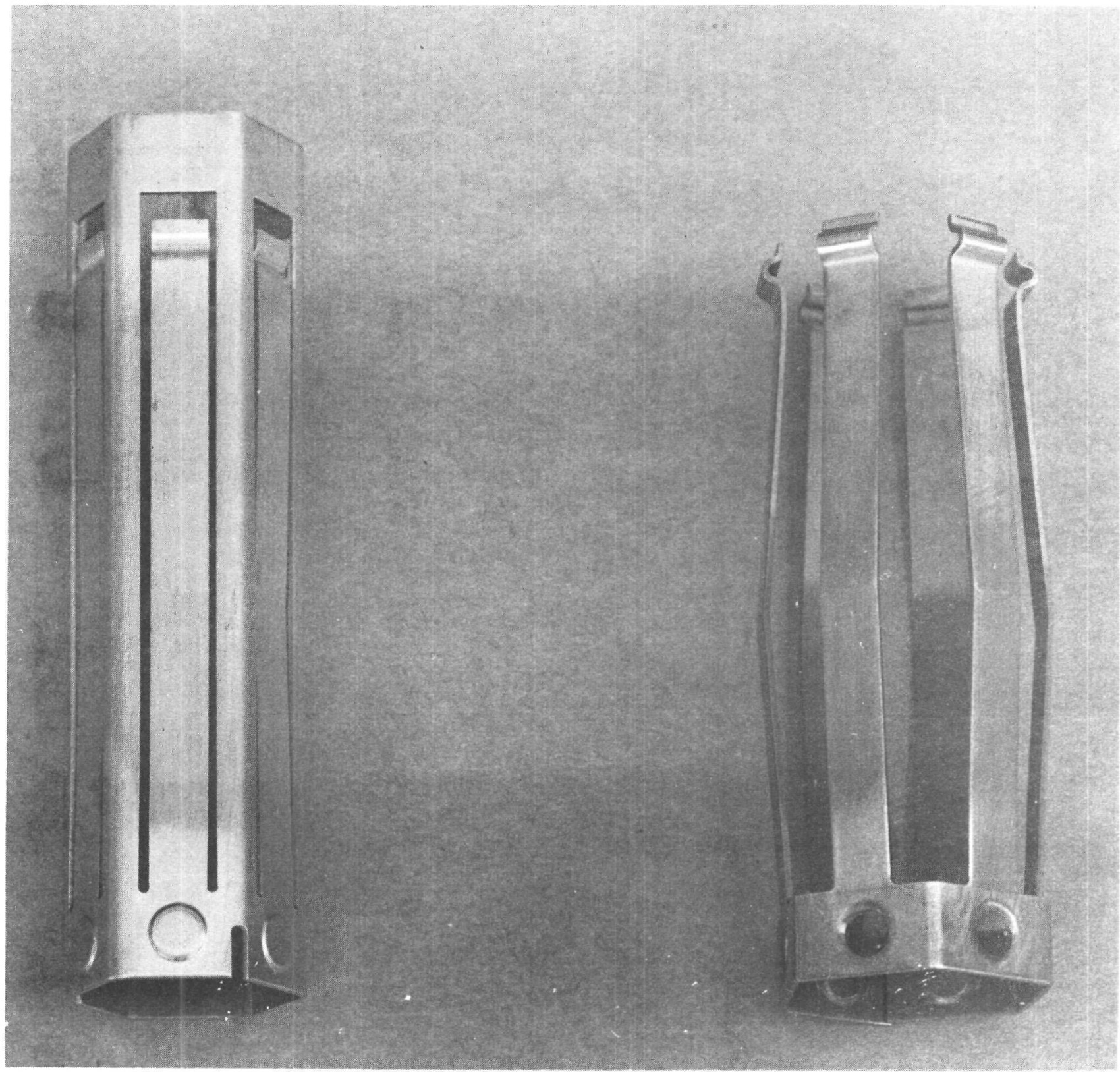

INTERNAL SPRING

EXTERNAL SPRING

Figure 7-7. Tightener Sleeve Springs 
position. Additional tests were also made which showed there was sufficient friction force from the tightener spring contacts to hold the tightener rod in any desired partially withdrawn position. Based on these tests, the bottom spring was determined to be unnecessary and was eliminated from the final design.

\subsection{ASSEMBLY AND FINAL TESTING}

The detailed fabrication procędure is given in Appendix II.

A mock-up assembly was fabricated and assembled using dummy components. Terts using the mock-up showed that the tightener rod could not be easily inserted or withdrawn because of the tight tolerance through the internal spring region. It was found that adequate clearance could be obtained by running a 0.894 inch diameter mandrel through the spring area of each tightener sleeve to seat the internal springs against the hexagonal tubes.

After the fabrication of the tightener sleeves was completed, each assembly was given a mock-up test and a pull test was performed to insure that each tightener rod could be withdrawn with a pull force of less than 75 pounds.

Welds in the tightener sleeve fabrication were all made by manual control. Photographs of typical weld sections are shown in Figures 7-8 and 7-9.

A test was performed to thermally shock stress the spring assembly in excess of conditions expected during the life of the tightener sleeves. The thermal shock test is described in Appendix $V$.

The cut-aways in the hexagonal tubes were stamped out by Reliance Tool and Die, Inc., San Jose, California. Deburring was a major problem due to the inaccessibility of the burr and the gummy nature of 304 stainless steel. 


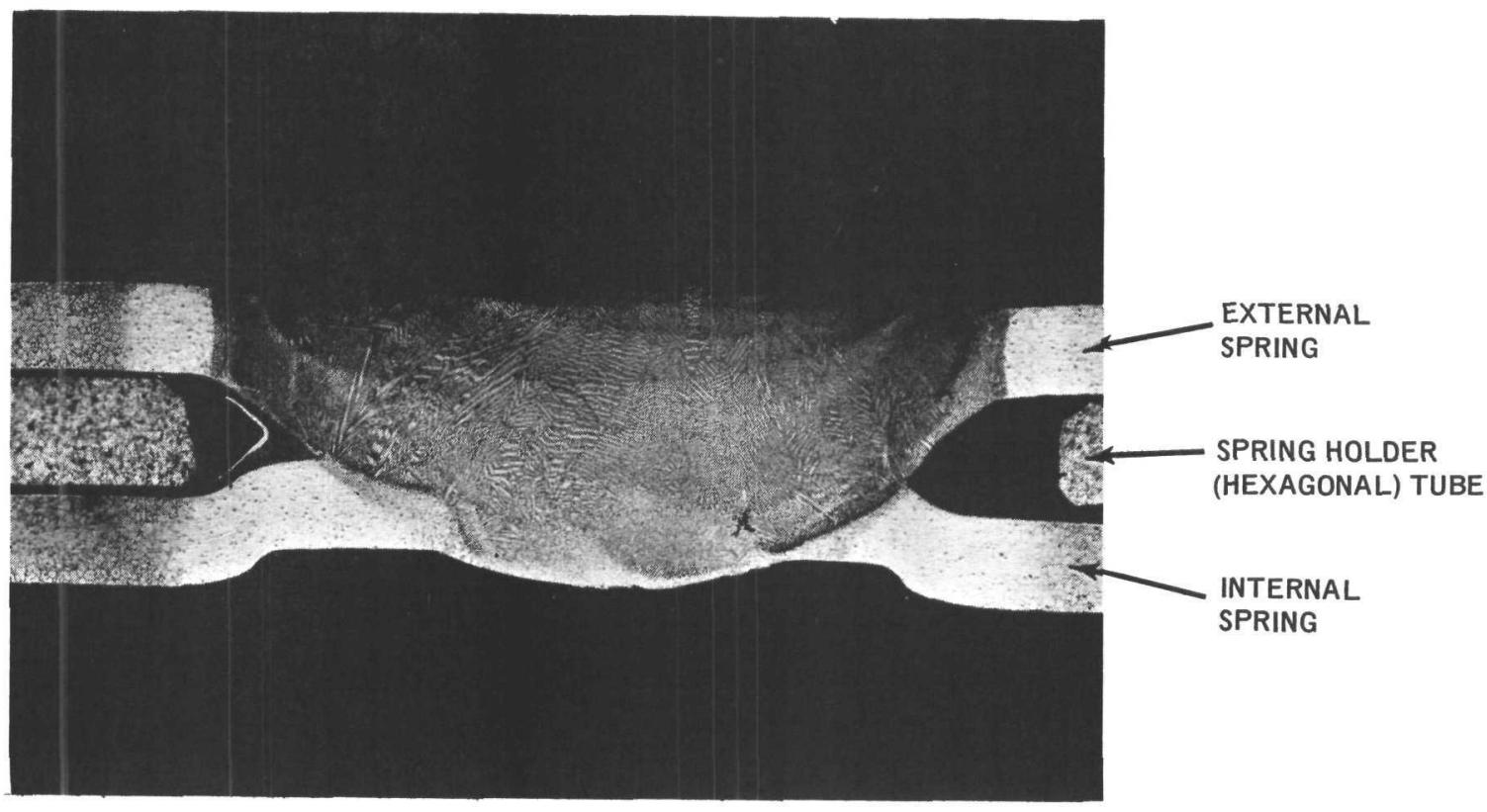

TYPICAL SPRING FINGER-TIP WELD

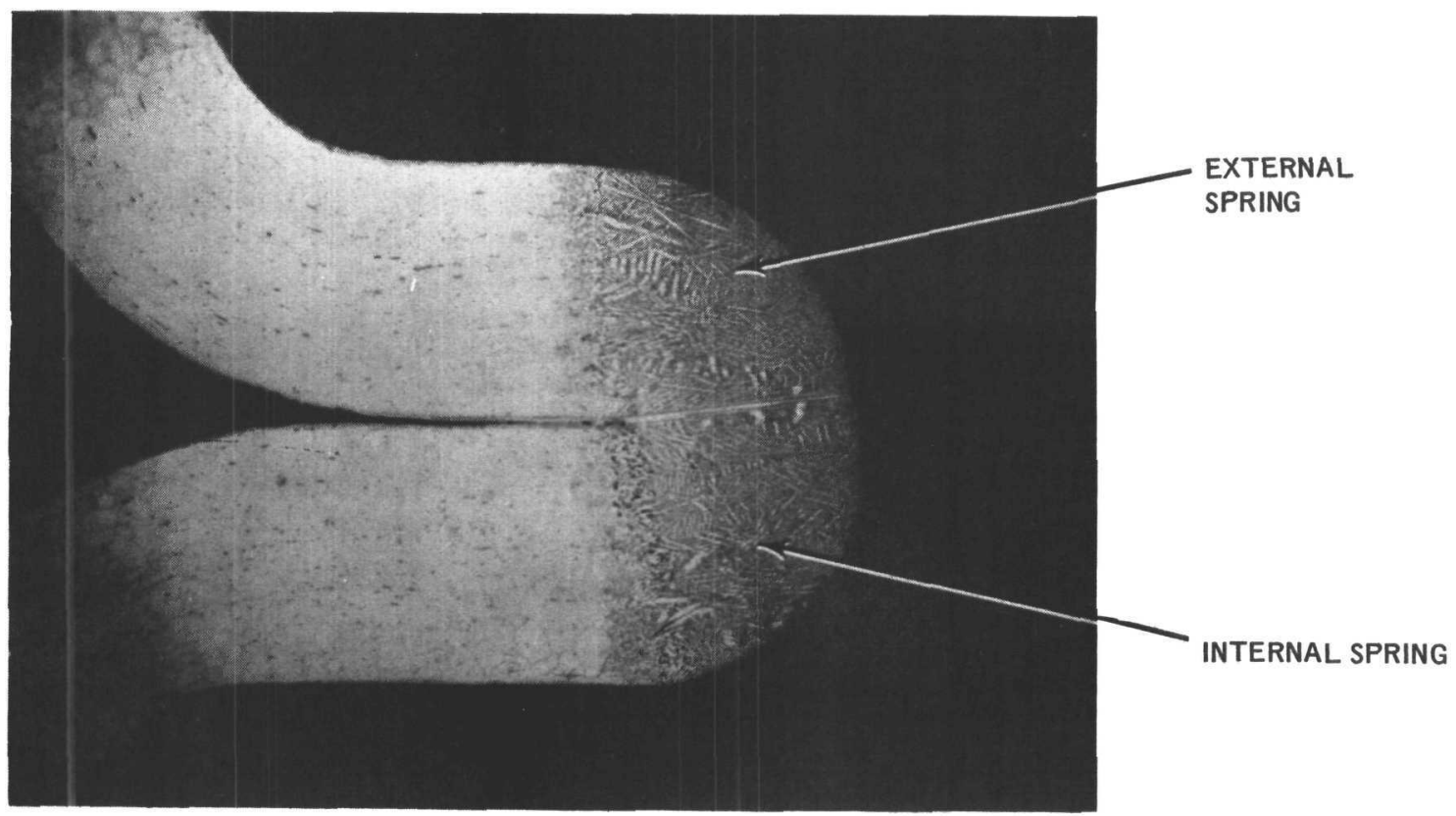

Figure 7-8. Tightener Sleeve Spring Weld: Typical Upper Weld (External Spring-to-Internal Spring Weld) and Typical Spring Finger-Tip Weld 


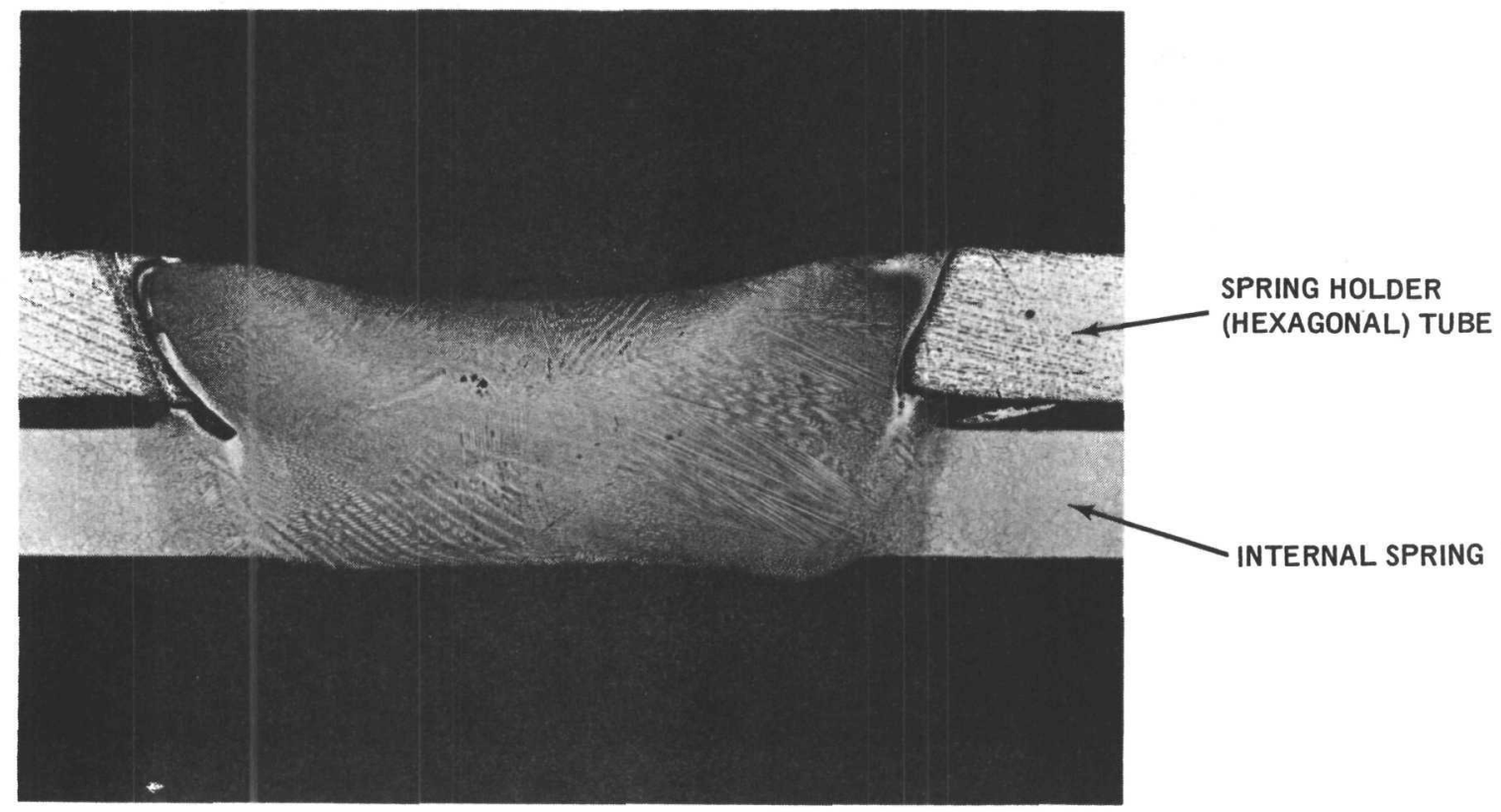

Figure 7-9. Tightener Sleeve Spring Weld: Typical Lower Weld (Internal Spring-to-Hexagonal Tube Weld) 


\section{INSTRUMENTED TIGHTENER SLEEVE (UPPER AND LOWER)}

The hexagonal tubes for these assemblies were machined by GE-Vallecitos Nuclear Center machine shop. The instrumented tightener sleeves were assembled in the identical manner as the regular tightener sleeves described above. A subsequent report will describe the instrumented fuel assembly fabrication.

\section{FOIL HOLDER ROD AND SURVEILLANCE RODS}

These rods were machined and assembled in a routine hardware fabrication procedure similar to those described in Sections 5 and 6.

\section{QUALITY CONTROL}

\subsection{PROCESS GUIDES}

The general instructions for fabrication procedures were outlined in the "Development Guide for the Fabrication of Extension and Tightener Rods" and "Procedures for Assembly of Tightener Sleeves" and are presented in Appendix I and II, respectively.

\subsection{QUALITY CONTROL PLAN}

The Project Quality Control Plan (Appendix III) was followed to maintain product quality. In-process quality control was maintained by a constant audit of the fabrication processes and travel cards. Final inspection was performed on $100 \%$ of the rods and tightener sleeves produced.

\subsection{PROCESS CONTROL}

Process control of the extension and tightener rods was maintained by a travel card which accompanied the rods through the entire processing sequence.

Control of the fabrication process for the tightener sleeves was maintained by a work station log. After each series of operation, the operator initialed the checklist to certify that the operation was performed.

\section{ACKNOWLEDGEMENT}

The authors wish to acknowledge the assistance of $W$. H. Arlt, and H. S. Clair of the Fuels Laboratory, and W. H. Rodgers of Purchasing for their cooperation and their major contribution to the program. The authors also extend acknowledgements to H. M. Cooper, M. A. Bell, and D. E. Lewis of the Fuels Laboratory for their special efforts and accomplishments in the fabrication processes; to D. J.
Schiro, BRDO, for his help on design problems; and to $G$. G. Gaul, BRDO, for his helpful consultation on material problems.

A special thanks goes to each and every member of the Fuels Laboratory for their extraordinary response to the difficult and urgent demands for the production of the SEFOR core components. 
GEAP-13595

APPENDIX I

Development Guide for Fabrication of SEFOR R\&D Extension and Tightener Rods 49. 


\section{GEAP-13595}

FULL NLVLLOPIIFAT TLOORANLU! INO. SE

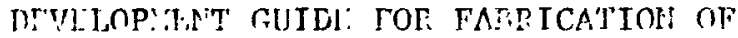

GEFOR FAT L:TTESIOA AND TIGHTENER LODS

Preparei iy:

Approvec by:

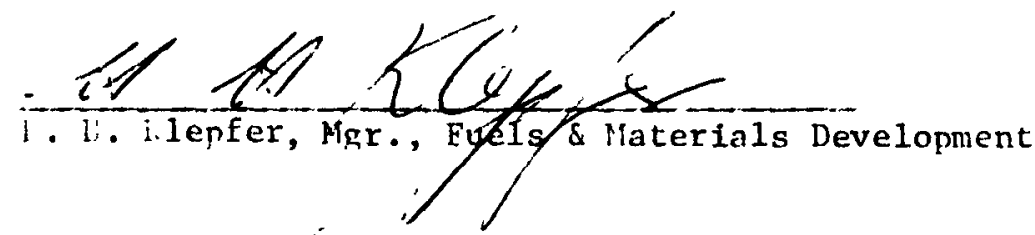

Reviewed iv:

San Josr iuclear Safety Council

necerher $14,196.7$ 


\section{DEVELOPMENT GUIDE FOR FABRICATION OF SEFOR RED EXTENSION AND TIGHTENER RODS}

\subsection{General}

This development guide describes the procedures for the fabrication of the SEFOR R\&D Extension and Tightener Rods in the Fuels Laboratory.

\subsection{Spectal Requirements}

2.1 All persons assigned to this project shall read guides for his work assignment prior to performing his particular task. Any deviations from the guides shall be brought to the attention of the process engineer immediately.

2.2 All persons assigned to this profect shall read and be thoroughly familiar with the safety instructions described herein prior to performing his particular task.

2.3 Beryllium oxide ( $\mathrm{Be} 0$ ) pellets will be used in the tightener rods. Beo is a highly toxic material; therefore, all personnel handing BeO must be thoroughly famillar with the safety instructions described herein.

2.4 Boron carbide $\left(\mathrm{B}_{4} \mathrm{C}\right)$ is a nuclear poison. It is absolutely essential that no $\mathrm{B}_{4} \mathrm{C}$ powder be allowed to contaminate $\mathrm{UO}_{2}$ fuel. Therefore, all personnel must handle $\mathrm{B}_{4} \mathrm{C}$ powder in a manner that absolutely prevents cross-contamination possibilities.

\subsection{General Description of the Rods}

3.1 Extension Rods are Type 316 stainless steel formed tubes filled with $\mathrm{B}_{4} \mathrm{C}$ powder or $\mathrm{B}_{4} \mathrm{C}$ powder-stainless steel ball mixture. These rods are to be assembled onto the upper end of the core fuel rods.

3.2 Tightener rods are Type 316 stainless steel formed tubes consisting of two adjoining parts, upper and lower sections. The lower sections, loaded with BeO pellets and nickel reflectors, comprise the center rod of the fuel rod cluster. The upper section will contain a $\mathrm{B}_{4} \mathrm{C}$ powderstainless steel ball mixture and become part of the extension rod region. 
The tightener rods, Located in the center position of a six-rod cluster of fuel, holds the fuel rods in position.

4.0 Drawings

The principal drawings are:

$\begin{array}{ll}\text { Drawing No. } & \text { Title } \\ 112 \mathrm{C} 2072 & \text { Extension Rod } \\ 846 \mathrm{~F} 777 & \text { Tightening Rod }\end{array}$

\subsection{Flow Charts}

General flow charts for the fahrication process are shown in Figures 1 and 2 .

\subsection{Process Check List Procedure}

6.1 Each batch of in-process tubes shall be accompanied by a travel card. The travel card is a flow diagram giving snecific parts to be used at their resnective sten in the process.

6.2 The nrocess onerator shall enter fabrication data onto the travel card, where recuired, and place his inftial adjacent to the anpronriate step upon completion of his task.

\subsection{Quality Control Procedure}

7.1 OC-Purchased Materials shall provide inspection of incoming materials.

7.2 OC-Fuels shall perform in-nrocess audit and final inspection of the rods.

7.3 Parts and rods which do not meet specifications shall be rejected by the blue taf nrocedure.

7.4 Disposition of the rejected parts will be determined by the I. R. procedure.

\subsection{In-process Tube Identification}

A series of numbers have been assigned to each group of tubes. These numbers shall be electroetched near the ends of each tube. 
FIGURE I-I

Extension Rocis

$112 \mathrm{C} 2072$

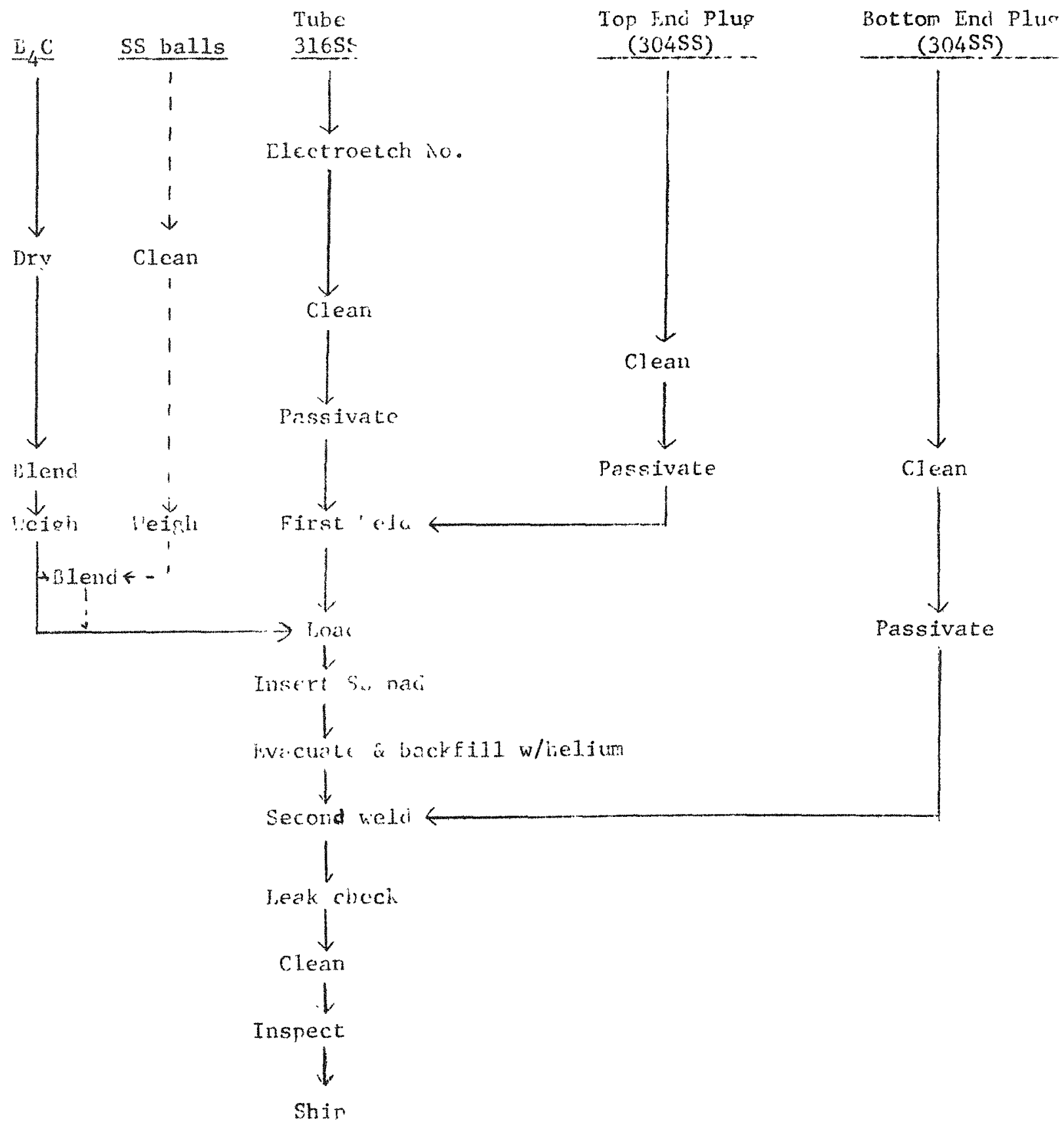


EIGURE I-2

\section{Tightener Fods}

8460777

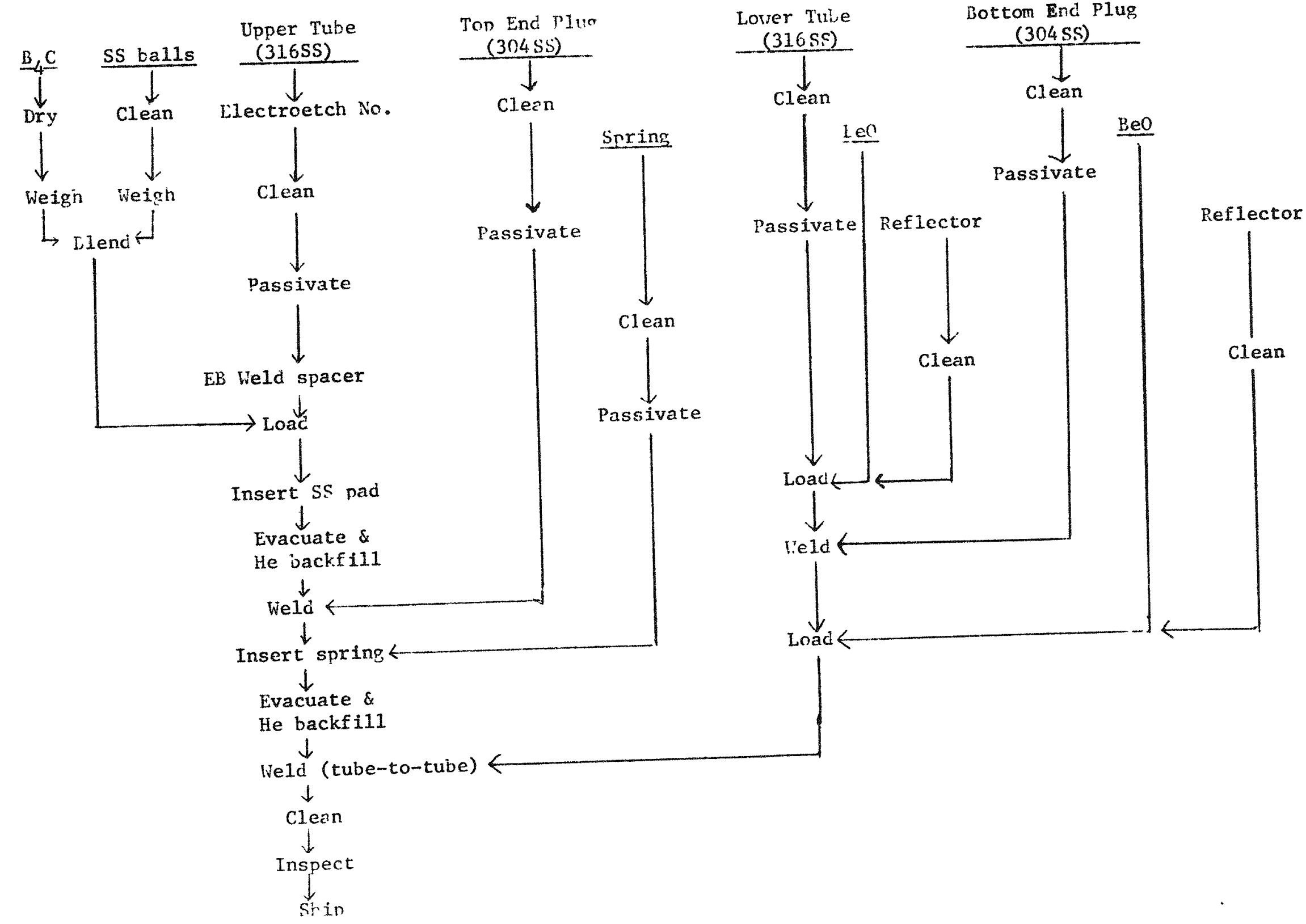




\subsection{Cleaning}

\subsection{Special Instructions}

a. Thoroughly clean all tanks before charging.

b. Check purity of deionized water with the solubridge.

c. Turn on agitator pump in Tank 非.

\subsection{Safety Instructions}

a. Operator must wear a face mask, plastic apron, and gloves when handling cleaning solutions.

b. In prenaring cleaning solutions, the Oakite 90 or nitric acid must be poured into the water, not vice versa.

\subsection{Preparation of Cleaning Tank}

Tank No. Fill with

$1 \quad 10 \%$ bv vol. Oakite 90

Bal.ance - - Tap water

2 Soft water

3 Deionized Water

$4 \quad 18-25 \%$ by vol. $\mathrm{HNO}_{3} 42^{\circ}$ Fie Balance - - Tan water

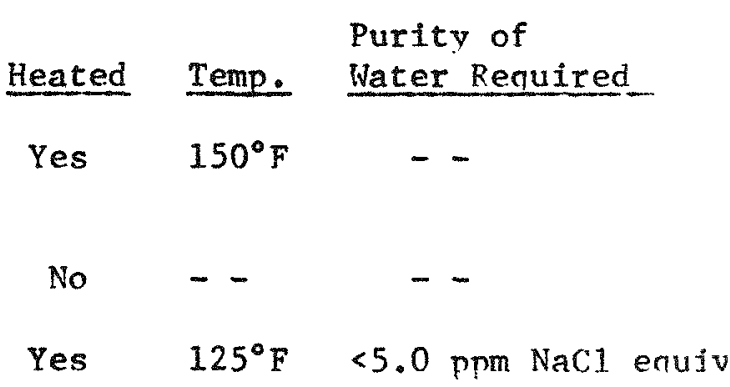

\subsection{Procedure}

a. Place parts in hot nakite 90 solution (Tank 1) for a total residence time of 10 minutes.

b. Rinse in soft water (Tank 2).

c. Place parts into nitric acid tank (Tank 4) for 10 minutes.

d. Rinse in soft water (Tank 2).

e. Drain rinse water thoroughlv; then soak in hot delonized water (Tank 3) for 10 minutes.

f. Air-dry tubes in an upright position for at least 15 minutes.

g. Put cleaned narts into plastic bags.

\subsection{Process Control}

A. A cotton swab dampened with acetone shall be passed through two 
tubes per batch. If the swab is discolored, the entire batch of tubes must be recleaned.

b. Visuallv check for moisture in the tubes.

c. Process engineer shall make perfodic Inspection of the tubes. 


\subsection{Weld Qualification}

10.1 Weld parameters shall give a minimum weld penetration of $100 \%$ of tube wa11 thickness.

10.2 Weld samples sha11 be examined for minimum and maximum weld current fluctuations.

10.3 After the final weld Darameters are established, five (5) consecutive welds shall be made and examined metallogranhicallv. All welds must have a minimum of $100 \%$ penetration.

10.4 Retain strin chart recordings of aualifying welds for use as a reference standard. 
11.0 First End Plug Welds (Out-of-box welds)

\subsection{Special Instructions}

a. At the beginning of each shift, check the inert gas tanks.

b. Trace all welds on recorder.

\subsection{Procedure}

a. Check weld settings.

b. Check timing of tube revolution.

c. Weld on automatic sequence.

d. Make weld samples at the beginning of each shift and after every twenty (20) welds thereafter.

e. Check each weld for comoleteness, annearance, and bead contour.

f. Check weld trace and identify by tube numbers. Deviations from the reference trace shall be brought to the attention of the process engineer.

\subsection{Process Contro1}

a. Weld samples shall be examined metallogranhically by the process engineer.

b. The process engineer shall make periodic examinations of weld anpearance. 
$12.0 \quad P_{4}$ C Loading

\subsection{Special Instructions}

a. The tubes shall be loadec as follows:

Lxtension rods (1) 11202472 )

$\mathrm{GI}$ and $\mathrm{C} 2$ lin. $70 \% \mathrm{~T} \cdot \mathrm{I} \cdot{ }^{3} \mathrm{C}$

C.3 anc $\mathrm{C}_{4}$ 50\% by vol. $\mathrm{D}_{4} \mathrm{C}$

jor by "ol. Stainless stecl shot

Iishtener "ads (; wr 4460777 )

Q1 50\% by vol. $\quad .4 \mathrm{C}$

50\% by vol. Gtajnjess steel shot

b. Ihe ${ }^{2}{ }_{4} \mathrm{C}$ powcer must be used in the following weight fraction:

$\begin{array}{lr}35 \% & 14-20 \text { mesh } \\ 45 i & 60-80 \text { mesh } \\ 10 \% & 200-325 \text { riesh } \\ 10 \% & -200 \text { mesh }\end{array}$

c. After dryine tive ${ }_{4} \mathrm{C}$ powcer, exposure to the atmosphere shall ve iopt to o rjuinum.

\subsection{Safety Instructions:}

a. Before loakirm $={ }_{4} \mathrm{C}$ power, all fuel and fuel containers in the South lab hust he coverer vith parer or polyethylene sieets.

b. The $b_{4} \mathrm{C}$ povtier Ioading area shall be serregated from the fuels area.

c. The ${ }_{1}{ }_{4} \mathrm{C}$ powier must be containeu at all tines to prevent particles becoming airborne or spilled on the floor and tracked into the controlled fuel area.

d. Good housekeeping must be maintained to prevent potential spread of $\mathrm{B}_{4} \mathrm{C}$ particles.

e. Rubber gloves and rubber shoes used in the $\mathrm{B}_{4} \mathrm{C}$ area liust be segreg, ted and cleaned separately from those used in the fuel area.

\subsection{Preparation of $\mathrm{B}_{4} \mathrm{C}$ Powder}

a. Weigh and blend the $\mathrm{B}_{4} \mathrm{C}$ powder to the weight fraction specified above. 
b. Dry the powder at $100^{\circ} \mathrm{C}$ for 1 hour.

c. Weigh amounts required per tube directly from the oven and put in polyethylene bottles. Tape the cap with plastic tape to seal the bottle.

\subsection{Procedure}

a. For the Extension Rods (G1 and (22), fill the tubes with the preweighed $\mathrm{B}_{4} \mathrm{C}$ powder and vipak to $73 \%$ of theoretical density.

b. For the Extension Rods (G3 and G4) and Tightener Rods, the $\mathrm{B}_{4} \mathrm{C}$ powder shall be blended with the stainless steel shot and vipaked Into the tubes.

\subsection{Process Control}

a. Random samples of the $\mathrm{B}_{4} \mathrm{C}$ and $\mathrm{B}_{4} \mathrm{C}$-stainless steel shot charges will be check-weighed by the nrocess engineer.

b. Column height of filled tubes will be randomly checked by the process engineer.

c. Rods will be randomly x-rayed to check for segregation of stainless steel balls and position of Internal components of the tightener rods. 


\section{GEAP-13595}

\subsection{Berv1lium Oxide (Beo) Loading}

\subsection{Special Instructions}

a. All personnel who will be handling Beo shall read APED - Industrial Hygiene Standard 4.A.2-1 prior to performing his task.

b. All operations involving BeO must be performed in a glove box.

c. No Beo bearing rod shall be removed from the glove box without end plugs or plastic caps on the ends of the tubes.

d. Smears taken on areas exposed to BeO shall not exceed 5 micrograms/ square foot.

\subsection{Safety Instructions}

a. BeO must never be stored adjacent to any nuclear material. Beo is a moderator with capabilitv for substantially diminishing the minimum critical mass compared to the unmoderated condition.

b. BeO is a very toxic material when ingested and therefore should be handled with the same care as with radioactive materials.

c. BeO must not be handled with the bare hands.

d. Anyone receiving the slightest wound which could possibly be contaminated with Beo will report for medical treatment immediatelv.

\subsection{Procedure}

a. Weigh one long Ben pellet (Dwg 159A2789-P2) and record weight on travel card.

b. Insert the long BeO pellet and nickel reflector (Dwg 175A9312-P1) into the bottom end of Tightener Rod tube (Dwg 135B8710-P1).

c. Weld the bottom end plug.

d. Mock-up 25 short BeO pellets (Dwg 159A2789-P1) on loading channe1. Obtain BeO weight and record on travel card.

e. Load the short Beo pellets into Tightener Rod tube.

f. Welgh one long Beo pellet (Dwg 159A2789-P2) and record weight 
on travel card.

8. Insert the long Beo pellet and nickel reflector (DWg 159A2792-p1) into the Tightener Rod tube.

h. Place plastic can on open end of tuhe until ready for final weld closure.

\subsection{Process control}

a. Process engineer shall audit Beo pellet weights.

b. Process engineer shall check the initial mock-up of short Dellets.

c. Process engineer sha11 check the loading seauence. 


\subsection{Closure Welds (In-box welds)}

\subsection{Special Instructions}

a. At the beginning of each shift, check the inert gas tanks.

b. Trace all welds on recorder and identify strin chart by tube numbers.

\subsection{Procedure}

a. Evacuate weld chamber to a minimum of 500 micron and backfill with helium to one atmosohere.

b. Check weld setting.

c. Check timing of tube revolution.

d. Weld on automatic secuence.

e. Make weld samnles at the heginning of each shift and in each weld chamber load.

f. Check each weld for completeness, anpearance, and bead contour.

g. Check weld trace. Deviations shall be reviewed by the process engineer.

\subsection{Process Contro1}

a. Weld samoles shall be examined metallographically bv the process engineer.

b. The process engineer shall make veriodic examination of weld appearance. 


\subsection{Helium Leak Check}

15.1 Helium leak rate shall not exceed $1 \times 10^{-8} \mathrm{std} . \mathrm{cc} / \mathrm{sec}$ with a vacuum of less than 5 microns.

15.2 A second leak check shall be made on 10 percent of the rods two weeks after the first check.

\subsection{Final Inspection}

Final inspection shall be performed hy nc - Fuels.

\subsection{Final Cleaning}

17.1 Fuel rods shall be cleaned with acetone after helium leak check.

17.2 White lint-free gloves shal1 be worn to handle cleaned rods.

17.3 After cleaning, fuel rods shall be packaged in polyethylene tubes. 


\section{Addendum to Development Guide}

1. Para. 5.0 - Fig. 2 was revised as in attached travel card.

2. Para. 9.2b - Delete Oakite 90 and insert Kelite 236.

3. Para. 9.3

Tank No. Fil1 With

1

$$
8-10 \text { oz/gal Kelite } 236
$$

Heated Temp.

$$
\text { Yes } \quad 170^{\circ}-200^{\circ} \mathrm{F}
$$

4. Para. 9.4

a. Substitute Ke1ite 236 for Oakite 90.

c. 10 minutes should read "30" minutes.

5. Para. 10.1 - Should read,...."minimum weld penetration of $93 \%$ of tube wall thickness."

6. Para. 10.3 - Should read,...."93\% penetration." 


\section{Tightener Rod}

(8460777)

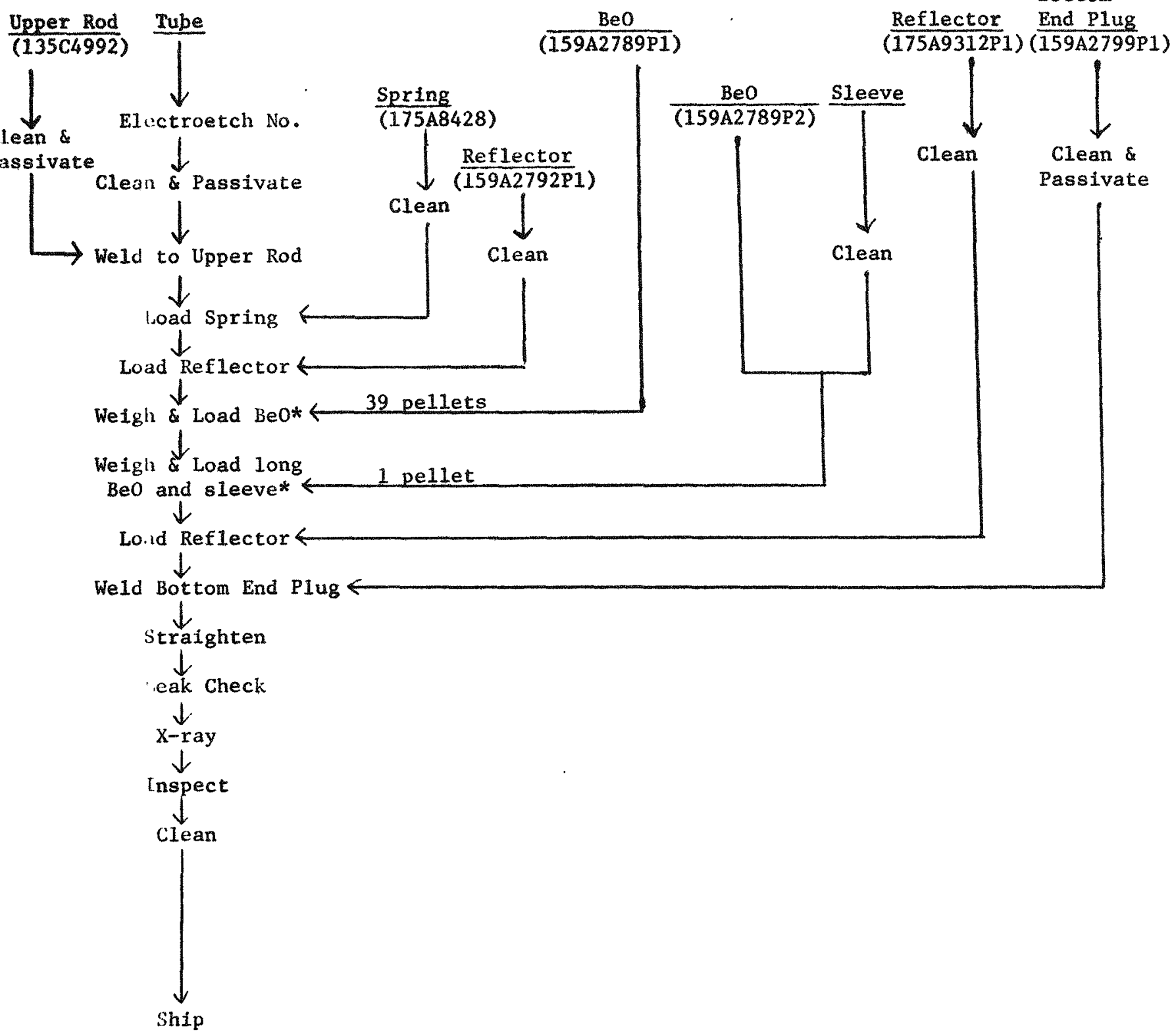

* See backs $j$ e for Beo Weights. 
GEAP-13595

APPENDIX \|

Procedures for Assembly of Tightener Sleeves 
APPENDIX II

\section{PROCEDURES FOR ASSEMBLY OF TIGHTENER SLEEVES}

\section{General Instructions:}

1. Wear cotton gloves to handle parts.

2. Hole at bottom of hex tube is reference orientation index. Side with hole is slde $\|_{1}$. Sides are numbered clockwise, looking at bottom end view.

3. Line up reference marker of each tool with hole on side $\|_{1}$ of hex tube.

4. Operations in numerical series are for forming dimples. Operations in alphabetical series are for welding springs.

5. Each operator must perform pertinent tests as required in the procedure below. If the test results are satisfactory, he must mark his initial in the appropriate place on the checklist.

\section{Assemb1y Procedure:}

1. Push pusher through to check for dents in hex tube.

2. Stamp tube number in numerical sequence.

3. Mark tube side orientation number. Side 1 is side with reference hole punched at bottom end. Sides are to be numbered clockwise, looking at bottom end view.

\section{Operation A}

a. Insert long internal spring into position using spring pusher. (Station \#2)

b. Slide long external spring onto hex tube but do not position in place yet. (Station 非)

c. Position and expand expander tool at dimples at base of spring. (Station 非)

d. Now slide external spring into position.

e. Clamp down base edge of external spring with external spring holder. (Station \#3)

f. Weld spring finger tips. (Station 非3)

g. Weld external spring to internal spring at the base of the springs. (Station \#3)

h. Re-position expander at lower end of spring. (Station \#3) 
i. Weld lower end of spring. (Station 非)

j. Remove external spring holder and expander tool. (Station \#3)

$k$. Check for excessive weld bead buildup, incomplete fusion, shrinkage cracks and general quality of welds. (Station 非)

1. Check for free motion of spring fingers. (Station 非)

m. Check to insure spring-to-spring contact at converging point of spring fingers. (Station $\left.\right|^{3}$ )

n. Insert . $875^{\prime \prime}$ tube gage to check for tube clearance. (Station \#2)

o. Drive $.894^{\prime \prime}$ driver through the spring from the bottom end of the tube.

p. Check spring clearance with $.890^{\prime \prime}$ gage.

5. Operation B (Long Spring)

Same as for Operation A.

6. Operation C (Long Spring)

Same as for Operation A.

7. Fin 非 (Plain Fin) - (Station 非)

a. Place hex tube in holding fixture with side 2 up.

b. Weld on sides $2-4-6$.

c. Insert and position aluminum chill block.

d. Clamp fins into position using length gage marked, "42-5/32".

e. Make fusion weld.

f. Rotate 2 faces.

g. Repeat steps $c, d$, and $e$.

h. Rotate 2 more faces.

i. Repeat steps $c, d$, and $e$.

8. Operation $\mathbb{N}_{1}$ (Station \#1)

a. Slide on external punch guide.

b. Align holes and dimple OUT on sides $2-4-6$.

c. Remove tools.

d. Check dimple heights with "GO - NO GO" gage. 
9. Operation $\# 2$ (Station $\# 1$ )

a. Place hex tube with reference hole on top side.

b. Slide on external punch guid, dith length gage arm on side 1.

c. Insert Tool H - H. Match side 1 of tool to side 1 of hex tube.

d. Dimple IN on sides $6-1-2$.

e. Removal tools.

f. Check dimples with internal dimple "GO - NO GO" gage.

10. Fin \#2 (Lipped Fin) - (Station \#4)

a. Place hex tube in holding fixture with side 1 up.

b. Weld on sides $1-3-5$.

c. Same as for Fin $\|_{1}$ except use length gage marked "33-21/32".

11. Operation 非 (Station 非1)

a. Slide on external punch guide.

b. Align holes and dimple OUT on sides $1-3-5$.

c. Remove tools.

d. Check dimple heights with "GO - NO GO" gage.

12. Operation D (Long Spring)

Same as for Operation A.

13. Fin 非 (P1ain Fin) - (Station \#4)

a. Same as for Fin $\# 1$ except use length gage marked "17-17/32".

b. Weld on sides $2-4-6$.

14. Operation \#4 (Station \#1)

a. Slide on external punch guide.

b. Align holes and dimple OUT on sides $2-4-6$.

c. Remove tools.

d. Check dimple heights with "GO - No GO" gage.

15. Operation \#5 (Station \#1)

a. Place hex tube with reference hole on top side.

b. Slide on external punch guide with length gage arm on side 1 .

c. Insert Tool G-G. Match side 1 of tool to side 1 of hex tube.

d. Dimple IN on sides $3-4-5$.

e. Remove tools.

f. Check dimples with internal dimple "CO - No GO" gage. 
16. Operation \#6 (Station \#1)

a. Slide on external punch guide.

b. Align holes and dimple OUT on sides $1-3-5$.

c. Remove tools.

d. Check dimple heights with "GO - NO GO" gage.

17. Fin 非 (Long Fin)

a. Place hex tube in holding fixture with side 1 up.

b. Weld on side $1-3-5$.

c. Insert and position aluminum chill block for welding the fins at the taper position first.

d. Clamp fins into position.

e. Make fusion welds.

f. Reposition chill block and weld progressively to the top end of the tube.

g. Rotate 2 faces.

h. Repeat steps $c, d$, and $e$.

i. Rotate 2 more faces.

j. Repeat steps $c, d$, and e.

18. Deleted

19. Spot Weld Fins

a. Clamp the fin tabs together with a vise grip to cinch down the fins snugly against the hex tube.

b. Spot weld the tabs.

Sequence: Spot weld the 2 tabs on the same edge first; then rotate tube to the next position.

20. Make casting-to-hex tube weld.

Make sure one of the casting legs is aligned with the reference hole in the tube.

21. Visually inspect assembly for fabrication defects.

22. Test tightener sleeve by assembling a mock-up.

23. Wipe assembly with acetone for final cleaning and shipping. 
GEAP-13595

APPENDIX $\| 1$

SEFOR R\&D (Tightener and Tightener Rods)

Project Quality Control Plan 
ATOMIC IOWER EQUIPMENI' DEPARTMENT

PROJECT QUALTTY CONTROL, PLAN

TITLE: SEFOR R \& D (TIGHTENER \& EXIENSION RODS)

Part Drawing

Name General No.

Prepared by ACl: Date $9 / \% / 4$, Approved by $-1+2$ Date $4-1+2]$ Reviewed by If Date $9-26 \cdot 6$ ?

\subsection{PURPOSE}

This Quality Plan sets forth the practices, kinds and frequencies of tests and inspections necessary to demonstrate that the product design has been fulfilled on all items produced.

This plan does not circumvent any inspection or requirement as defined by Specification 22A1658, applicable code, purchase orders or drawings.

2.0 SCOPE

Prior to production, the vendor for formed tubing (Drawing Nos. i12C3406 and 135B8710) shall submit for approval by General Electric NID-NL the complete process outline, quality control plan and design of special inspection and test devices. No material having operations perforned prior to this approval shall be used in the final product.

3.0 SOURCE INSPECTION AND AUDIT

General Electric APED shall have the right to inspect the work and artivities of a vendor for tube material and tube forming at such reasciable times and in such minner as is nocessary. A vendor shall notify General Electric at least 48 hours in advance of any qualification testing so that a General Eiectric representalive niay witness the tests.

\subsection{Shipping}

When a product is ready for shipinent a vendor shall give the same advance notice and prior to shipment shall submit to Gencral Electric APED the following:

(a) Evidence that all applicable practices, tests and inspections required in the final product and in all components and materials has been performed satisfactorily with acceptable results. 


\section{STPOR $R$ \& $D$ (TJGHTLNER \& LXTENSION RODS)}

Goneral

(b) Certification to the above and to all specifications and drawing requirements.

No release of a shipment shall be made unless the shipment is accompanied by the requisite certifications.

3.2 If non-confomance of a material or process is established, a vendor shall quarantine all material not clearly identifiable as acceptable and shall subnit for General Electric NID-NL. approval:

(a) The nature and extent of deviating material.

(b) planncd disposition of deviating material.

(c) Changes in process or methods to reduce or eliminate non-conformance to specifications or drawing requirements.

\subsection{RESPONSIBILITIES}

$4.1 \quad \mathrm{NTD}-\mathrm{NL}$

It is the responsibility of NID-NL to:

(a) Perform disposition of discrepant material.

(b) Maintain copies of vendor certifications, test results and all in-process inspections, audits and final inspection documents.

4.2 Quality Control - Purchased Malerials

It is the responsibility of cuality Control-Purchascd Materials to:

(a) Perform source inspections and audits as applicable and to furmish to NTD-NL copies of vendor inspections.

(b) Perform inspection and tests on in-coming material as required and to furnish to NID-NL copies of certificates and test rosults accompanying each shipment.

\subsection{Quality Control - Fuels}

It is the responsibility of Quality Control Fuels to: 
SLIOR $R$ \& $D$ (TIGITENER \& EXTENSION RODS)

General

(a) Witness and audit work performed at General Elcctric San Jose and to ensure that proper in-process documentation is maintained.

(b) Perform final inspection services for those product characteristics verifiable at the product stage. 
ATOMIC PONER LQUIPMENT DEPARTIMENT

PROJECT QUALITY CONTROL PLAN

TITLE: SEFOR R \& D (TIGITIENER \& EXTENSION RODS)

part Drawing

Nane Botton End Plug

No.

Prepared by ho

Date $\left.9 / a^{2} / 6\right)$

Approved by T/5) Date 4 -14.4e?

Reviewed by DII Date $9 \cdot 26 \cdot 67$

\subsection{SPECIFICATIONS}

The following specifications shall apply to this part:

(a) GE Specification B50YP17 A2 or B2

(b) Specification ESDYP3

(c) ASTM-A276

\subsection{CERTIFICATTONS}

2.1 Chemical Conposition

Vendor shall certify that impurities and alloying elements conform to the requirements of ASTM-A276. Chenical composition shalI be determined for each heat.

\begin{tabular}{ll} 
ELEMENT & PER CENT \\
\hline Carbon & 0.08 (max) \\
Phosphorus & $0.045(\max )$ \\
Sulfur & 0.030 (max) \\
Silicon & $1.00(\max )$ \\
Chronium & $18.00-20.00$ \\
Nickel & $8.00-12.00$
\end{tabular}

2.2 Mechanical Properties

Vendor shall certify that mechanical properties conform to the requiremonts of ASTM-A276. Certification shall be submitted for ultimate tensile, yicld strength (offset), reduction in area, $\%$ elongation and hardness for each heat. Acceptable limits for these properties are listed in General Electric Specification B50YP17 A2 or B2.

\subsection{Physical Integrity}

Vendor shall certify that physical integrity of the material has been testal per Gencral Elcctric Test Method E5UYP3

"Ultrasonic Inspection" for $100^{\circ}$ of product. 
SIFOR R \& D (ILLILILILR \& EXTENSION RODS)

Bottom End PIug - Tightener Rod

2.3.1 Vendor shal1 submit Ultrasonic test plan for approval by General Electric NDD-NL prior to production.

\subsection{PREIRODUCITON}

Vendor shall subuit three (3) samples for approval by NID-NL of dimensional characteristics prior to full production. Quality Control-Purchased Materials shall perfom the pre-production inspections as directed by NTD-NL.

\subsection{RECEIVING INSPECITION OF PRODUCTTON LOTS}

Quality Control-Purchased Materials shall perform the following inspections to verify that dimensional characteristics conform to drawing rcquircments and that vendor inspection results are as statcd.

\subsection{Weld Prep Zone}

Weld prep zone end shall be visually inspected for 100\% of end plugs. Ends are to be shaip, clean and free of damage (nicks, scratches, pits, etc.).

I.D. of weld prep zone $\left(0.795^{\prime \prime}-0.803\right)$ and wall thicluess and and le of cut to wall shall be inepected on $20 \%$ of a $10 t$. The lot is acceptable if one (1) or less rejects are found. If two or more rejects are found, $100 \%$ inspection for these characteristics shall be performed.

\subsection{Other Dimcusional Inspection}

All other dinensionil inspoctions for uraving requirenents shall be performcd on ten (10) end plugs selected at random. If one (1) or more causes for rejection are found, an additional ten (10) enk piugs shall be selceted at randon and inspected. If one (1) or more causes for rejection are found in the second group, 100\% inspection shall be perfomed on the ranainder of the lot. (If less than 300 end plugs are shipped at one tine, scale sample sizes proportionately).

\subsection{Discrepant Matcrial}

Non-confoming material shall be segregated and disposition determined by NID-NL. 
ATOMIC POWER EQUIPMENI DEPARTMENT

PROJECT QUALITY CONTROL PLAN

TITLE: SEFOR R \& D (TIGITENER \& EXTENSION RODS)

Part

Drawing

Nime Bottom End Plug

No.

$117 \mathrm{C} 1378$

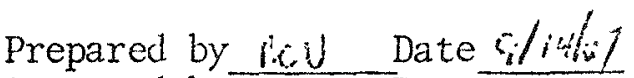

Approved by 1,22 Date $4-14-6$ ?

Reviewed by DT/ Date $9-26-6$,

\subsection{SPECIIICATIONS}

The following specifications shall apply to this part:

(a) GE Specification B50YP17 A2 or B2

(b) Specification E5DYP3

(c) ASTM-A276

\subsection{CERTIFICATIONS}

2.1 Chemical Composition

Vendor shall certify that impurities and alloying elements con-

form to the requirements of ASTM-A276. Chemical composition shal1 be determined for each heat.

$\begin{array}{lc}\text { ELEMENT } & \text { PER CENT } \\ \text { Carbon } & 0.08 \text { (max) } \\ \text { Phosphorus } & 0.045(\max ) \\ \text { Sulfur } & 0.030(\max ) \\ \text { Silicon } & 1.00(\max ) \\ \text { Chromium } & 18.00-20.00 \\ \text { Nickel } & 8.00-12.00\end{array}$

\subsection{Mechanical Properties}

Vendor shall certify that mechanical properties conform to the requirements of ASTM-A276. Certification shal1 be submitted for ultimate tensile, yield strength (offset), reduction in area, : elongation and hardness for each heat. Acceptable limits for these properties are listed in General Electric Specification B50YP17 A2 or B2.

\subsection{Physical Integrity}

Vendor shall certify that physical integrity of the naterial has been restel per General Electric Test Method L5DYP3

"Ultrasonic Inspection" for 100\% of product. 
SEFOR R \& D (TIGHTENER \& EXTENSTON RODS)

Bottom End Plug - Extension Rod

2.3.1 Vendor shall submit U1trasonic test plan for approval by General Electric NTD-NL prior to production.

3.0 PREPRODUCTION

Vendor shall submit three (3) samples for approval by NTD-NL of dimensional characteristics prior to full production. Quality Control-Purchased Materials shall perform the pre-production inspections as directed by NTD-NL.

4.0 RECEIVING INSPECTION OF PRODUCTION LOTS

Quality Control=Purchased Materials shall perform the following inspections to verify that dimensional characteristics conform to drawing requirements and that vendor inspection results are as stated.

\section{I WELD PREP ZONE}

Weld prep zone end shall be visually inspected for $100 \%$ of end plugs. Ends are to be sharp, clean and free of damage (nicks, scratches, pits, etc.).

I.D. of weld prep zone $\left(0.795^{\prime \prime}+0.808\right)$ and wall thickness and angle of cut to wall shall be inspected on $20 \%$ of a lot. The $10 t$ is acceptable if one (1) or less rejects are found. If two or more rejects are found, $100 \%$ inspection for these characteristics shall be performed.

4.2 Inspection shall be performed on the following characteristics for the sample sizes listed:

\section{CHARACTERISTIC}

" $\mathrm{C}$ " Dimension

"B" Dimension

Distance from right

hand end (Drawing reference) to center

of countersunk hole

$\left(0.594^{\prime \prime}+0.003^{\prime \prime}\right)$

Countersünk holes,

diancter and centering

\begin{tabular}{lccc}
\multicolumn{5}{c}{ SAMPLE } & SIZE \\
\hline Part & Part & Part & Part \\
No.1 & No.2 & No.3 & No.4
\end{tabular}

$\begin{array}{rrrr}70 & 10 & 10 & 10 \\ 70 & 10 & 10 & 10 \\ 30 & 5 & 5 & 5\end{array}$

$\begin{array}{llll}30 & 5 & 5 & 5\end{array}$

Inspect $100 \%$ if one (1) or more defects are found per the above table. 
SEFOR R \& D (TIGHTENER \& EXTENSION RODS)

Bottom End Plug - Extension Rod

4.3 All other dimensiona1 inspections for drawing requirements shall be performed on ten (10) end plugs for Part 1, and two (2) each of Part Nos. 2, 3 and 4. selected at random from each lot. If one or more causes for rejection are found, an additional sample shall be drawn and inspected. If one or more causes for rejection are found in a second sample, $100 \%$ inspection shall be performed.

4.4 Discrepant Material

Non-conforming material shall be segregated and disposition determined by NTD-NL. 


\section{ATOMIC POWER EQUIPMENT DEPARTMENT}

PROJECT QUALITY CONTROL PLAN

TITLE: SEFOR R \& D (TIGHTENER \& EXTENSION RODS)

\begin{tabular}{|c|c|c|c|}
\hline & & pared & Date $8 / m^{\prime} / 67$ \\
\hline $\begin{array}{l}\text { Part } \\
\text { Name Top End Plug }\end{array}$ & $\begin{array}{l}\text { Drawing } \\
\text { No. } 117 \mathrm{C} 1376\end{array}$ & $\begin{array}{l}\text { Approved by }-T, 2,7 \\
\text { Reviewed by }\end{array}$ & $\begin{array}{l}\text { Date } \frac{9-14-67}{9-26-67} \\
\text { Date }\end{array}$ \\
\hline
\end{tabular}

\subsection{SPECIFICATIONS}

The following specifications sha11 apply to this part:

(a) GE Specification B50YP17 A2 or B2

(b) Specification ESDYP3

(c) ASTM-A276

\subsection{CERTIFICATIONS}

\subsection{Chemical Composition}

Vendor shall certify that impurities and alloying elements conform to the requirements of ASTM-A276. Chemical composition sha11 be determined for each heat.

$\begin{array}{ll}\text { ELEMENT } & \text { PER CENT } \\ \text { Carbon } & 0.08(\max ) \\ \text { Phosphorus } & 0.045(\max ) \\ \text { Sulfur } & 0.030(\max ) \\ \text { Silicon } & 1.00(\max ) \\ \text { Chromium } & 18.00-20.00 \\ \text { Nickel } & 8.00-12.00\end{array}$

\subsection{Mechanical Properties}

Vendor shall certify that mechanical properties conform to the requirements of ASTM-A276. Certification shall be submitted for ultimate tensile, yield strength (offset), reduction in area, $\because$ elongation and hardness for each heat. Acceptable limits for these properties are listed in General Electric Specification B50YP17 A2 or B2.

\subsection{Physical Integrity}

Vendor shall certify that physical integrity of the material has been tested per General Electric Test Method E5DYP3 "Ultrasonic Inspection" for $100 \%$ of product. 
SEFOR R \& D (TIGHTENER \& EXTENSTON RODS)

Top End Plug

2.3.1 Vendor shall submit Ultrasonic test plan for approval by General Electric NTD-NL prior to production.

\subsection{PREPRODUCTION}

- Vendor shall submit three (3) samples for approval by NTD-NL of dimensional characteristics prior to full production. Quality Control-Purchased Materials shall perform the pre-production inspections as directed by NTD-NL.

\subsection{RECEIVING INSPECTION OF PRODUCTION LOTS}

Quality Control-Purchased Materials shall perform the following inspections to verify that dimensional characteristics conform to drawing requirements and that vendor inspection results are as stated.

\subsection{Weld Prep Zone}

Weld prep zone end shall be visually inspected for $100 \%$ of end plugs. Ends are to be sharp, clean and free of damage (nicks, scratches, pits, etc.).

I.D. of weld prep zone $\left(0.795^{\prime \prime}+0.0002\right)$ and wall thickness and angle of cut to wall shall be inspected on $20 \%$ of a $10 t$. The lot is acceptable if one (1) or less rejects are found. If two or more rejects are found, $100 \%$ inspection for these characteristics shall be performed.

4.2 Inspection shall be performed visually on $100 \%$ of a lot for verification that identification machining conforms to drawing.

4.3 Inspection shall be performed on the following characteristics for the sample sizes listed:

CHARACTERISTIC

Shank diameter $\left(0.375^{\prime \prime} \pm 0.003^{\prime \prime}\right)$

Shank concentricity $(0.002 "$ TIR to A)
SAMPLE SIZE

Part Part Part Part Part

No.1 No.2 No.3 No.4 No.5

$\begin{array}{lllll}10 & 20 & 5 & 5 & 5\end{array}$

$\begin{array}{lllll}10 & 20 & 5 & 5 & 5\end{array}$

Inspect $100 \%$ if one (1) or more defects are found per the above table. 
SEFOR R \& D (TIGIMIENIR \& EUTSNSION RODS)

Top End plug

4.4 Al1 other dimensional inspections for drawing requircuints shall be performed on five end plugs for Part No. 1, ion end plugs for Part No.2 and two each of Part Nos. 3,4 and 5 selectod at random from each lot. If one or more causes for rejection are found, an additional sample shall bo drain and inspected. If one or more causes for rejection are found in a second sample, $100 \%$ inspection shall be performod.

\subsection{Discrepant Material}

Non-conforming material shall be segregated and disposition 1 determined by NID-NL. 
GEAP.13595

Section 5 of 10

Deleted 


\section{ATOMIC POWER EQUIPMENT DEPARTMENT}

PROJECT QUALITY CONTROL PLAN

TITLE: SEFOR R \& D (TIGHTENER \& EXTENSION RODS)

Part Drawing

Name Reflector

No. 159A2792

Prepared by M.U Date il: \% 1 Approved by $1+1$ Date $114-t$ ? Reviewed by $\$ \frac{1}{11}$ Date $\frac{9-x 6}{4-67}$

1.0 SPECIFICATIONS

The following specifications shall apply to this part:

(a) ASTM-B160

2.0 CERTIFICATIONS

2.1 Chemical Composition

Vendor shall certify that impurities and alloying elements conform to the requirements of ASTM-B160. Chemical composition shall be determined for each heat.

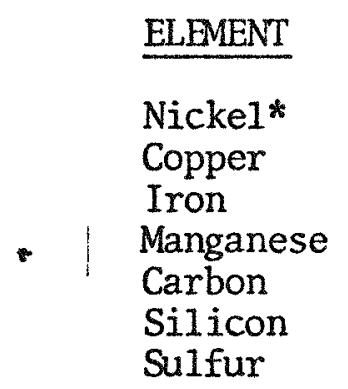

* Cobalt counting as nickel

\section{PER CENT}

$99.0(\min )$

$0.25(\max )$

$0.40(\max )$

$0.35(\max )$

$0.15(\max )$

$0.35(\max )$

$0.01(\max )$

\subsection{RECEIVING INSPECTION}

Quality Control - Purchased Materials shall inspect five (5) reflector rods selected at random from a lot for O.D. verification $\left(0.655^{\prime \prime}+0.000^{\prime \prime}\right)$. If one or more rods is rejected, $100 \%$ inspection shall be performed.

\subsection{DISCREPANT MATERIAL}

Non-conforming material shall be segregated and disposition determined by NTD-NL. 
SEFOR $R$ \& D (TIGITLENER \& EXTENSION RODS)

Reflector

4.0 NTD-NL PRODUCTION (FUEL LAB)

Machining of reflector stock shall be qualified by complete inspection of dimensional characteristics for first piece and at any set-up change. Bow characteristic shall be inspected for first five pieces produced consccutively and if no rejection, one in every twenty picces produced. If a reject occurs, five consecutive pieces shall be found free of defects before inspection may again revert to one in twenty.

\subsection{DISCREPANT MATERIAL}

Non-conforming material shall be segregated and disposition determined by NTD-NL. 


\section{ATOMIC POWER EQUITIENT DEPARTMENT}

PROJECT QUALITY CONTROL PLAN

TITLE: SEFOR R \& D (TIGITENER \& EXTENSION RODS)

Part Drawing

Nane Reflector No. 175 A9312

Prepared by ict Datedligh

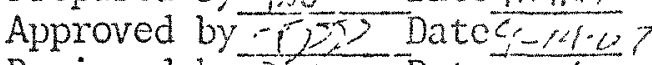

Reviewed by $D T$ Date $\{-26 \cdot 69$

\subsection{SPECIFICATIONS}

The following specifications shall apply to this part:

(a) ASTM-B160

\subsection{CERTIFICATIONS}

\subsection{Chemical Composition}

Vendor shall certify that impurities and alloying elements conform to the requirements of ASTM-B160. Chemical composition shall be determined for each heat.

\begin{tabular}{lc} 
ELEMEN & PER CENI \\
\hline Nicke1* & 99.0 (min) \\
Copper & 0.25 (max) \\
Iron & 0.40 (max) \\
Manganese & 0.35 (max) \\
Carbon & 0.15 (max) \\
Silicon & 0.35 (max) \\
Sulfur & 0.01 (max)
\end{tabular}

* Cobalt counting as njckel

\subsection{RECEIVING INSPECTION}

Quality Control - Purchased Materials shall inspect five (5) reflector rods selected at randon from a lot for O.D. verification $\left(0.780^{\prime \prime}+0.000^{\prime \prime}\right)$. If one or more rods is rejected, $100 \%$ inspection sha11 be pertormed.

\subsection{DISCREPANT MATERIAL}

Non-confoming material shall be scgregated and disposition determined by NID-NL. 
SEIOR $R$ \& D (TIGITENER \& EXTENSION RODS)

$\underline{\text { Refloctor }}$

4.0 NTD-NL PRODUCTION (FUEL LAB)

Machining of reflector stock shall be qualified by complete inspection of dimensional characteristics for first picce and at any set-up change. Bow characteristic shall bo inspected for first five pieces produced consecutively and if no rejection, one in every twenty pieces produced. If a reject occurs, five consccutive pieces shall be found free of defects before inspection may again revert to one in twenty.

4.1 DISCLEPANT MATERIAL

Non-conforming material shall be segregated and disposition determined by NID-NL. 
ATONIC POIER EQUIMUENT DEPARTMENT

PROJECT QUNLITY CONIROL PLAN

TITLE: SEFOR R \& D (TIGHTENER \& EXTENSION RODS)

Part Drawing

Name Spring No. 175A8428

Prepared by ned Dateciliflot

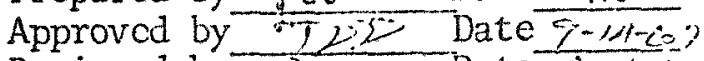
Reviewed by DTI Datc $4-266-21$

\subsection{SPECIFICATIONS}

The following specifications shall apply to this part:

(a) ASTM-A313

\subsection{CERTIFICATIONS}

\subsection{Chemical Composition}

Vendor shall certify that impurities and alloying elements conform to the requirements of ASTM-A313. Chemical composition shall be determined for each heat.

$\begin{array}{ll}\text { ELEMENT } & \text { PER CENT } \\ \text { Carbon } & 0.15(\max ) \\ \text { Manganese } & 2.00(\max ) \\ \text { Silicon } & 1.00(\max ) \\ \text { Phosphorus } & 0.04(\max ) \\ \text { Sulfur } & 0.03(\max ) \\ \text { Chromium } & 18.00-20.00 \\ \text { Nickel } & 8.00-9.50\end{array}$

\subsection{Tensile Properties}

Vendor shall certify that tensile strength conforms to the requircments of ASTM-A213 (min. 260,000; $\max 290,000$ ).

3.0 RECEIVING INSPECTION

Quality Control-Purchased Materials shall select five samples at random from a lot and perform inspections and tests for those characteristics specificd in the reference drawing. If one or more caluses for rejection are found, an additional sample of five shall be selectod at random. If one or more causes for rejection are found in the second sample, 100\% inspection shall be performed.

\subsection{Discrepant Material}

Non-conforming material shall be segregated and disposition determined by NID-NL. 
ATOMIC POWLR LOUIINENT DEPARTIENT

PROJECT QUALITY CONTROL PLAN

TITLE: SIFOR R \& D (TIGHTENER \& EXTENSION RODS)

Part Drawing

Nane Tube No. Sce Below

\subsection{SPECIFICATIONS}

The following specifications shall apply to this part:

(a) G. E. Specification B50YP79 A1 or A2

(b) G. E. Test Micthod E5DYP3

(c) ASTM-A269

1.1 This quality plan references all applicable provisions for Tube Drawing Nos: 13588710, 129 B2368 and $112 \mathrm{C} 3406$.

\subsection{CERTIFICATIONS}

\section{I Chemical Composition}

Vendor shall certify that impurities and alloying elcments conform to the requirements of ASTM-A269. Chemical composition sha11 bc determined for each heat.

2.2 Mcchanical Properties

Vendor sha11 certify that mechmical propertics conform to the requirenents of $A S T M-A 269$ and $B 50 Y P 79$ AI or $A 2$. Cerlification shall be subnitted for ultimate tensile, yield (offset), elongation, flaring or flange, or reverse flatiening.

\section{3 physical Intogrity}

Vonlor shall certify that hardness, grain size, surface finish requiremenis conform to $A S T M-\Lambda 269$ and $B 50 Y P 79 \Lambda 1$ or $A 2$ and shill also certify that physical interrity has beon tosted per General Elcctric lest Mcthod E5DYP3 "Ultrasonic Inspection" for $100^{\circ}$ of produci.

\subsubsection{Venklor shall submit Ultrasonic test plan for approval by Genoral Llcctric NID-NL prior to production.}

\subsection{LREPRODUCLION - INITIN. IUBE}

Vontor shall subinit one (1) full longth ubo sample from which a three (3) foot long scction will bo cul and propared by quality controlPurchased Materials for use as an $u / s$ standarl by ventor. 
SEFOR R \& D (TIGIMLENER \& EXTENSION RODS)

Tube

Quality Control-Purchascd Materials shall submit the remainder of the tube for verification of chemical, mechanical and physical properties required by $B 50 Y P 79$ Al or $A 2$.

\subsection{SOURCE INSPECTION}

A Q.C. representative shall audit the Quality Control efforts of the vendor to assure compliance to the requirements of the Purchase Order, specifications, codes and drawings. Source inspection shall be performed at the site of the vendor supplying initial tubes and at the site of the vendor supplying formed tubes.

\subsection{PREPRODUCTION - FORMED TUBE}

Vendor shall submit four (4) formed tubes for qualification of tubeforming process. Each tube shall be inspected for conformance to all drawing dimensions except wall thickness by Quality ControlPurchased Materials. Wall thickness measurements shall be performed by NID-NL. Approval for tube-forming process shall be done by NTDNL.

\subsection{RECEIVING INSPECTION - FORMED TUBE}

formed tubing, all tube ends and weld prep zones shall be sharp, free of burrs and undamaged as determined by $100 \%$ visual inspection.

6.1 A11 other drawing dimensions shall be inspected per the following sampling plan:

$\begin{array}{ccc}\text { LOT SIZE } & \text { SAMPLE SIZE } & \begin{array}{c}\text { NUMBER OF } \\ \text { REJECTS NLIONED }\end{array} \\ 101-200 & 15 & 0 \\ 601-800 & 35 & 0\end{array}$

The tube length for as-formed tubes shall be at least 4 " beyond the dimension given in Dwg. 135B8710, Rev. 1.

If one or more causes for rejection are found, $100 \%$ inspection shall be institured.

\subsection{RECEIVING INSPECTION - EB WELDED TUBE}

Quality Control-Purchased Materials shall inspect EB welded tubes $100 \%$ for spacer location, and visually for weld zone discoloration and tube surface appearance. 
SEFOR R \& D (TIGITENER \& EXTENSION RODS)

Tube

NTD-NL shall section and examine one (1) EB weldod tube for weld integrity. No production lot received shall be released until NID-NL has approved the weld.

8.0 EB WELD QUALIFICATION

Vendor shall submit samples of EB welds to NTD-NL for approval of weld process prior to production. No tubes welded before approval shall be acceptable. 
ATOMIC POWER EQUIPMENT DEPARTMENT

PROJECT QUALITY CONTROL PLAN

TITLE: SEFOR $R \& D$ (TIGHIENER \& EXTENSION RODS)

Part Quality Control

Name In-Process Audit \& Final Inspection

Drawing 112C2072 Extension Rod

Prepared by , icic!? D Date

Approved by _...i. Date

No. $846 \mathrm{~F} 777$ Tightener Rod

\subsection{SPECIFICATIONS}

The following specifications shall apply:

(a) APO Spec $22 \mathrm{~A} 1658$

(b) GE Spec P4AYP1

(c) GE Spec P4CYP3

\subsection{CERTIFICATIONS}

2.1 Release for shipping

Quality Control shall verify that all material acceptable at final inspection has met the criteria established in this Quality Plan; that vendor material certifications are complete and that disposition of any material not meeting drawings and specifications has been documented and resolved.

\subsection{MATERTAL CONTROL}

3.1 A record shall be made for each type tube by serial number, which shall accompany the tube through the process and shall show each operation as complete; and after loading, shall show the contained weight of $\mathrm{BeO}$ and/or $\mathrm{B}_{4} \mathrm{C}$ and steel shot.

3.2 Scales used for weighing $\mathrm{BeO}, \mathrm{B}_{4} \mathrm{C}$ and steel shot shall be calibrated at the start of each shift.

\subsection{PROCESS CONTROL}

4.1 Control of the passivation process shall be demonstrated by chemical analysis of the acid bath prior to start of production and by further analyses made at least once a week. Chloride ion content of the deionized water rinse shall be no greater than $15.0 \mathrm{ppm} \mathrm{NaCI}$ equivalent. 
4.2 Welding Control shall be demonstrated prior to start of production by qualification of the weld parameters and operators as follows:

(a) Five consecutive welds shall be made and examined metallographically. All welds mist have a minimum of $93 \%$ penetration. (These welds shall be made at the nominal weld current setting)

(b) An operator shall not be considered qualified until he has made at least two consecutive successful welds using established parameters for this process.

All welds shall be recorded on a weld trace chart. Any weld which has been made by parameters exceeding the standard limits shall be considered discrepant and shall be segregated and identified. Special disposition sha11 be made in these cases.

Weld in-process qualification shall be performed during each shift by making one weld which meets penetration requirements as examined metallographically and visual requirements on completeness, appearance and bead contour. Failure of the in-process qualification samples shall mean that all subsequent welds must be identified and segregated, and further that $100 \%$ $X$-ray examination be made of all suspect welds.

4.3 Rod weight control $\left(B_{4} C\right)$ shall be maintained by audit examination of the $\mathrm{B}_{4} \mathrm{C}$ charges and by stack height examination of filled extension rods. Rod weight control of these blended $\mathrm{B}_{4} \mathrm{C}$ and stainless steel shot-filled tubes shall be audited similarly.

4.4 Control of Beo rod weights shall be maintained by audit examination of mockup charge weights and lengths.

\subsection{FINAL INSEECTION}

5.1 Helium leak check shall be performed on 100\% of all rod types initially and on $10 \%$ of all rod types after a two week time lapse. If one or more leaking rods are found, all rods shall be re-leak checked.

The leak detector shall be calibrated at least once every four hours of operation. A station $\log$ shall be maintained which shall show that this operation has been performed and shall be initialed by the operator.

5.2 At least $10 \%$ of rods shall be inspected dimensionally for conformance to drawing requirements, Particularly, dimple and spring location and bow shall be inspected. Runout up to .050" TIR shall be examined on formed tubes using Vee-blocks at tube expanded area and measuring TIR at these locations. 


\section{SEFOR R \& D (TIGHTENER \& EXTENSION RODS)}

5.3 All welds shall be inspected visually for surface smoothness, weld soundness (craters, lack of fusion, undercutting, etc.).

5.4 All rods shall be inspected visually for physical integrity (scratches, nicks, dents, etc.).

\subsection{RECORDS AND DOCUMENTATION}

6.1 An Audit Report shall be written for each audit tour conducted by Q.C.-Fuels during in-process operations which shall indicate degree of conformance to the Process Development Guide and to applicable drawings, specifications and Quality Control Requirements

6.2 All records required by the Process Development Guide shall be filed and maintained for a period to be determined by the customer.

6.3 All certifications and material releases from Receiving Inspection and Source Inspection shall be filed and maintained for a period to be determined by the customer. 
ATOMIC POWER EQUIPMENT DEPARTMENT

PROJECT QUALITY CONTROL PLAN

\# P-2288-68

Title: SEFOR R\&D

Part

Name: Tightener Sleeve
Dwg .

No.:
Proposed by:

Approved by:

Reviewed by
Date: $5-14-6:$

Date: $\cdots \because \cdots$ :

Date: $-2-22-6$

\subsection{PURPOSE AND SCOPE:}

This Quality Plan describes the method of inprocess control and the final inspection to be performed to demonstrate that the product design has been fulfilled.

\subsection{INPROCESS CONTROL:}

2.1 The F.\&.M.D. Project Engineer shall prepare a detailed procedure guide for the assembly of the tightener sleeves. The procedure shall include a check list where the operators shall record the satisfactory completion of the assembly operations and checks.

2.2 Q.C. Fuels Auditors shall audit the operations for compliance to instructions. Particular attention to inprocess measurements will be necessary since measurements at final inspection are extremely impractical for many of the product characteristics.

2.3 F.R.M.D. shall make mock-up assemblies of tightener sleeves, dummy rods, and channels until 10 successive assemblies have been made which require no repair, rework, or modifications to the tightener sleeves. After 10 sequentially successful assemblies, reduce the mock-up testing to 1 per 10 assemblies (i.e., I per lot). If a failure occurs, test the representative lot $100 \%$ and the next lot 100\%. If all assembilies in the lot after the failure are successful, again reduce the testing to 1 per 1 ot.

2.4 Q.C. Fuels shall observe the assembly of the first 10 mock-ups. Additional mock-ups shall be observed by Q.C. Fuels on an audit basis.

\subsection{FINAL INSPECTION:}

3.1 Q.C. Fuels shall perform a $100 \%$ visual inspection prior to packaging.

3.2 Q.C. Fuels shall review the check lists for completion.

3.3 Q.C. Fuels shall test 1 assembly per lot (10 assemblles) per drawing note 3 .

3.4 Q.C. Fuels shall test I assembly per lot for dimple, fin and spring locations and visually examine the 10 assemblies per lot for symmetry. 
GEAP-13595

APPENDIX IV

Experiments Conducted with Extension Rod Tubing

.99 . 


\section{APPENDIX IV}

It was found after assembly that a portion of the tubing used in the extension rod fabrication contained shallow-stress corrosion attack. This possibility was recognized from the investigation into the attack found on the I.D. of the original order of tightener rod tubing when it was noted both tube orders were made from the same heat.

All of the tubes had been ultrasonically inspected to discriminate for defects greater than $10 \%$ of the wall thickness (.004 inches). Since the minimum attack was less than $2-1 / 2$ mils deep and because of the random nature of the attack, the surface defect was undetected during the extension rod fabrication.

An ultrasonic test was devised to determine the number of extension rods so affected and to determine the degree, if any, of the attack.( 1 ) An attenuation measurement technique was devised to grade the full cladiing surface finish. The basic technique measured the decay curve of the reflections within the material. The material with the shorter time constant decay curve contained the greater number of imperfections. The tests determined that of the 743 extension rods tested, 98 were found to possess surface cracks between 1 to 2-1/2 mils deep. The grading of each rod was recorded.

An experiment was conducted to determine the susceptibility of the tubing to propagation of the intergranular attack under SEFOR conditions. (2) Autoclave tests were conducted with saturated steam at $350^{\circ} \mathrm{F}$, $546^{\circ} \mathrm{F}$, and $800^{\circ} \mathrm{F}$ on specimens under no load, below yield, at yield, and plastically deformed. No progression of the original $2 \mathrm{mil}$ intergranular attack occurred. 


\section{GEAP-13595}

Furnace tests at $800^{\circ} \mathrm{F}$ with closed capsules made from affected tubing filled with $\mathrm{B}_{4} \mathrm{C}$ were also conducted.(2) Three conditions of $\mathrm{B}_{4} \mathrm{C}$ were used; 1) vacuum dried, 2) air dried, and 3) exposed to air for 36 hours. Again no progression of the intergranular attack was detected.

From these tests, it was concluded that failure of extension rods by propagation of surface cracking was of low probability. Rods that were determined to have the greatest surface effects will be held in reserve.

\section{References}

1. T.G. Lambert, V.J. Lovelace, "UItrasonic Inspection of Extension Rods for Stress Corrosion Attack", letter to F.E. Young, November 6, 1968.

2. G.G. Gaul, C.N. Spalaris, "Experiments with Tubing from SEFOR FueI Extension Rods", to Distribution, November 12, 1968. 
GEAP-13595

APPENDIX V

Thermal Cycling Tests on Tightener Sleeve Spring Assemblies 
GEAP-13595

\section{APPENDIX V}

\section{INTRODUCTION}

Metallographic examination of a production run SEFOR tightener sleeve revealed some lack of fusion in the finger weld and around the circumference of the upper weld (Figure V-I (Dwg. 706E958), Section B-B). Since these are only location welds the primary concern is that the cracks do not propagate from the roots of the cold-shuts during service.

It was determined the most severe condition imposed upon the spring was during the planned thermal cycle transients. The design basis for the spring was 30 cycles with a $150^{\circ} \mathrm{F}$ temperature differential between the outside and inside spring fingers.

\section{TEST DESCRIPTION}

A test program was established to thermal-stress the spring assembly while under compression in excess of the thermal-stresses expected during the life of the tightener sleeve. The test was accomplished by heating the spring within an RF field. By this means differential eddy-current heating of the inner and outer spring fingers caused differential expansion creating shear forces across the welds.

The test set-up is shown in Figure $V-2$ where the test spring assembly is shown inserted within an RF coil. The RF coil is attached to the $45 \mathrm{KVA}$ LapeI $R F$ generator in the background. Figure $V-3$ shows the thermocouple locations on the test assembly. 

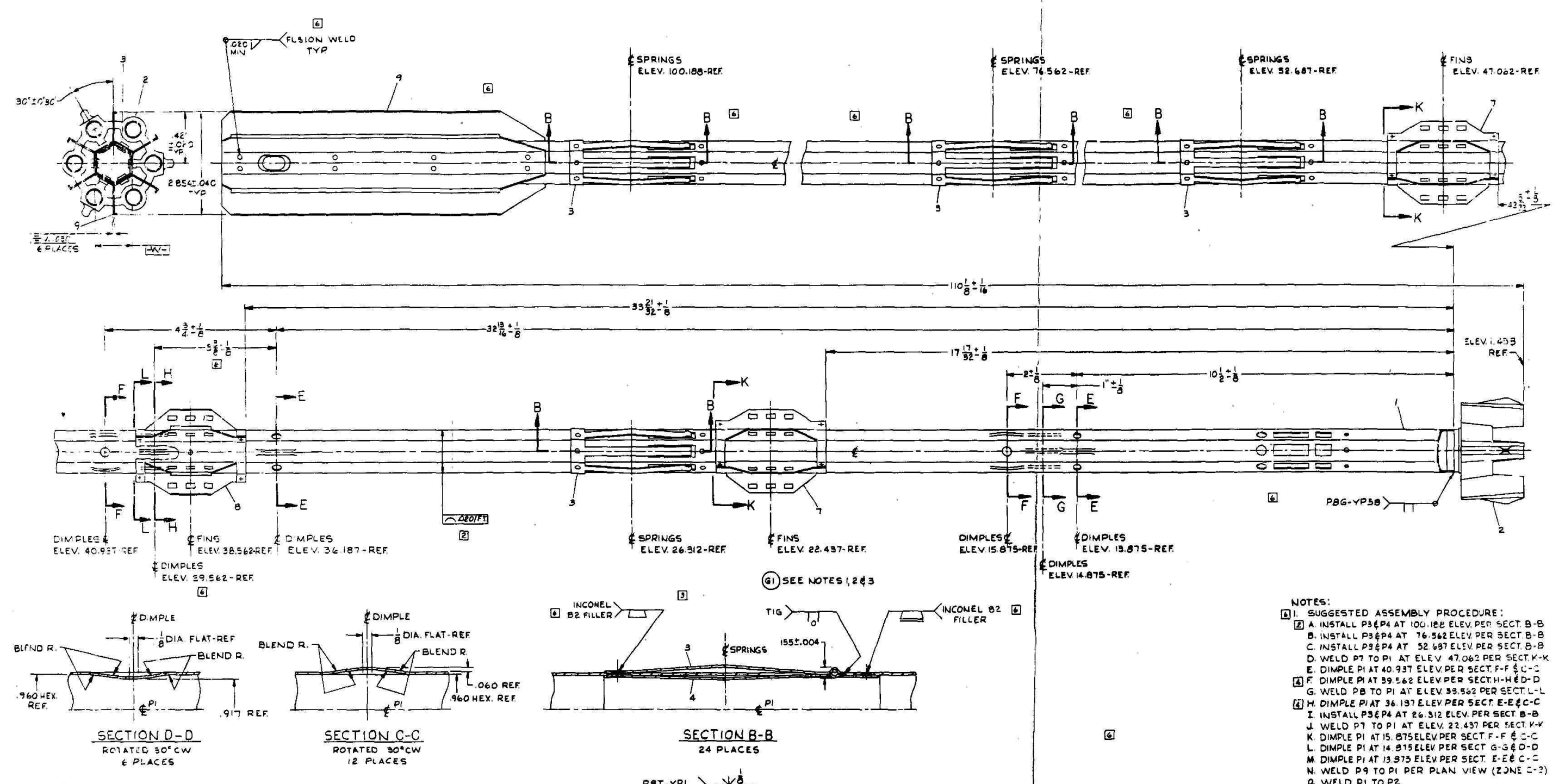
FteVt14.975-RE.
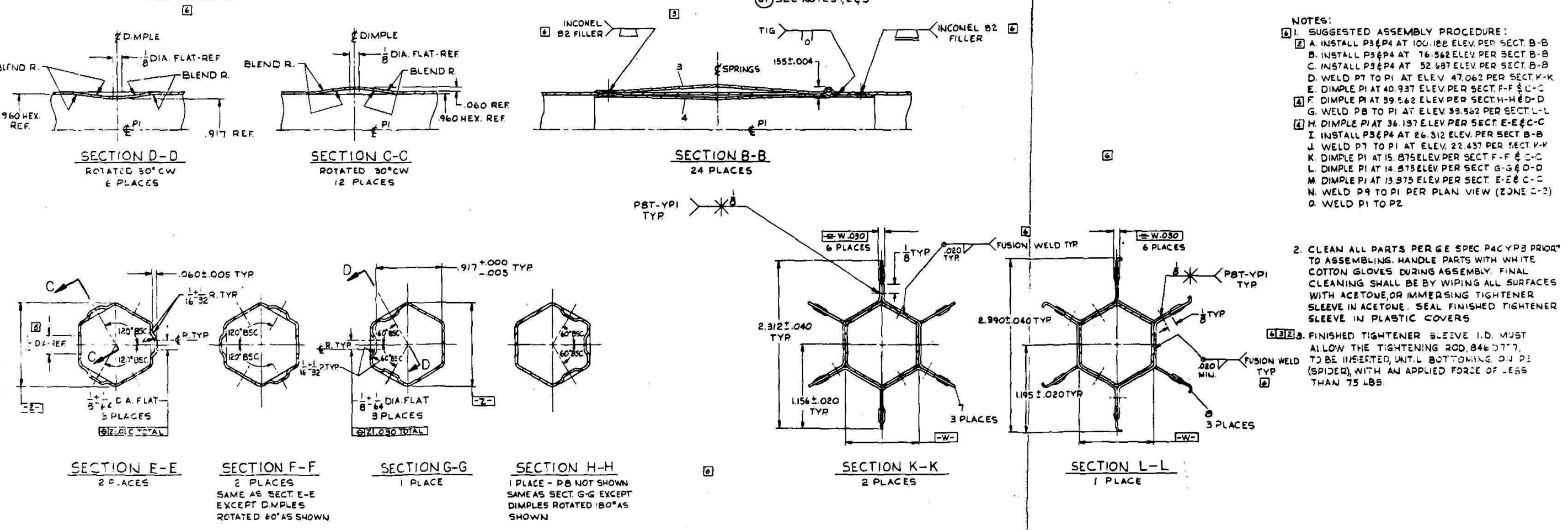

Figure V-1. Tightener Sleeve 


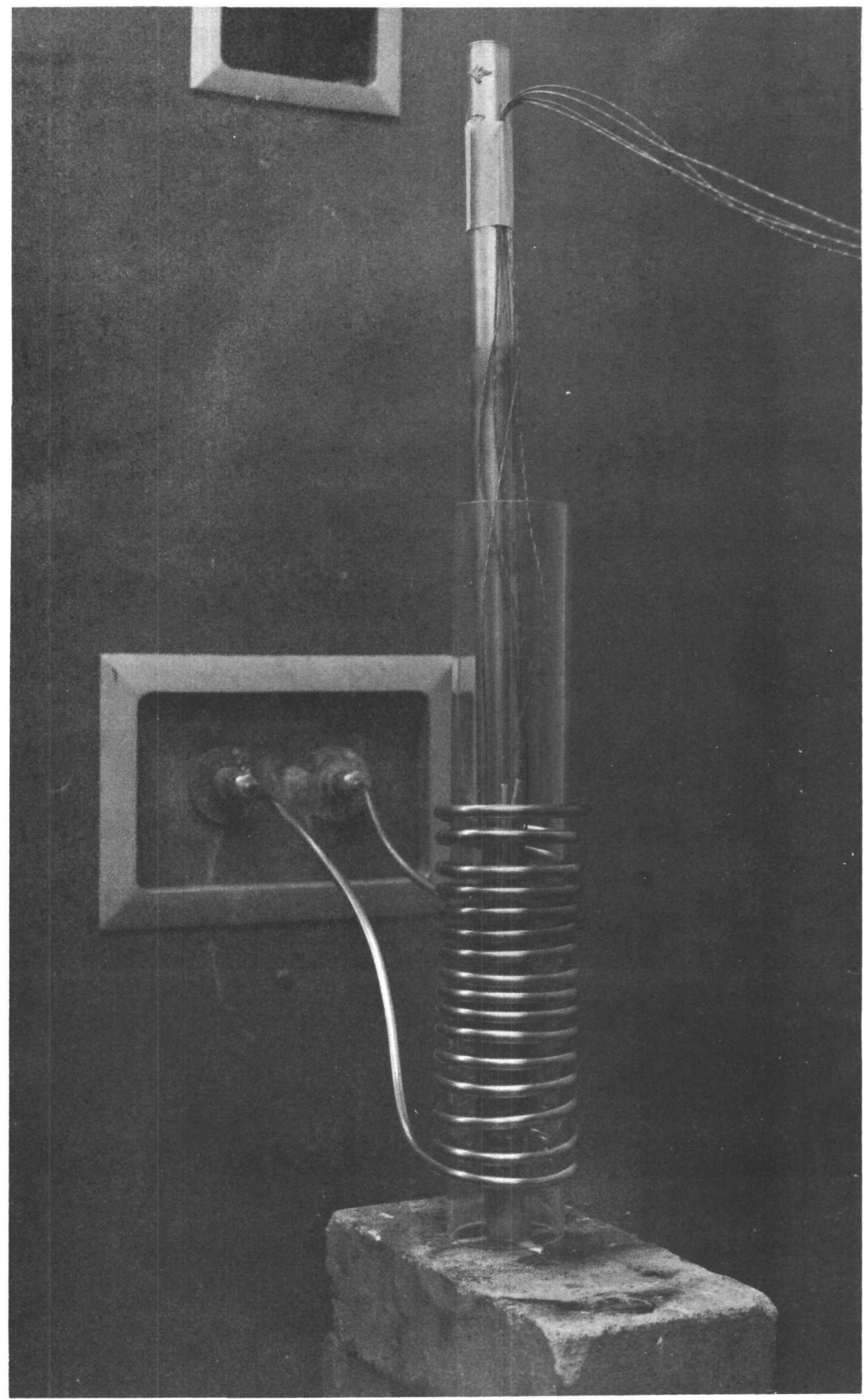

Figure V-2. Thermal Cycle Test Set-Up Showing Spring Assembly Inserted within the RF Coil 


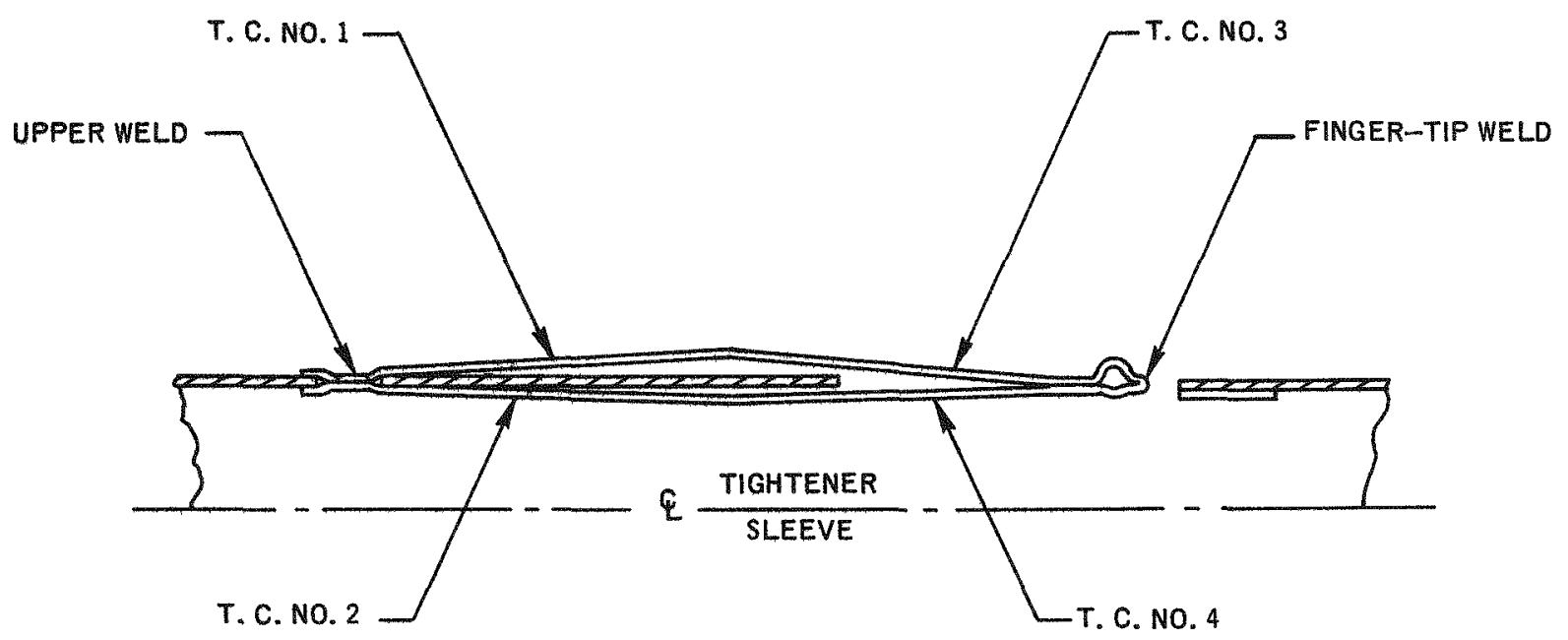

Figure V-3. Thermocouple Locations 


\section{GEAP-13595}

\section{RESULT}

Measured temperature differentials were as follows:

$$
\begin{aligned}
& \Delta \mathrm{T}=\mathrm{T} \cdot \mathrm{C} \cdot \# \mathrm{I}-\mathrm{T} \cdot \mathrm{C} \cdot \# 2=195^{\circ} \mathrm{F} \text { to } 270^{\circ} \mathrm{F} \text { (225 } \mathrm{F} \text { average) } \\
& \Delta \mathrm{T}=\mathrm{T} \cdot \mathrm{C} \cdot \# 3-\mathrm{T} \cdot \mathrm{C} \cdot \# 4=150^{\circ} \mathrm{F}
\end{aligned}
$$

Figure $V-4$ is a typical thermocouple trace during the thermal cycling. Metallographic examination showed no weld failure at these more rigid thermal stress conditions (Figures $V-5$ and $V-6$ ). 


\section{GEAP.13595}

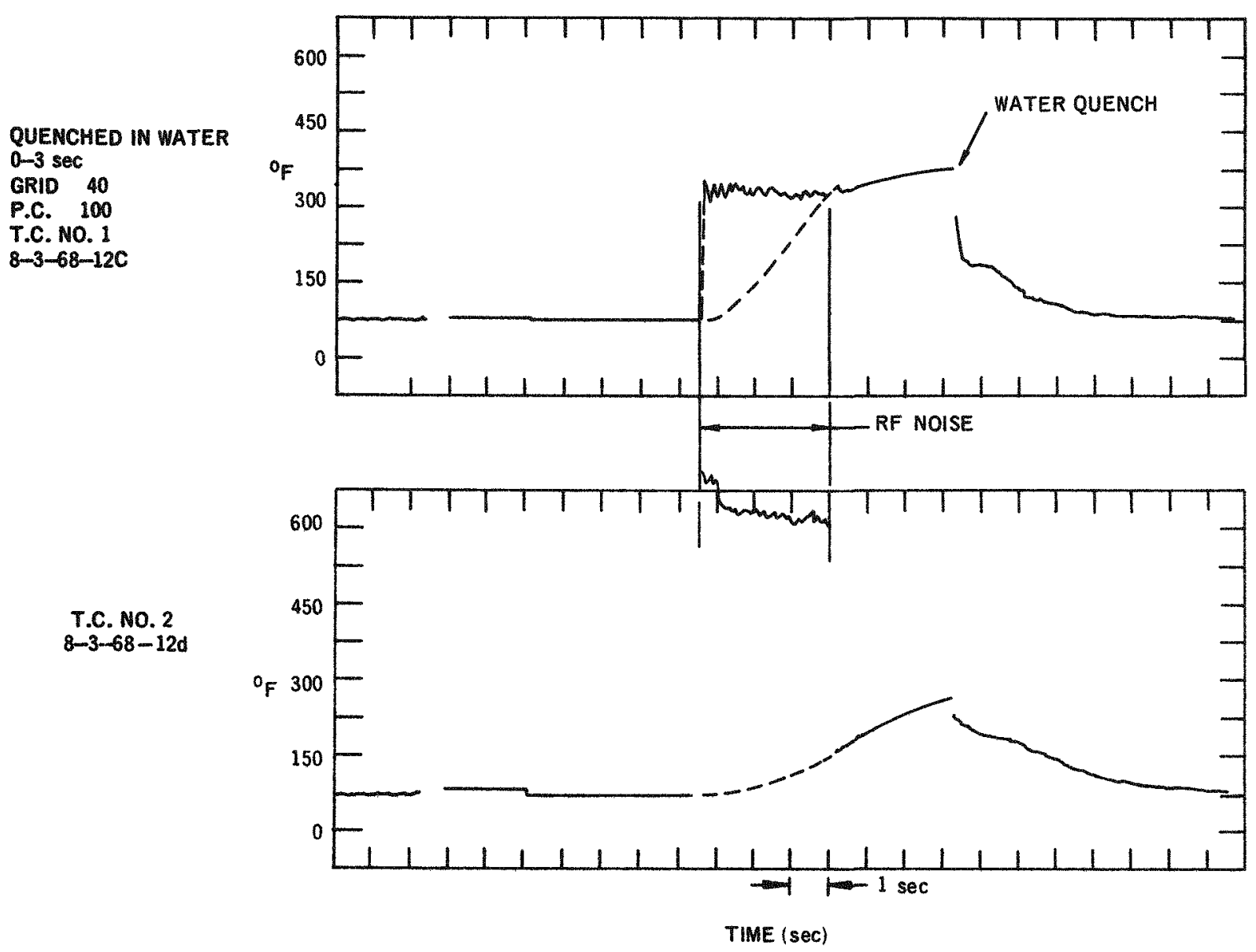

Figure V-4. Typical Time-Temperature Trace for Spring Assembly No. 4 


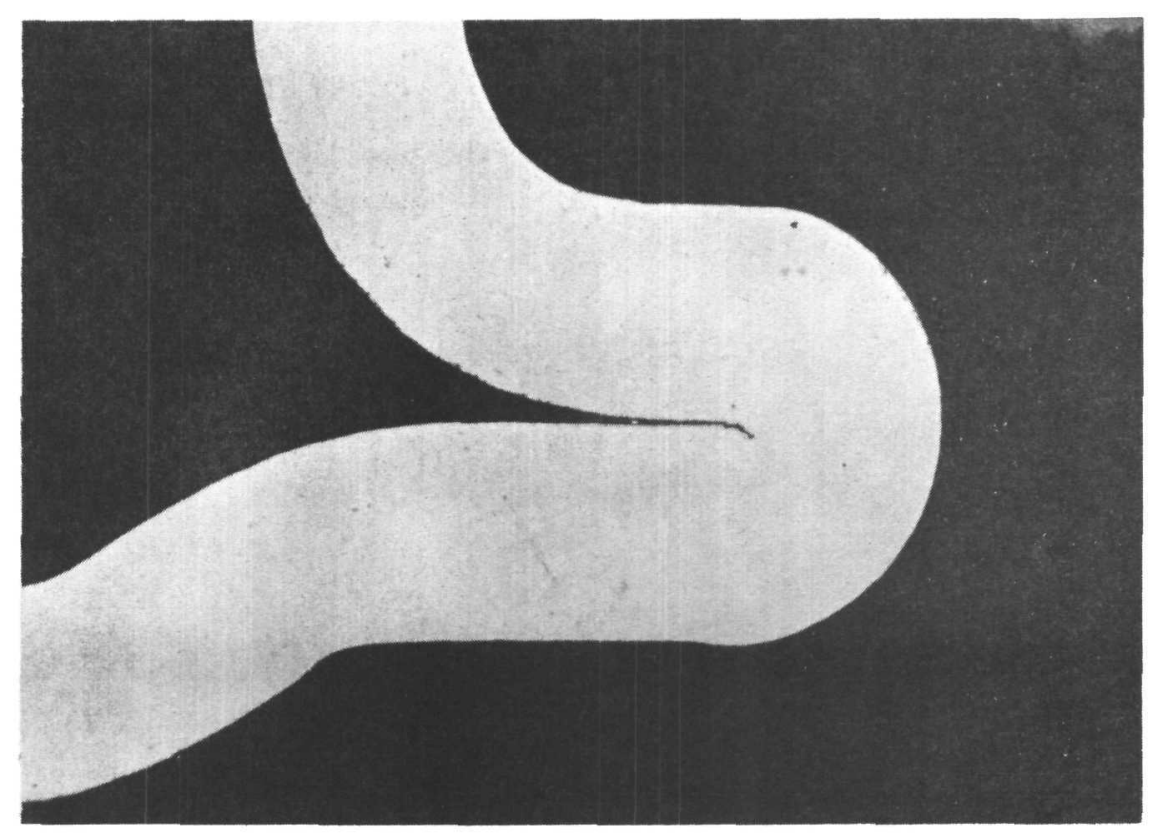

Figure V-5. Spring Assembly No. 4 Finger Weld, Post Thermocycle

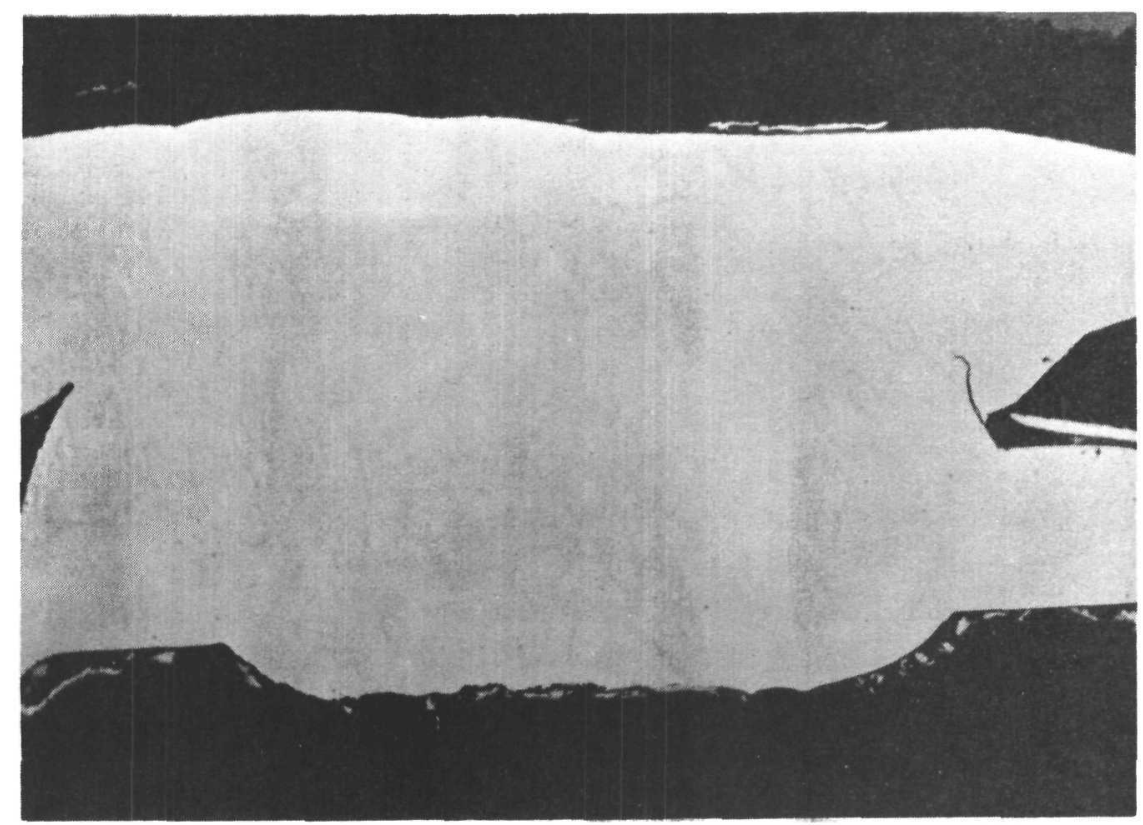

Figure V-6. Spring Assembly No. 4 Upper Weld, Post Thermocycle 
GEAP-13595

ÁPPENDIX VI

Beryllium Oxide Specifications and Certification

$-113$. 


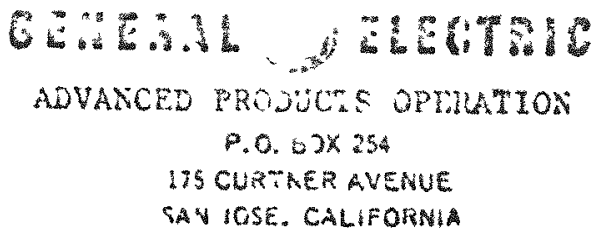

PROJECT: SEFOR

SPECIFICATION AND REV. NO.

$22 \mathrm{~A} 1585$ ReV. 0

$104-463$ SPECIFICATION TITLE Beryllia Rod ior SEFOR

TABLE OF CONTENTS

SECTION

1.0

2.0

3.0
TITLE

Scope \& Definitions

berylida Rod

Quainty Control
PACE

1

1

3

ISSUED BY

SEFOR : n 


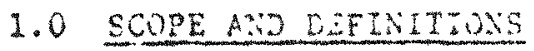

1.1 This specitation defines tiv reculrements for sintered Beo which Wil. be usta in the tifintening rod c the Southwest Experimental rast Oxide Reactor (SEFOR).

1.2 The work done by the Sellez in acccriance with this spectfication shall include all procurenent of rat material, fabrication, quality control, preparation for sispment, thd shipment.

1.3 The Suller shall accept Eull reworkibllity for his work and for conpliance witi this sracizictcin. Review or approval of the

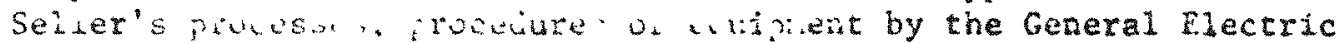

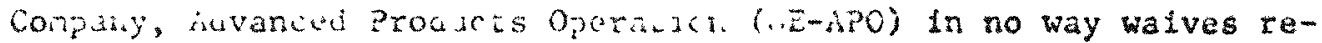
quirements atablished oy this sper:fication and the purchase contract.

1.4 The cem "powier lot" simil reier to all berylla powder which has been prepared from raw hateriala at one time under ldentical condtalons. anc is untform in composition for sxinpling purposes. The term "batch" shall refer to all Beo rods prepared from the powder at one time by one process.

\subsection{BERYLEA ROD}

2.1 Process, Componition, Density ano Gain Size

2.1.1 Bof shali be prepared by the process oi cola-pressing (for length/dimeter ratios of 1.15 or Iess) or extruding sinterabl. powdor (ror length-diamater ratjos grater than 1.25) ank firlng in air, nitrogen, or helium. Average rod deasty shali be $2.9 \mathrm{gm} / \mathrm{cc}$ or greata". Minimum rod density shall be $2.85 \mathrm{gm} / \mathrm{cc}$.

2.1.2 Average grain size in the sintered rod shal be 25 macons or less.

2.1.3 The sum of the tmpurities Ifited in Table $i$ shald not exced 6000 pon by weight ia the finished rod. Levels of individual ejements shall not excet tha values stated. Binders, iubricants, cleaning solutions, additives and dye penerrants, if used, shall be classed as insurities.

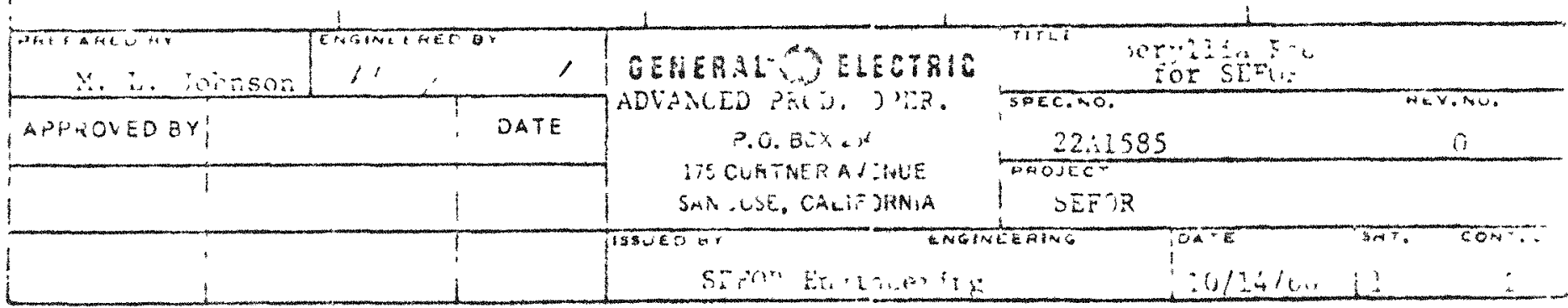




\section{GEMEALOECTHC}

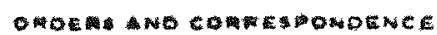

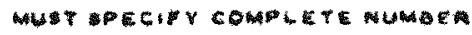

SFEOHICATION

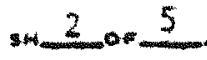

\section{MABELI}

\section{MAXTMLY PERYTSSIBLE YRPURTRY LEVELS}

\begin{tabular}{|c|c|c|c|}
\hline Element & Limit (ppr) & Ëement & Limit (ppm) \\
\hline$A I$ & 500 & H & 50 \\
\hline $\mathrm{Ag}$ & 10 & $\mathrm{Li}$ & 20 \\
\hline B & 20 & $\mathrm{Mg}$ & 4000 \\
\hline $\mathrm{Ba}$ & 100 & Mn & 20 \\
\hline C & 600 & No & 40 \\
\hline $\mathrm{Ca}$ & 500 & $\therefore a$ & 250 \\
\hline $\mathrm{Cd}$ & 20 & $\therefore i$ & 150 \\
\hline $\mathrm{Cl}$ & 20 & Pis & $\therefore 0$ \\
\hline Co & 26 & $s i$ & 560 \\
\hline $\mathrm{Cr}$ & 100 & s.s & 20 \\
\hline $\mathrm{Cu}$ & 100 & $5:$ & 200 \\
\hline $\mathrm{F}$ & 200 & $T i$ & 20 \\
\hline $\mathrm{Fe}$ & 200 & $z n$ & 40 \\
\hline
\end{tabular}

\subsection{Ientification}

Powder iots and batches shall be seyregated throughout production, and $\mathrm{records}$ mintained so that any : od may be traced to its batch ani powder iot.

\subsection{Dusicas inturity}

2.3.1 Modulus of rupture for the rods snali be 25000 psi or greater.

2.3.2 Totil surfare area of end ch..ps shail not exceed 20 per cent of the surface area of the end of the rod.

2.3.3 Depth of surface pits shail not exceed .020 inch. Rods having cracks detectabie by an approvec dye check shall be rejected. 


\section{GEAP.13696:

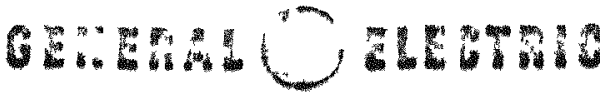

SPECIEICATICN

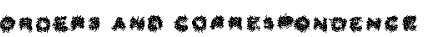

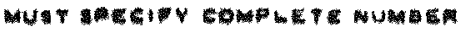

3.

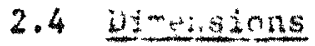

Draw ing 159 A2789 shows ail ditenstonal reguirements. Rods of each size shali be inspecied io straightness by passing through a hardened stee: or cara. . ring gat Javing a ground bore 0.003 Inch larger than the naximum roc a daneter plus bow. Gage length shail be greater than ros length.

\section{$2.5 \quad$ Cleaning}

roos sirall de cleaned by an aproved cleaning process. Beo powdur removable by a wipe test sikci $i$ mi aceed 200 micrograms $/ \mathrm{ft}^{2}$. Cleaning shall foliow the dye-penerrint check.

\subsection{Packing and Shizping}

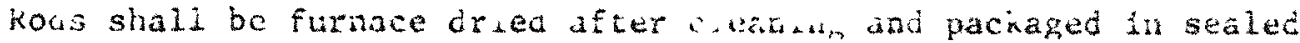
containers containing suitable dessicants. Supping containets shail be or materlais and construction proven sutable for Ben shipments by past experience. Containers and paclaging shall comply with ail existang applicabie regulations. Rosis shall be packed to prevent c..jiping and dusting during shipment. Destination of shipment will be San Jose, Californda.

\subsection{QUALITY CONTROL}

3.1 Inspection by the Buyer

A represcntative of the Juyer shail te granted access to the Seiler's production facility at any time during production of the rods and may require performance in his presence of any of the inspections specifled herein.

\subsection{Inspection Requirements}

3.2.1 An inspection plan shali be estaiblished and conducteo by the Seller to insure compliance with these specifications. Minimur. inspection requirements are tabulated below.

\begin{tabular}{|c|c|c|}
\hline \multirow{2}{*}{ Parajrass } & Inspection & \multirow[b]{2}{*}{ Yethod } \\
\hline & Recilred & \\
\hline 2.1 .1 & Density & $\begin{array}{l}\text { Weigit and neasured } \\
\text { volume }\end{array}$ \\
\hline 2.1 .2 & Grain Size & 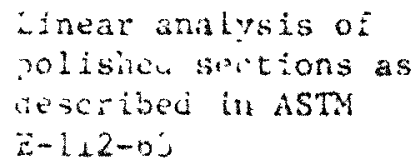 \\
\hline
\end{tabular}

Ereruency 
SPEFFIFATON

$$
4 \text { or } 5
$$

Buryiarions for seror

\begin{tabular}{|c|c|c|c|}
\hline Parastapi: & $\begin{array}{l}\text { asspect hom } \\
\text { gequired } \\
\end{array}$ & $2 \times E^{*}=c^{\circ}$ & Frequency \\
\hline $2 \cdot 2 \cdot 3$ & Inpurdteds & 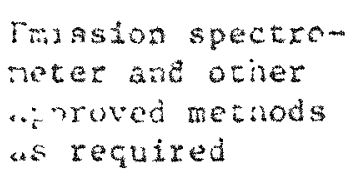 & $\begin{array}{l}\text { Mindmum of three rods } \\
\text { from each powder iot } \\
\text { and process }\end{array}$ \\
\hline $2 \cdot 3 \cdot 1$ & $\begin{array}{l}\text { Moduius of } \\
\text { Rupture }\end{array}$ & As aproved & $\begin{array}{l}\text { Winimum of five tests } \\
\text { From each powier iot } \\
\text { and process }\end{array}$ \\
\hline 2.3 .2 & Ch.ips & $\forall i+x+a 1$ & 90-95 confidence ieve: \\
\hline 2.3 .3 & Pits \& Cracks & $\begin{array}{l}\text { Lubal s dye } \\
\text { penetrant }\end{array}$ & $90-95$ confiaence ievel \\
\hline 2.4 & Dimensions & As approved & $90-95$ confidence ievei. \\
\hline 2.5 & $\begin{array}{l}\text { Suratic } \\
\text { Poncer }\end{array}$ & As àproved & $90-95$ contidence leve \\
\hline 2.6 & Iatenger & Visuai & Each contalner \\
\hline
\end{tabular}

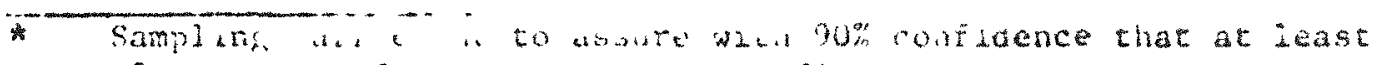
95 per certe $u^{-}$ine ivas net rpeeificat on.

** Sampling suáticient to assure wan $45 \%$ confidence tiat at least 95 per chat of the rods neet specification.

3.2.2 Rejection of any bach or lut shall result in an cxtensive resamplang plan approveri by fria-4aj io dotermine extent of defective materdal.

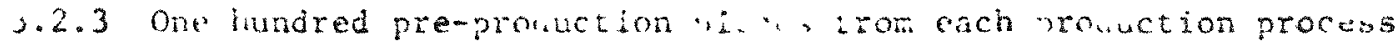
represerting equally eari id

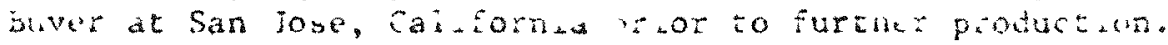
Furtice production shal not : perateded until twe pre-

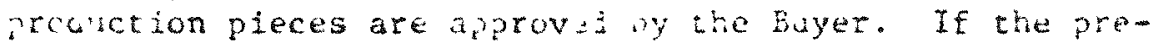

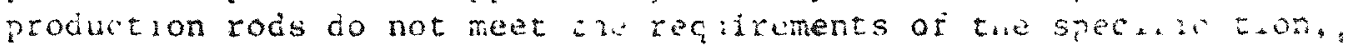
auditional lots snail be subinteu until acceptabie rous are prouluced. 


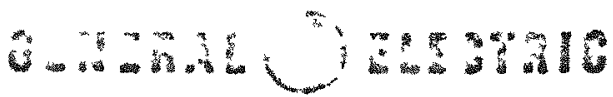

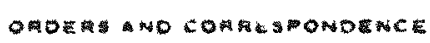

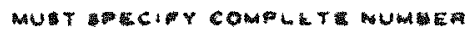

$$
5 \text { or } 5
$$

\section{SPECIECATIOY}

\subsection{Recoras and Rezorts}

Records of ali measuretents mede in zompliance with Section 3.2 .5

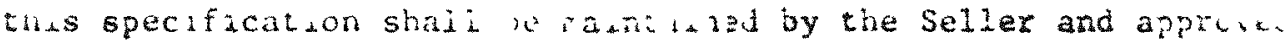

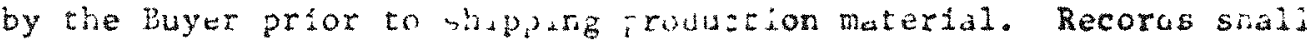
relate each test piece to its batei and powder lot. 


\section{GEA.13585
GT}

\section{Di' IKEUYE}

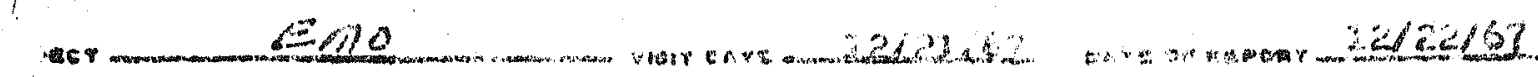

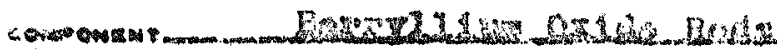

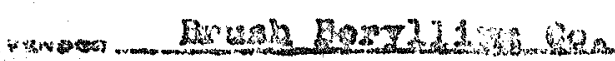

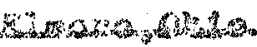

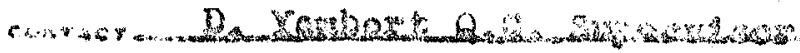

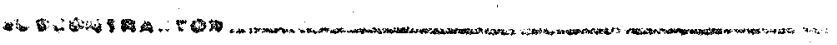

(.)OM $A=4$

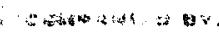

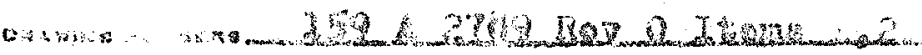

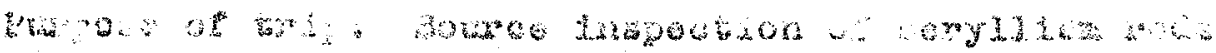

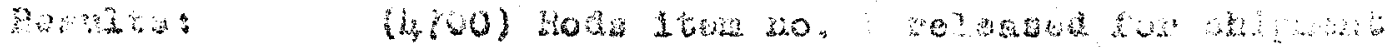

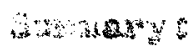

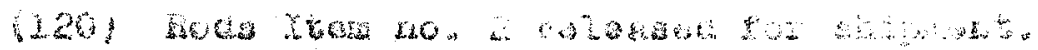

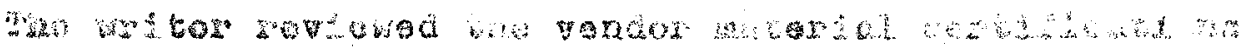

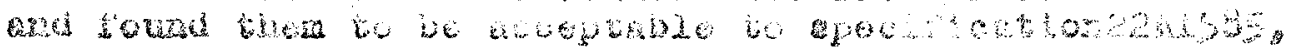

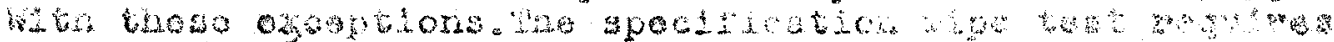

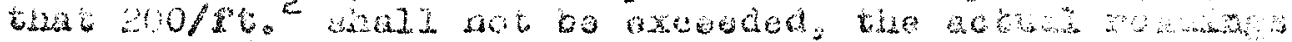

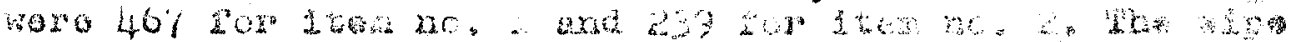
sost rogula ol Sar Jobo $126216 \%$.

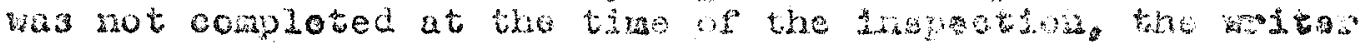

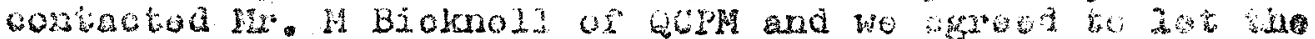

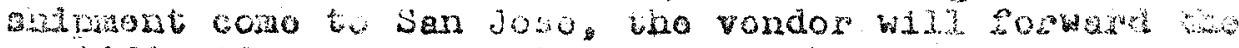
cortification usu complobion, of tho tort.

Itom no. I comista of powdor lot D-2 Run 0-1, and Powder $20 t$ Do-3 Kung $0-2,0-3$.

It no.2consits of powior lot $\mathrm{C}-\mathrm{I}$ 
THE BRUSH BERYLIIUM COMPANY

EIMORE, OHIO

CERTIFICATE OF COMPLIANCE

TO: GENERAL ELECTRIC CONPANY 175 CURTNER AVENUE

SAN JOSE, CAIIFORNIA 95125
Date

Your PO

Our so

Item No.

Quantity
$12 / 22 / 67$ 205-K1080-G $\mathrm{U}-961$ 1 - RUN O1 3,662 PCS.

It is hereby certified that all articles herewith furnished in the quantities as called for in the above purchase order are in conformance with the requirements, specifications, and drawings applicable to that order.

All physical, chemical or other tests applicable to your order are on file, and copies of such reports will be furnished upon request.

POWDER LOT - D-2

Chemical Analysis - See attached sheet Grain Size:

Sample 1 Sample 2 Sample 3

THE BRUSH BERYIIIUM COMPANY

10.0 Microns 10.3

Density $-2 . .879 \mathrm{~g} / \mathrm{cc}$ average

Modulus of Rupture - 33,486 PSI

Surface Powder - 467 Micrograms Per Sq. Ft.

Don E. Yahfibert

Quality fontrol Supervisor

Ceramic Department 
POWDER LOT D-2

CHEMICAL ANALYSIS

SAMPLE HI

\begin{tabular}{|c|c|c|}
\hline AI & 50 & $\mathrm{PPM}^{\prime}$ \\
\hline$\frac{\mathrm{Ag}}{\mathrm{B}}$ & $\begin{array}{l}-1 \\
-1\end{array}$ & n' \\
\hline $\mathrm{Ba}$ & 2 & n. \\
\hline 6 & 64 & $n$ \\
\hline $\mathrm{Ca}$ & 50 & $"$ \\
\hline $\mathrm{Cd}$ & ND & \\
\hline Co & -1 & m \\
\hline $\mathrm{Cr}$ & 6 & m \\
\hline $\mathrm{Cu}$ & 2 & " \\
\hline$F$ & 70 & $\mathrm{~m}$ \\
\hline $\mathrm{Fe}$ & 50 & " \\
\hline$H$ & 18 & "1. \\
\hline $\mathrm{Li}$ & 3 & $n$ \\
\hline $\mathrm{Mg}$ & 680 & $n$ \\
\hline $\mathrm{Mn}$ & -2 & " \\
\hline Mo & -3 & n. \\
\hline $\mathrm{Na}$ & 50 & $n$ \\
\hline $\mathrm{Ni}$ & 10 & $n$ \\
\hline $\mathrm{Pb}$ & -2 & $n$ \\
\hline Si & 165 & $n$ \\
\hline $\mathrm{Sn}$ & 1 & 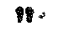 \\
\hline Sr & 2 & pe. \\
\hline $\mathrm{Ti}$ & -2 & $n$ \\
\hline $2 n$ & -20 & \\
\hline
\end{tabular}

(ND) - Not Detected

(-) - Less Than

\section{SAMPLE \#2}

AI $55 \mathrm{PPM}$

$\mathrm{Ag}-1$

Ba 2 "

C $26 "$

$\mathrm{Ca} 50 \%$

Cd ND

Co $-1 "$

Cr 7 "

$\mathrm{Cu} \quad-2$ "

F 85 "

$\mathrm{Fe} 50 \%$

H 10 "

Li 2 "

$\mathrm{Mg} 760$ n

Mn -2 "

Mo -3 n

$\mathrm{Na} \quad 30 "$

Ni $10 \%$

$\mathrm{Pb} \quad-2 "$

Si 180 "

Sn $2 "$

Sr 2 "

Ti 2 "

$\mathrm{Zn}-20$
SAMPLE \#3

A1 $90 \mathrm{PPM}$

$\mathrm{Ag} \quad-1$ "

$\mathrm{Ba} 2 n$

C 11 *

Ca 50 "

Cd ND

Co -1 "

Cr 9 "

Cr $\quad-2$ "

F 78 "

Fe 80 "

H 9 "

Li 3 "

$\mathrm{Mg} 780 \mathrm{n}$

Mn -2 ต

Mo $-3 n$

$\mathrm{Na} 80$ "

Ni 12 "

$\mathrm{Pb} \quad-2$ "

Si. $180 "$

Sn 1 "

Sr 2 "

m $-2 n$

$\mathrm{Zn}-20$ " 


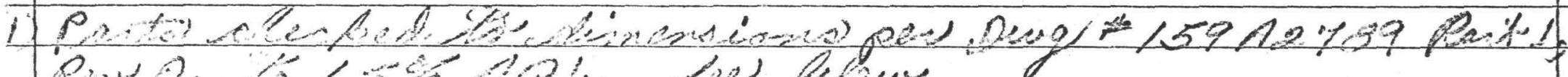

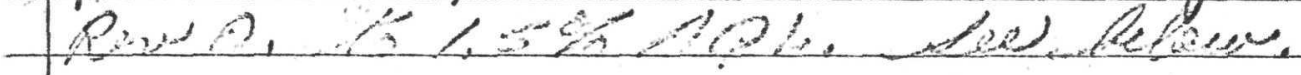

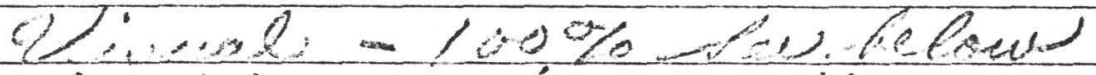

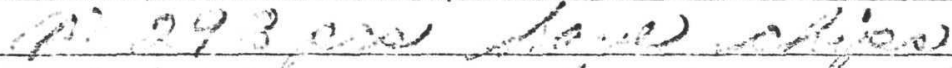

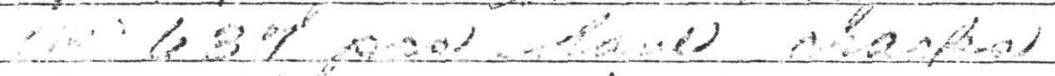

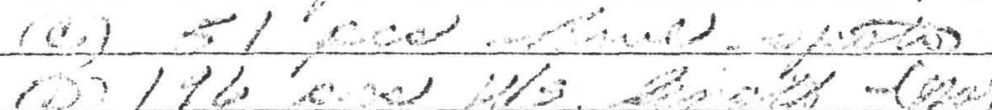

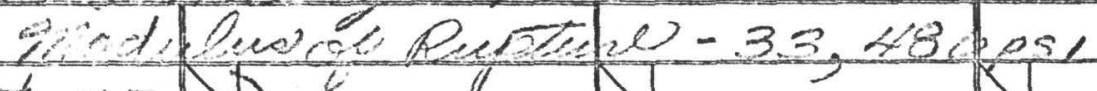

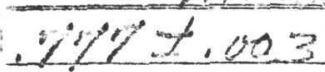

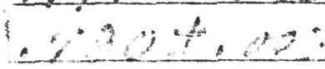

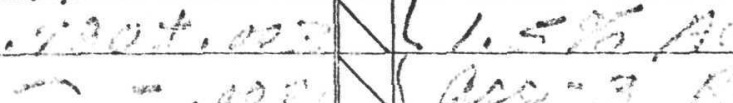
$1+20$
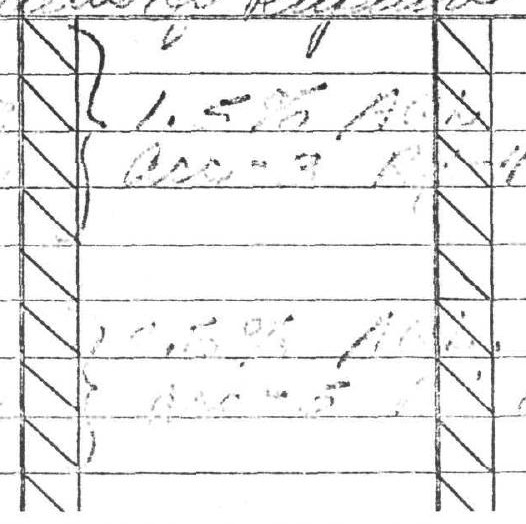
APPROPRIATE DRAWINGS AND SPECIFICATIONS ON EACH ITEM FOR PURCHASE ORDER. ABOVF, PARTS CHECKED IN ACCORDANCE WITH MIL STD. 105D, 29 APRIL 1963.

INSPECTION LEVEL (CIRCLE ONE):

(I) II III OTHER - - 
THE BRUSH BERYLIIUM COMPANY

ELMORE, OHIO

CERTIFICATE OF COMPLIANCE

TO: GENERAL FLECTRIC CONPANY

175 CURTNER AVENUE

SAN JOSE, CALIFORNIA 95125
Date

Your PO

our so

Item No.

Quantity
$12 / 22 / 67$

205-K1080-G

U-961

$1-$ RUN 02

785 PCS.

It is hereby certified that all articles herewith furnished in the quantities as called for in the above purchase order are in conformance with the requirements, specifications, and drawings applicable to that order.

All physical, chemical or other tests applicable to your order are on file, and copies of such reports will be furnished upon request.

POWDER LOT - D-3

Chemical Analysis - See attached sheet

\section{Grain Size:}

Sample 1

Sample 2

Sample

THE BRUSH BERYLIIUM COMPANY

\subsection{Microns; 12.3} 11.3-

Density - $2.883 \mathrm{~g} / \mathrm{cc}$ average'

Modulus of Rupture - 25,708 PSI

Surface Powder - 467 Micrograms Per Sq. Ft.

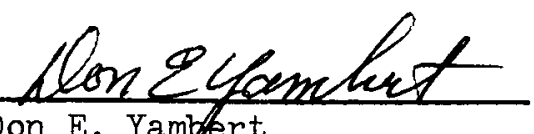

Don E. Yambert

Quality Cohtrol Supervisor

Ceramic Department 
POUDER LOT D-3

CHEMICAL ANALYSIS

SAMPIE \#1

AI $110 \mathrm{PPM}^{\prime}$

Ag $-2 "$ "

$B,-I n=$

$\mathrm{Ba} 2 n$,

C $10 \mathrm{n}$,

$\mathrm{Ca} 50 \mathrm{n} /$

Cd ND.

Co $-1 n$,

Cr 4 ",

$\mathrm{Cu} \quad-2 \mathrm{n}$

F 63 ".

re 60 "1

42 "

Ii $3 "$

$\mathrm{Mg} 700 \mathrm{~N}$.

$\mathrm{Mn}-2 \mathrm{~N}$.

No -3 "

$\mathrm{Na} \quad 40 \mathrm{~N}$ -

$\mathrm{Ni} \quad 10$ "

Pi $\quad-2 n$

Si $320 "$.

Sn 1 "

Sr $2 "$

$\begin{array}{lll}\mathrm{Ti} & -2 & n \\ \mathrm{Zn} & -20 & n .\end{array}$

(ND) - Not Detected

(-) - Less Than
SAMPLE \#2

Al $60 \mathrm{PPI}$

Ag -1 "

$\mathrm{B}-1$ "

$\mathrm{Ba} 2 "$

C $12 "$

$\mathrm{Ca} 60 " 11$

Cd ND

Co -111

Cr 4 "

Cu -2 v

F 72 "

$\mathrm{Fe} 70$ "

H 15 "

Ii $3 "$

$\mathrm{Mg} 680 "$

$\mathrm{Mn} \quad-2$ "

Mo $-3 "$

$\mathrm{Na} \quad 4 \mathrm{O} "$

$\mathrm{Ni} 12 "$

$\mathrm{Pb} \quad-2 n$

Si $270 "$

Sn 2 "

$\mathrm{S}{ }^{\circ} \quad 2 "$

$\mathrm{mi}-2 "$

$\mathrm{Zn}-20$ "
SAMPLE \#3

AI $65 \mathrm{PPM}$

Ag -1 "I

$B$ - I"

$\mathrm{Ba} 2 "$

C $12 "$

Ca $50 "$

Cd ND

Co -1 "

Cr 4 "

Cu -2 "

F 61 "

Fe $60 "$

H 13 "

ii 2 "

$\mathrm{Mg} 740 \mathrm{n}$

$\mathrm{Mn}-2$ "

Mo $-3 "$

$\mathrm{Na} \quad 40$ "

Ni. $10 "$

$\mathrm{Pb} \quad-2$ "

Si $280 " n$

Sn -1

Sr 2 "

TI $-2 "$

$\mathrm{Zn}-20 "$ 
BRUSH BERYLLIUM COMPANY

CERAMIC DEPARTMENT

iE, OIIIO

INSPECTION REPORT

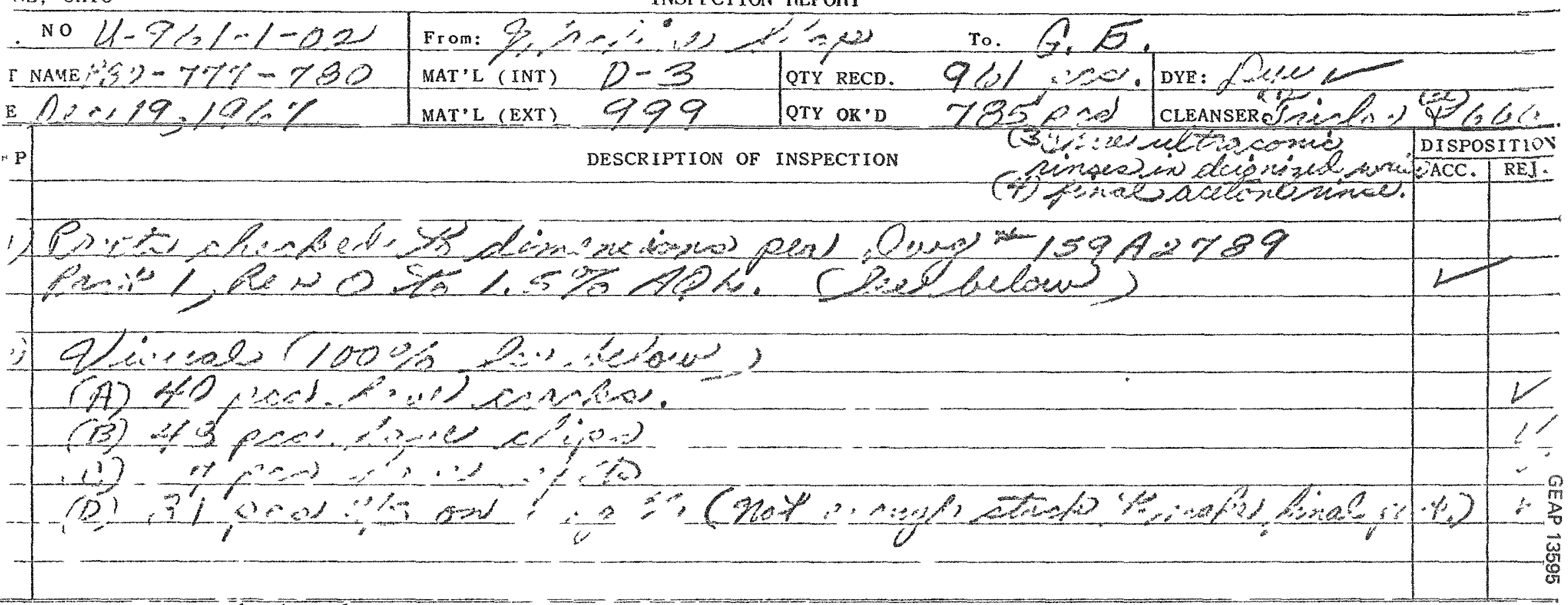

PECTEN BY: 2,200

QTY REQ'D FOR SHIPMENT

OVERAGE

QTY REL'D FOR SHIPMENT $232 \% 2 \%$ COMPLETE:

TETS

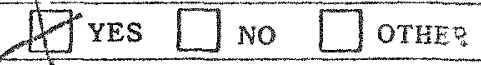

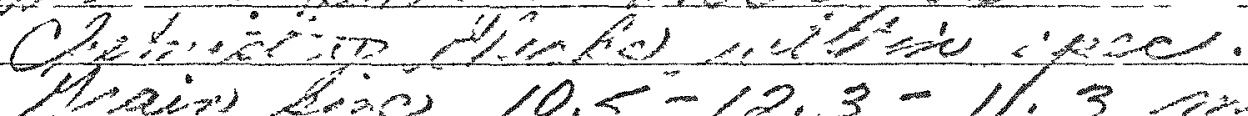

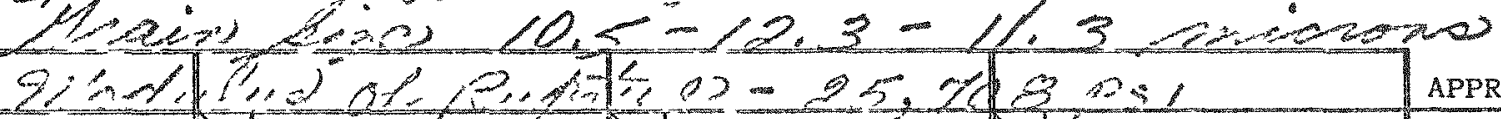

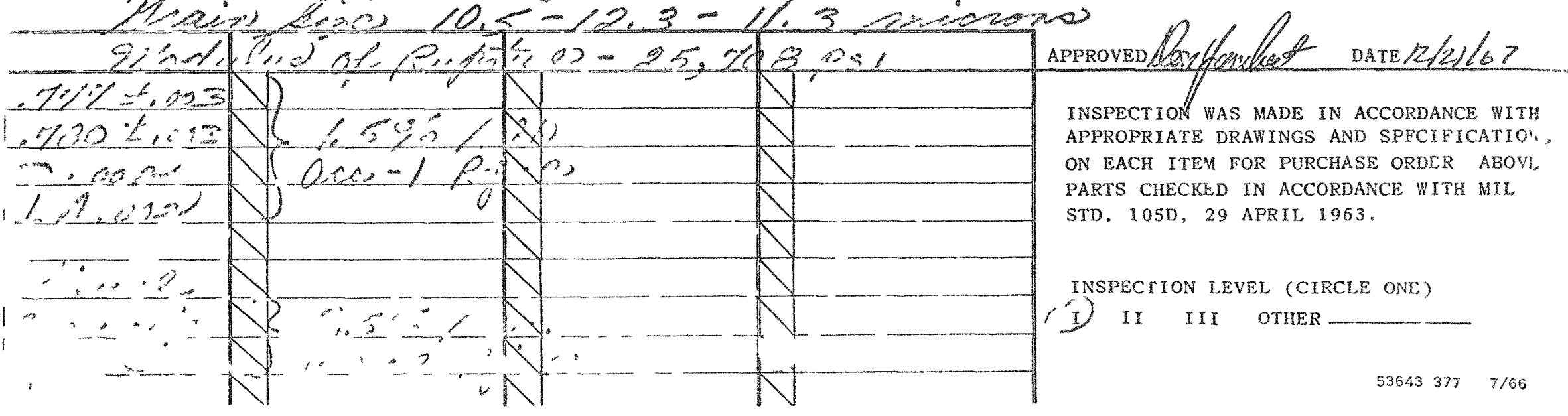


THE BRUSH BERYLIIUM COMPANY

EIMORE, OHIO

GERTIFICATE OF COMPLIANCE

TO: GENERAL ELECTRIC COMPANY 175 CURTNER AVENUE

SAN JOSE, CALIFORNIA 92125
Date

Your PO

Our so

Item No.

Quantity
$12 / 22 / 67$

$205-11080-G$

U-96I

$1-$ RUN O3

253 PCS.

It is hereby certified that all articles herewith furnished in the quantities as called for in the above purchase order are in conformance with the requirements, specifications, and drawings applicable to that order.

All physical, chemical or other tests applicable to your order are on file, and copies of such reports will be furnished upon request.

POWDER LOT - D-3

Chemical Analysis - See attached sheet

Grain Size:

THE BRUSH BERYIIIUM COMPANY

Sample 1

Sample 2

Sample 3

10.5 Microns, 12.3 -

11.3

Density $-2.883 \mathrm{~g} / \mathrm{cc}$ average

Modulus of Rupture - 25,708 PSI -

Surface Powder - 467 MICROGRAMS Per Sq. Ft.Don E. Yambert

Quality Cdntrol Supervisor

Ceramic Department 
POWDER LOT D-3

CHEMICAL ANALYSIS

SAMPLE \#1

AI 110 PPM.

$\mathrm{Ag}-1$ "

$B \quad-1$ "

$\mathrm{Ba} 2$

C 10 "

$\mathrm{Ca} 50$ "

Cd ND -

Co -1 "

Cr 4 "

Cu -2 .

F 63 "

Fe 60 ?

H 12 "

Ii. 3 "

$\mathrm{Mg} 700$ "'

Mn -2 n

Mo -3 "

$\mathrm{Na} \quad 40 \cdots$

Ni 10 "

$\mathrm{Pb} \quad-2$ "

Si $320 "$

Sn $1 "$

Sr 2 "

$\mathrm{Ti}-2 \quad$

$\mathrm{Zn} \quad-20$ "
SAMPLE \#2

A1 60 PPM

Ag $-1 n$

$B \quad-1$ "

$\mathrm{Ba} 2$

C $12 "$

Ca 60 .

Cd ND

Co -1 "

Cr 4 "

Cu $-2 n$

F 72 "

$\mathrm{Fe} 70$ "

H $15 \%$

Ii. 3 "

$\mathrm{Mg} 680$ "

Mn -2 n

Mo -3 '

$\mathrm{Na} \quad 40 \mathrm{O}$

Ni 12 "

$\mathrm{Pb} \quad-2$ "

Si. 270

$\mathrm{Sn} 2$

Sr $2 "$

1i -2

$\mathrm{Zn}-20$ "
SAMPLE \#3

A1 $65 \mathrm{PPM}$

Ag -1 "

B -1 "

$\mathrm{Ba} 2$ "

C $12 n$

Ca 50 .

Cd ND

Co -1 "

Cr 4 n

$\mathrm{Cu} \quad-2$ v

F 61 n

Fe 60 "

H 13 "

Ifi 2 "

$\mathrm{Mg} 740$ n

Mn -2 "

Mo -3 "

$\mathrm{Na} \quad 40$ "

Ni. $10 "$

$\mathrm{Pb} \quad-2$ *

Si 280 "

Sn -1

Sr 2 *

$\mathrm{M}-2$.

$\mathrm{Zn}-20$ "

(ND) - Not Detected

(-) - Less Than 


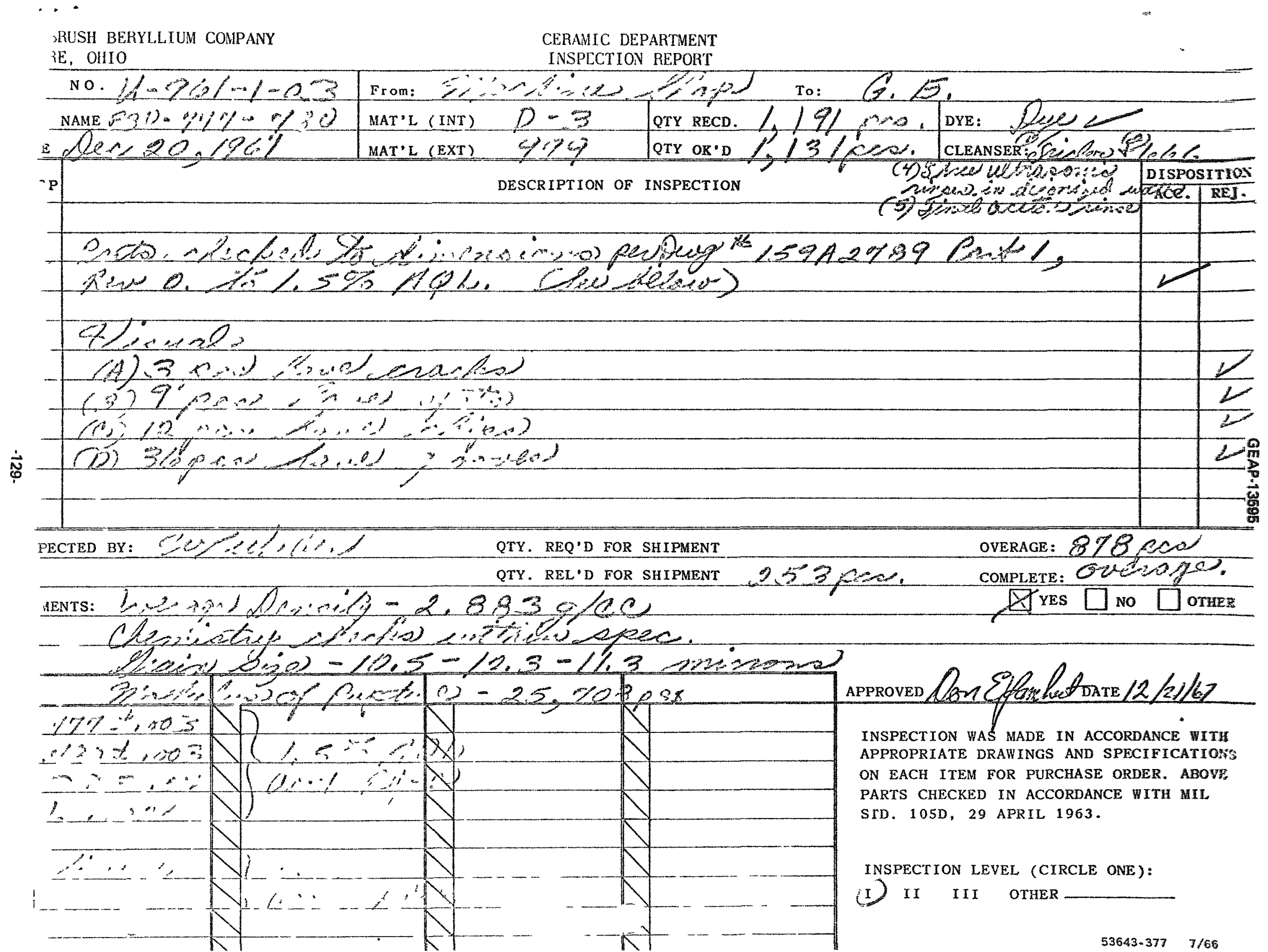


THE BRUSH BERYIITUM COMPANY

ELMORE, OHIO

CERTIFICATE OF COMPLIANCE

To:

GENERAI, ELECTRTC COMPANY
175 CURTNER AVENUE
SAN JOSE, CALIFORNIA 95125

Date $\frac{\frac{12 / 22 / 67}{205-101080-\mathrm{G}}}{\text { Your PO } \frac{U-961}{2-\text { RUN OI }}}$
Our SO
Item No. $\frac{20 \text { PCS. }}{\text { Quantity }}$

It is hereby certified that all articles herewith fumished in the quantities as called for in the above purchase order are in conformance with the requirements, specifications, and drawings applicable to that order.

All physical, chemical or other tests applicable to your order are on file, and copies of such reports will be furnished upon request.

POWDER LOT - C-1

Chemical Analysis - See attached sheet

Grain Size:

Sample 1

Sample 2

Sample 3

THE BRUSH BERYIIIUM COMPANY

14.3 Microns - 16.4 .14 .5 .

Density - $2.907 \mathrm{~g} / \mathrm{cc}$ average

Modulus of Rupture - 28,940 PSI

Surface Powder - 239 Mierograms Per Sq. Ft.

Don E. Yarbert

Quality fontrol Supervisor

Ceramic Department 
POWDER LOT C-1

CHEMICAL ANALYSIS

\section{SAMPLE \#1}

AI 45 PPM $^{\prime}$

$\mathrm{Ag}-1$ "

$B \quad-1$ "

$\mathrm{Ba}-2 \mathrm{~m}$,

C $38 n$.

Ca 40 .

$\mathrm{Cd} N$ -

Co $-1 "$

$\mathrm{Cr} \quad 12$ "

$*$ F

$\mathrm{Fe} 65$ "I

*H

Li $2 "$

$\mathrm{Mg} 800$ "

Mn $\quad-2$ "

$\mathrm{Na} 60$ "

$\mathrm{Ni} 12$.

$\mathrm{Pb} \quad-2$ "

Si 300 n.

Sn -1 .

Sr $\quad-2$ *

Ti $\quad-2 \quad$ "

Zn -20

\section{SAMPLE \#2}

A] 50 PPM

$\mathrm{Ag} \quad-1$ "

$\mathrm{Ba}-2$ "

$\begin{array}{lll}\mathrm{C} & 22 & \\ \mathrm{C} & 40 & \end{array}$

Cd ND

Co -I "

Cr $12 n$

Cu -2

$\mathrm{Fe} 70$ "

Li. 3 "

$\mathrm{Mg} 800 \mathrm{n}$

Mn -2 "

Mo -3 "

$\mathrm{Na} 60$ "

Ni $12 "$

$\mathrm{Pb} \quad-2 "$

Si $330 n$

Sn -1 n

Sr -2 "

Ti $-2 \quad$ "

$\mathrm{Zn} \quad-20 \quad$ n

\section{SAMPLE \#3}

AI 55 PPM

$\mathrm{Ag} \quad-1$ "

B -1 "

Ba -2 n

C $34 "$

$\mathrm{Ca} 40$ :

Cd ND

Co -1 n

$\begin{array}{lll}\mathrm{Cr} & 12 & -2\end{array}$

$\mathrm{Pe} 70$ "

$\mathrm{Li} 2$ "

$\mathrm{Mg} 750$ "

Mn -2 "

Mo -3 "

$\mathrm{Na} 60 "$

Ni 12 "

$\mathrm{Pb} \quad-2$ "

Si 280 "

$\mathrm{Sn}-1 \mathrm{n}$

Sr -2 "

Ti $-2 n$

2n $\quad-20 \quad$

(ND) - Not Detected

(-) - Less Than

* Hydrogen and Fluorine Anaylsis not yet available, will forward as soon as possible. 


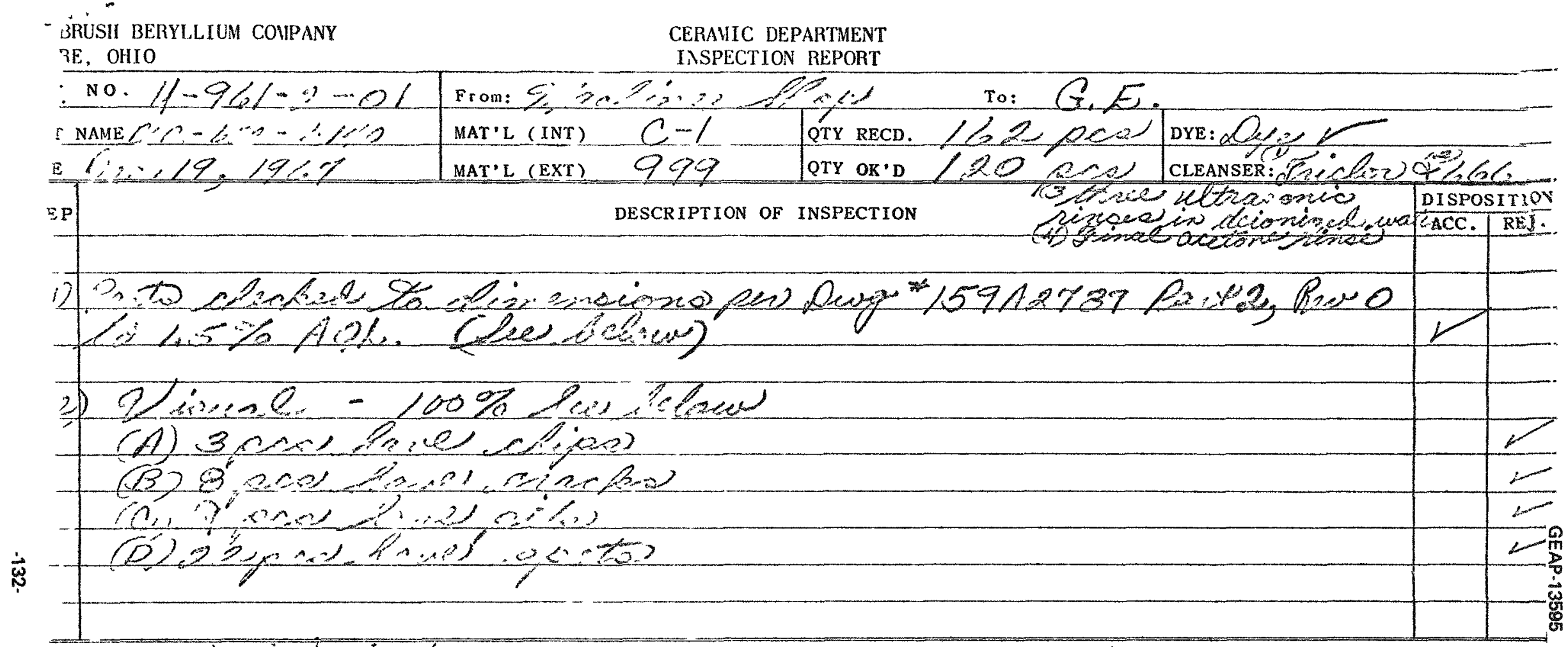

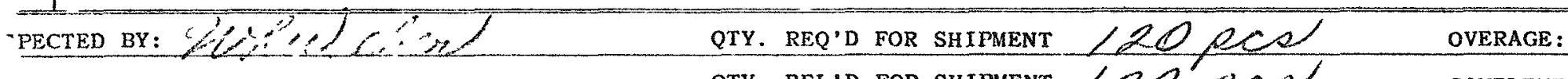

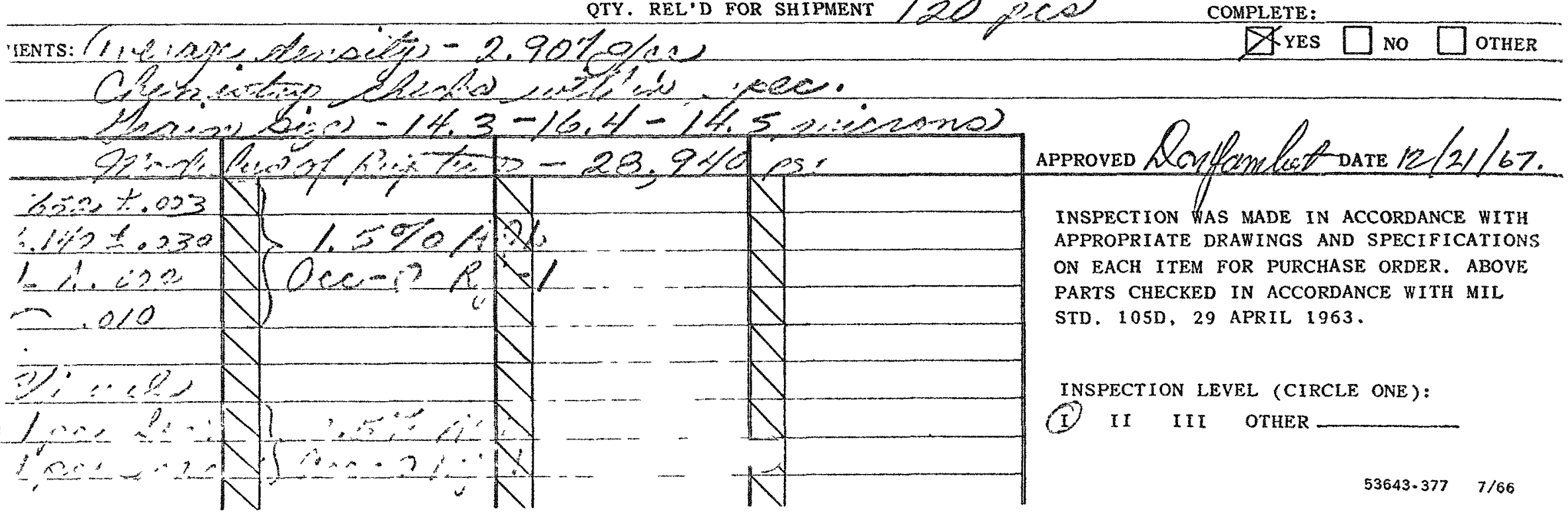




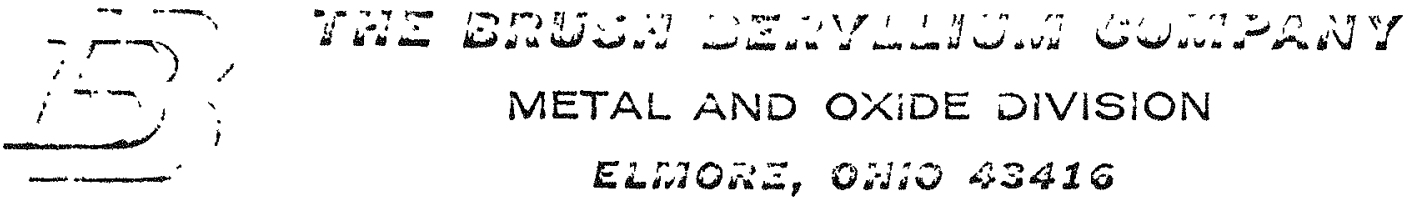

EERAMIES AND NON-METALLIC

Mr. George Barry

G. E. Atomic Power Equipment

Q. C. Dept.

175 Curtnex Avenue

San Jose, California 95125

Dear Mr. Barry,

Please find inclosed the Hydrogen and Fluorine Analysis that were not available at the time of sijpment. These values were added to the origional certification oi chemical analysis.

We are truly sorry for any inconvenience we may have caused you by the delay of this information.

Sincerely yours,

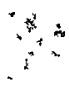

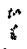

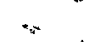

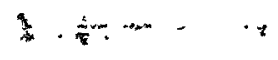

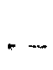

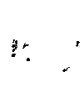
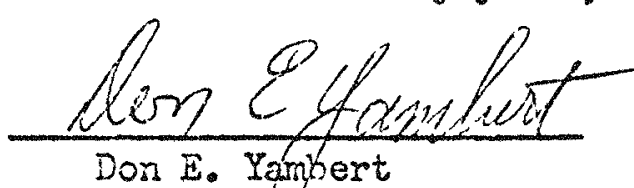

Dor E. Yambert

Quality Contrcl Supervisor

Ceramic Department 
THE BRUSH BERYLIIUM COMPANY

EIMORE, OIO
IVED

A $\because 081988$

W. H. RODGERS

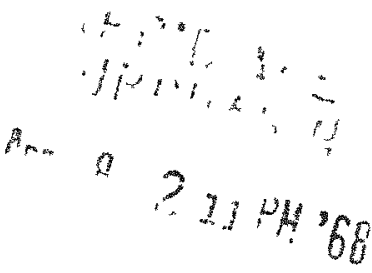

CERTIFICATE OF COMPLIANCE

For December 22, 1967 Shipment

To:

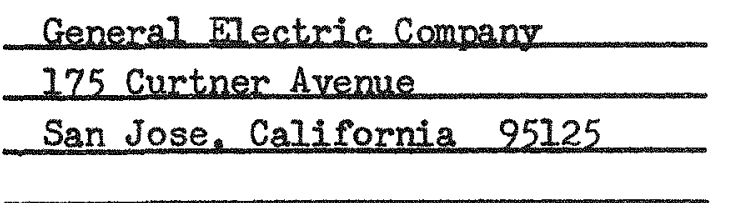

Date

Your PO

Apri1 5. 1968

Our so

Item No。

$205-\mathrm{K} 1080-6$

Quantity

U-961

2 Run 01

120 pcs.

It is hereby certified that all articles herewith furnished in the quantities as called for in the above purchase order are in conformance with the requirements, specifications, and drawings applicable to that order。

AII physical, chemical or other tests applicable to your order are on file, and copies of such reports will be furnished upon request.

Chlorine Content $1.2 \mathrm{ppm}$.

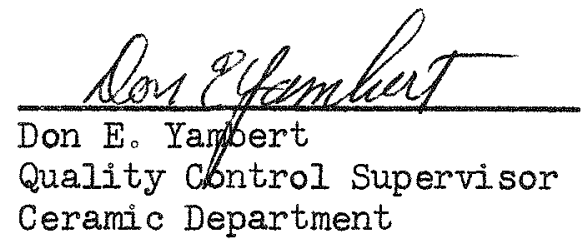


THE BRUSE BERYLIIUM COMPANY

ELMORE, OHIO

CERTIFICATE OF COMPLIANCE

For December 22, 1967 Shipment

To:

\begin{tabular}{l} 
General Electric Company \\
775 Curtner Avenue \\
San Jose, Californis 95125 \\
\hline
\end{tabular}

$\begin{array}{ll}\text { Date } & \frac{\text { ApriI } 5,1968}{205-K 1080-6} \\ \text { Your PO } & \frac{U-96 I}{1 \text { Run } 03} \\ \text { Our So } & \\ \text { Item No. } & \frac{253 \text { pes. }}{\text { Quantity }}\end{array}$

It is hereby certified that all articles herewith fumished in the quantities as called for in the above purchase order are in conformance with the requirements, specifications, and drawings applicable to that order.

All physical, chemical or other tests applicable to your order are on file, and copies of such reports will be furnished upon request.

Chlorine Content 1.4 ppm.

THE BRUSH BERYIIIUM COMPANY

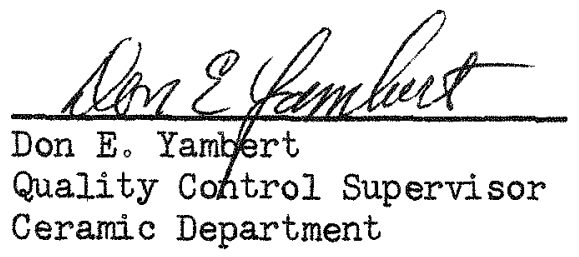


THE BRUSH BERYLITUM COMPANY

ELMCRE, OHIO

CERTIFICATE OF COMPIIANCE

For December 22, 1967 Shipment

\begin{tabular}{|c|c|c|c|}
\hline To: & General Blectric Company & Date & April 5. 1968 \\
\hline & 275 Curtner Aveme & Your PO & $205-17080-6$ \\
\hline & San Jose, California 95125 & our so & $0-961$ \\
\hline & & Item No。 & 1 -Run 01 \\
\hline & & Quantity & 3.662 pes. \\
\hline
\end{tabular}

It is hereby certified that all articles herewith furnished in the quantities as called for in the above purchase order are in conformance with the requirements, specifications, and drawings applicable to that order。

All physical, chemical or other tests applicable to your order are on file, and copies of such reports will be furnished upon request.

\section{Chlorine Content $2.7 \mathrm{ppm}$.}

THE BRUSH BERYLIIUM COMPANY

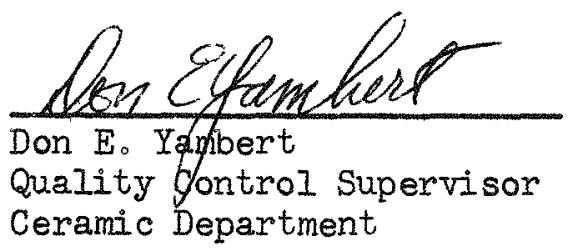


THE BRUSH BERYLIIUM COMPANY

EIMORE, OHIO

CERTIFICATE OF COMPLIANCE

For December 22, 1967 Shipment

\begin{tabular}{|c|c|c|}
\hline Genera] Electric Companr & Date & April 5,7968 \\
\hline 175 Curtner Arenue & Your PO & $205-K 1080-6$ \\
\hline San Jose, California 95125 & Our so & $\mathrm{U}-961$ \\
\hline & Item No。 & 1 Run 02 \\
\hline & Quantity & 785 \\
\hline
\end{tabular}

It is hereby certified that all articles herewith furnished in the quantities as called for in the above purchase order are in conformance with the requirements, specifications, and drawings applicable to that order.

All physical, chemical or other tests applicable to your order are on file, and copies of such reports will be furnished upon request.

Chlorine Content $1.4 \mathrm{ppm}$.

THE BRUSH BERYIIIUM COMPANY

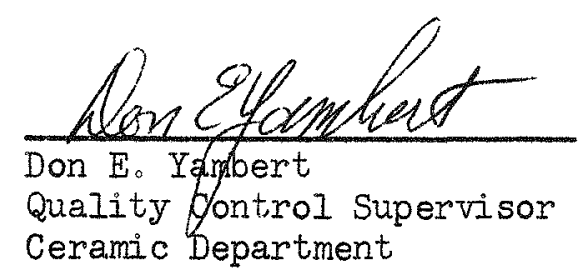


GEAP-13595

APPENDIX VII

Boron Carbide Specifications and Certifications 
STANDARDS

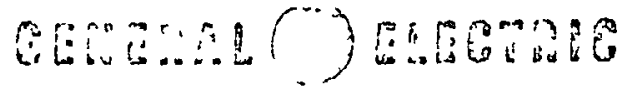

Atenic Powor Tegu! arsone Dopertinent

SPECIFICATIOH
A $508 i^{3}+3 \quad-53$

OROERE ANO CORREEPONDANCE

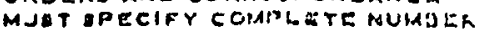

$5 H \quad 1$ OF

Supersedes ASOYP3 -S2

TITLE BORON CANBIDE - CONPIC MALLI CANDE:

\section{REFERENCl DOCIRAEITS}

The latest issues of the folluwing pubizcations form a part of this specification. ASTM B214 "Sieve Analysis of Granular Metal Powder"

"Scott's Standard Methods of Chemical Analysis" - Vol. 1, Edited by N. H. Furman, published by D. Van Nostrand Company, Inc., Princeton, N.J.

\section{$1.0 \quad$ SCORE}

1.1 This specification, 1dentified as A50YP3, defines the requirements for boron carbide in granular form.

1.2 The requirements of the specification are for lots of blended powdex of a given particle size distribution. The size of a lot shall be established by the Seller and shall be no larger than can be blended at any one operation.

\subsection{CIIEMICAI COAPOSITION}

The chemical composition shall be detemincd by the Scott's Standard Mothod of Cnemical Analy-is (Analysis of Boron Carbide) where applicable. The analyses for other elements shall be by agreement.

\subsection{Major Constituents}

$\%$ by Weight

Boron, min.

Carlon kemainder

2.2 Impurities, max.

Boren Anhydride
Iron
Titanium
Chlorine \& Fluorine, Total
Cobalt
Copper
Manganese
Sodium

(Continued on Page 2)

$$
\begin{gathered}
0.1 \\
0.8 \\
0.1 \\
100 \mathrm{ppm} \\
50 \mathrm{ppm} \\
100 \mathrm{ppm} \\
100^{\circ} \mathrm{ppm} \\
100 \mathrm{ppm}
\end{gathered}
$$




\subsection{Weight loss on Drying}

The weight loss of the material when heated for a minimum of one hour at a temperature of $400^{\circ} \mathrm{C} \pm 10^{\circ}$ in an inert atmosphere shall not exceed $500 \mathrm{pprn}$.

\section{- 2.4 Isotopic Composition}

The isotopic comosition shall be that which is normally found in Boron - $19.8 \pm 0.3$ atomic per cent or $18.3 \pm 0.3$ weight per cent of $B 10$.

\subsection{PHYSTCAL CHARACTERISTICS}

\subsection{Particle Size Distribution - As specified on Purchasing Contract}

The particle size distribution shall be uniform and shall be achieved through blending. The uniformity of the distribution shall be verified through a sieve analysis per ASTM B214, "Sieve Analysis of Granular Metal Powder," made by the Seller on two representative samples per lot of powder. The results of the test shall be reported to the Buyer as sieve fractions in the U.S. Standard Sieve Series.

\subsection{Particle Density, min.}

$2.38 \mathrm{~g} / \mathrm{cc}$

(95\% Theoretical)

\subsection{CERTIFTCATE OF TEST}

The Seller shall cartify in triplicate compliance with all requirements of the specification. The certification shall include a certified report of the results of the required tests: Chemical analysis, isotopic composition, weight loss on drying, and particle size distribution. The certification. shall specify the lot size, purchase order numier, and the G.E. specification designation.

\subsection{PACKING AND MARKING}

Material shall be shipped in standard comercial water-proof and air-tight containers to merL ICC and carriers' regulatjons. Each container shall be legably marked with the purclise order number, the manufacturer's name or trade naime, lot number, container number, shipper's gross, tare, net weights, and the G.E. desighialion. 
HERMANN C. STARCK BERLIN

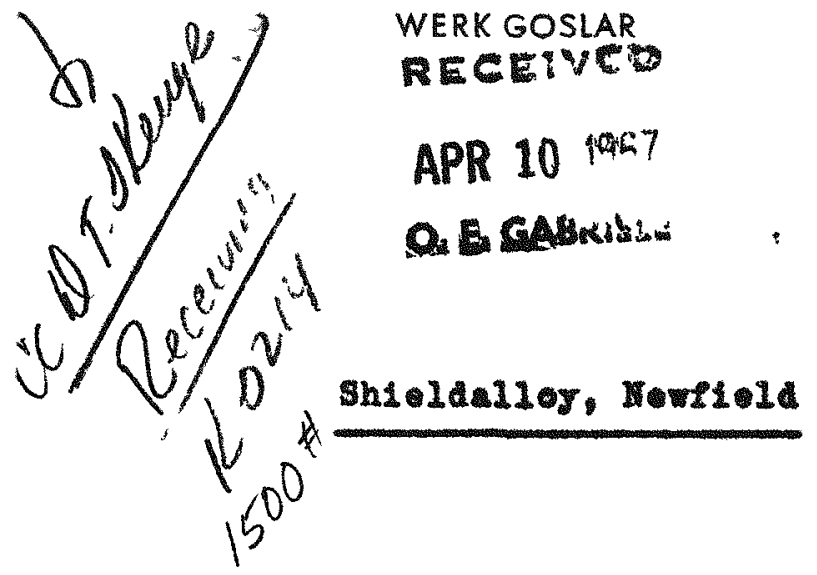

Forrespondenz. 338-GOSLAR (HARZ), POSTFACH 12 Telegromin: AMPERE GOSLAR

Telefon: (05321) 6501

Telex: $\quad 0953826$

Apri1 3, 1967

MII

\section{Amatres 10. 665 \\ Date of Shipsents \\ * A, B, C: Maroh 22, 1967 \\ Di' March 23, 1967}

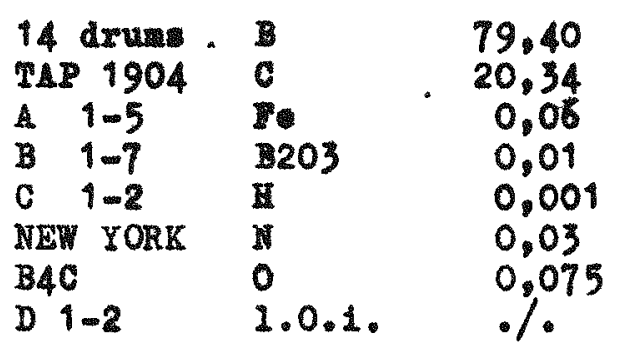

60-00 meh $200-325 \mathrm{~m}$

-200 ing

79,75
19,90
0,06
0,04
0,002
0,11
0,10
.1

00.33
19.00
0.12
0,05
0.004
0.20
0.25
0.02

78.99

19,47

0,075

0,085

0,013

0,60

0,60

0,04

Sorece Ansivsts

525 1b

14-20 mesh

$\begin{array}{ll}+14 & 0 \% \\ -14+18 & 37 \% \\ -18+20 & 51 \% \\ -20 & 12 \%\end{array}$
$6751 \mathrm{bs}$

60-80 weah

\begin{tabular}{lr}
+50 & $0,05 \%$ \\
\hline$-50+60$ & $5,85 \%$ \\
$-60+70$ & $38,40 \%$ \\
$-70+100$ & $54,90 \%$ \\
-100 & $0,80 \%$
\end{tabular}

$1501 \mathrm{bs}$

$200-325 \mathrm{mesh}$

$\begin{array}{ll}+170 & 0,2-\% \\ -170+200 & 35,8 \% \\ -200+270 & 21,8 \% \\ -270+325 & 31,3 \% \\ -325 & 10,9 \%\end{array}$
150168 -200 mesh

$\begin{array}{lr}+170 & 42.4 \% \\ -170+200 & 37.3 \% \\ -200+270 & 13.8 \% \\ -270+400 & 3.6 \% \\ -400 & 2.9 \%\end{array}$

General Electric San Jose, Calif. PO非K0214 


\section{(2) CARBORUNDUM}

The Carborundum Company - Electro Minerals Division - Post Office Box 423 - Niagara Falls, New York 14302

\section{CERTIFICATE OF QUALITI}

VENDOR: The Carborundum Company

Electro Minerals Division

*. Niagara Falls, New York

GUSTOMER: $\quad$ General Electric Company

Atomic Power Equipment Department

175 Curtner Avenue

San Jose, California 95125

MATERIAL:

Boron Carbide Powder - Nuclear Grade $14 / 20$ mesh

tot-68-1

100 pounds

Customer Order No. 205 A4847G

Carborundum Order No. 01-268-302 Item 1 Shipped 2/13/68

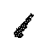

SPECIFICATION:

A 50 YP3 -53

Dated $5 / 5 / 66$

Seller certifies compliance with all requirements of the certification, except as herein noted.

Signed;

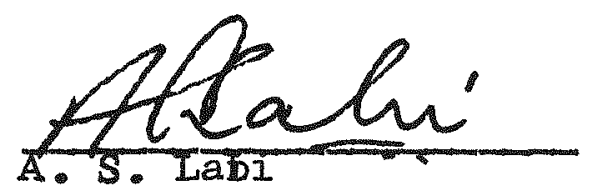

Title: Senior Engineer

Quality Control Department

Technical Branch

Date: 13 February 1968 


\section{ANALYTICAI DATA}

Data in percent unless otherwise indicated. $\mathrm{x}$ indicates average.

Boron

Carbon

*Boron Anhydride

Iron

Titanium

**Chloride, ppm

Fluorine

Cobalt, ppm

Copper, ppm

Manganese, ppm.

Sodium, ppm

***Drying Moisture

Density - grams/cc

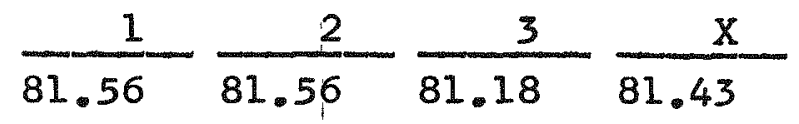

$\begin{array}{llll}16.40 & 16.54 & 16.43 & 16.46\end{array}$

$\begin{array}{llll}0.31 & 0.32 & 0.32 & 0.32\end{array}$

$\begin{array}{llll}0.87 & 0.77 & 0.75 & 0.79\end{array}$

$<0.05<0.05<0.05<0.05$

$$
\begin{array}{rr|cc}
- & - & - & <25 \\
<25 & <25 & <25 & <25 \\
<50 & <50 & <50 & <50 \\
<50 & <50 & <50 & <50 \\
<100 & <100 & <100 & <100 \\
- & - & - & 0.000 \\
2.38 & 2.37 & 2.38 & 2.38
\end{array}
$$

The isotopic composition is that which is normally found in Boron $18.3 \pm 0.3$ weight percent of B10.

* Specification $0.1 \%$ max.

**Specification chlorine + Fluorine $100 \mathrm{ppm}$

$* * *$ Dried at $200^{\circ} \mathrm{C}$ for one hour.

Particle Size Distribution

U.S.Standard Sieve Series

$+14$

$\frac{1}{0.7}$

$\frac{2}{0.6}$

$-14+20$

69.7

69.9

$-20$

29.6

29.5 


\section{(6) CARBDRUNDUM}

. se Carborundum Company - Electro Minerals Division Post Office Box $423 \cdot$ Niagara Falls, New York 14302

\section{CERTIFICATE OF QUALITY}

VENDOR:

The Carborundum Company Electro Minerals Division Niagara Falls, New York

GUSTOMER:

General Electric Company

Atomic Power Equipment Department

175 Curtner Avenue

San Jose, California 95125

MATERIAL:

Boron Carbide Powder - Nuclear Grade $60 / 80$ mesh

Lot $68-2$

200 pounds

Customer Order No. 205 A4847G

Carborundum Order No. 91-268-302 Item 2 shipped 2/13/68

SPECIFICATION:
A 50YP3-53
Dated $5 / 5 / 66$

Seller certifies compliance with all requirements of the certification, except as herein noted.

signed:

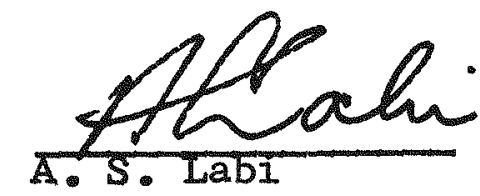

Title: Senior Engineer Quality Control Department Technical Branch

Date

13 February 1968 


\section{ANALYTICAL DATA}

Data in percent unless otherwise stated. $\mathrm{X}$ indicates average.

Boron

Carbon

*Boron Anhydride

Iron

Titanium

Chlorine + Fluorine, Total ppm

Cobalt, ppm

Copper, ppm

Manganese, ppm

Sodium, ppm

$\star \star$ Drying Moisture

Density - grams/cc

$$
\begin{array}{rcccc}
\frac{1}{79.11} & \frac{2}{78.95} & \frac{3}{79.20} & \frac{1 \mathrm{x}}{79.09} \\
19.57 & 19.53 & 19.52 & 19.54 \\
0.14 & 0.10 & 0.08 & 0.11 \\
0.48 & 0.52 & 0.52 & 0.51 \\
<0.05 & <0.05 & <0.05 & <0.05 \\
- & - & - & <20 \\
<25 & <25 & <25 & <25 \\
<50 & <50 & <50 & <50 \\
<50 & <50 & <50 & <50 \\
<100 & <100 & <100 & <100 \\
- & - & - & 0.005 \\
2.45 & 2.46 & 2.47 & 2.46
\end{array}
$$

The isotopic composition is that which is normally found in Boron - 18.3 \pm 0 . Weight percent of Blo.

* Specification $0.1 \%$ max.

**Dried at $200^{\circ} \mathrm{C}$ for one hour

Particle Size Distribution

U.S. Standard Sieve Series

$\begin{array}{lll}+60 & \frac{1}{10.3} & \frac{2}{10.4} \\ -60+80 & 38.5 & 38.6 \\ -80 & 51.2 & 51.0\end{array}$




\section{(a) BAIELEUNDUM}

1 he Carborundum Company - Electro Minerals Diviolon - Post Office Box $423 \cdot$ Niagara Falls, New York 14302

CERTIFIGATE OF QUALITY

VENDOR:

The Carborundum Company

Electro Minerals Division

Niagara Falls, New York

CUSTOMER :

General Electric Company

Atomic Power Equipment Department

175 Curtner Avenue

San Jose, California 95125

MATERIAL:

Boron Carbide Powder - Nuclear Grade $200 /$ Finer mesh

Lot $68-3$

30 pounds

Customer Order No. 205-A4847G

Carborundum Order No. 01-268-302 Item 3

Shipped $2 / 13 / 68$

SPECIFIGATION :

A 50YP3-53

Dated $5 / 5 / 66$

Seller certifies compliance with all requirements of the certification, except as herein noted.

Signed:

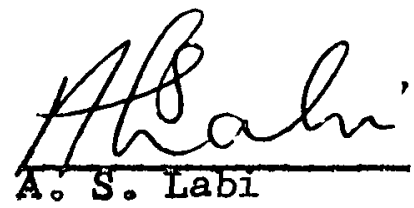

Title: Senior Engineer Quality Control Department Technical Branch

Date:

13 February 1968 


\section{ANALYTICAL DATA}

Data in percent unless otherwise stated. $X$ indicates average.

Boron

Carbon

Boron Anhydride

Iron

Titanium

Chlorine $f$ Fluorine, Total ppm

Cobalt, ppm

Copper, ppm

Manganese, ppm

Sodium, ppm

*orying moisture

Density - grams/cc

$\begin{array}{rccc}\frac{1}{79.74} & \frac{2}{79.71} & \frac{3}{79.70} & \frac{X}{79.72} \\ 18.30 & 18.36 & 18.41 & 18.36 \\ 0.02 & 00.02 & 0.02 & 0.02 \\ 0.46 & 0.44 & 0.43 & 0.44 \\ <0.05 & <0.05 & <0.05 & <0.05 \\ - & - & - & <20 \\ <25 & <25 & <25 & <25 \\ <50 & <50 & <50 & <50 \\ <50 & <50 & <50 & <50 \\ <100 & <100 & <100 & <100 \\ - & - & - & 0.007 \\ 2.47 & 2.47 & 2.48 & 2.47\end{array}$

The isotopic composition is that which is normally found in Boron - $18.3 \pm 0.3$ weight percent of $\mathrm{B} 10$.

*Dried at $200^{\circ} \mathrm{C}$ for one hour.

Particle Size Distribution

U.S. Standard Sieve Series

$+200$

$\begin{array}{ll}\frac{1}{1.8} & \frac{2}{1.4} \\ 26.6 & 27.2 \\ 71.6 & 71.3\end{array}$




\section{DISTRIBUTION}

Division of Technical Information Extension

U.S. Atomic Energy Commission

P. O. Box 62

Oak Ridge, Tennessee

Director

Research and Development Division

U.S. Atomic Energy Commission

Richland Operations Office

P. O. Box 550

Richland, Washington 99352

Mr. G. Vendryes

Cen Saclay

Boite Postale 2

Gif-Sur-Yvette (S et O) France

Dott, Ing. F. Pierantoni

CNEN

Viz Mazzini 2

Bologna, Italy

Chief

Fuel Fabrication Branch

DRD\&T, USAEC

Washington, D. C. 20545

Mr. F. W. Lewis, President

Lousiana Power and Light Company

142 Delaronde Street

New Orleans, Louisiana 70114

Mr. R. C. Green, President

Missouri Public Service Co.

10700 East 50 Highway

Kansas City, Missouri

Mr. L. J. Cucullu. President

New Orleans Public Service Inc.

317 Baronne Street

New Orleans, Louisiana 70160

Mr. B. S. Jeffrey, President

Kansas Power and Light Company

808 Kansas Avenue

Topeka, Kansas 66601

Mr. J. Robert Weish

Chairman of the Board

Southwestern Electric Power Company

P. O. Box 1106

Shreveport, Louisiana 71102

Power Reactor Development Company

1191 First Street

Detroit, Michigan 48226

Project Manager

FFTF Project

Pacific Northwest Laboratory

Richland, Washington 99352
15 Chief,

Fuels and Materials Branch

DRD\&T, USAEC

Washington, D. C. 20545

1 Assistant Director for Reactor Projects

Division of Reactor Licensing

DRD\&T, USAEC

Washington, D. C. 20545

Director

Los Alamos Scientific Laboratory

Los Alamos, New Mexico 87544

Dr. John C. Woodhouse

4

21 Woodbrook Circle

Wilmington, Delaware 19803

Senior Representative

U.S. Mission to EURATOM Communities

c/o U. S. Embassy

Brussels, Belgium

General Directorate

Research and Training

EURATOM

51.53 Rue Belliard

1 Brussels, Belgium

Attn: A. DeStordeur

Mr. F. H. Coughlin, Chairman of Board

1 P. O. Box 111

Alexandria, Louisiana 71301

Mr. John Stewart, President

111 East 11 th Street

Hays, Kansas 67601

Mr. Reeves Ritchie, President

1 Ninth and Louisian Street

Little Rock, Arkansas 72203

Mr. J. T. Jones, President

The Empire District Electric Co.

602 Joplin Street

Joplin, Missouri 64802

Mr. Harold E. Mortimer

Vice President

Assistant to Chairman of the Board

1 Gulf States Utilities Company

P. O. Box 2951

Beaumont, Texas 77704

$5 \quad$ Mr. C. F. Edwards, Vice President

Western Power Division

Central Telephone \& Utilities Corp.

P. O. Box 170

Great Bend, Kansas 
Gesellschaft fur Kernforschung m.b.H.

Projekt Schneller Bruter

75) Karlsruhe, Germany

Postfach 947

Director,

LMFBR Program Office

Argonne National Laboratory

South Cass Avenue

Argonne, Illinois 60439

Asst. Director for Plant Engineering

DRD\&T, USAEC

Washington, D. C. 20545

Asst. Director for Reactor Engineering

DRD\&T, USAEC

Washington, D. C. 20545

Brookhaven National Laboratory

Associated Universities, Inc.

Upton, Long Island, N. Y. 11973

Attn: Dr. C. H. Raseman

Project Manager

Special Projects Branch

DRD\&T, USAEC

Washington, D. C. 20545

Mr. G. W. Evans, President

Kansas Gas and Electric Company

201 North Market Street

Wichita, Kansas 67201

Mr. L. F. C. Reichle

Ebasco Services, Inc.

2 Rector Street

New York 6, New York

Mr. R. B. Wilson, President

Mississippi Power and Light Company

Electric Building

Jackson, Mississippi 39205

Mr. Ray W. Call, President

Missouri Utilities Company

400 Broadway

Cape Girardeau, Missouri 63701

Mr. W. A. Parker, President

Oklahoma Gas and Electric Company

321 North Harvey Street

Oklahoma City, Oklahoma 73101

Mr. D. J. Tuepker, Chairman

Public Service Company of Oklahoma

600 South Main Street

Tulsa, Oklahoma 74102

Chief,

Liquid Metal Project Branch

DRD\&T, USAEC

Washington, D. C. 20545

10

Asst. Director for Nuclear Safety

Washington, D. C. 20545

Director, Contracts Division

San Francisco Operations Office

2111 Bancroft Way

Berkeley, California 94704

F. W. Thalgott

2 Associate Director, Idaho Division Argonne National Laboratory

Box 1096

Idaho Falls, Idaho 83401

2

Director, Argonne National Laboratory

1

9800 South Cass Avenue

Argonne, lllinois 60439

Chief,

Reactor Physics Branch

DRD\&T, USAEC

Washington, D. C. 20545

Mr. C. C. Czeschin, President

Arkansas-Missouri Power Company

104 South Fifth Street

Blytheville, Arkansas 72316

1

Mr. T. Flynn

Mr. T. Flynicos, Inc

2 Rector Street

New York City 6, N. Y.

1

USAEC

Office of RDT Site Representative

310 DeGuigne Drive

Sunnyvale, California 94086

1 Attn; J. Levy

Director

Liquid Metals Information Center

P. O. Box 309

1 Canoga Park, California 91305

(Topicals only)

Mr. S. Golan, Project Manager

1000 MWe LMFBR Follow-On Study

Atomics International

P. O. Box 309

Canoga Park, California 91304

Mr. M. W. Croft, Project Manager

$1 \quad 1000$ MWe LMFBR Follow-On Study

The Babcock \& Wilcox Company

5061 Fort Avenue

P. O. Box 1260

Lynchburg, Virginia 24505

Dr. W. P. Staker, Project Manager

Combustion Engineering, Inc.

P. O. Box 500

Windsor, Connecticut 06095 
Mr. C. A. Anderson, Project Manager 1000 MWe LMFBR Follow-On Study Westinghouse Electric Corporation Advanced Reactors Division

Waltz Mill Site

P. O. Box 158

Madison, Pennsylvania 15663

Mr. L. W. Fromm, Manager

1000 MWe LMFBR Follow-On Study Project

Building 208

Argonne National Laboratory

9800 South Cass Avenue

Argonne, lllinois 60439

USAEC Scientific Representative

United States Embassy, Box 40

FPO

New York, N. Y. 09510 